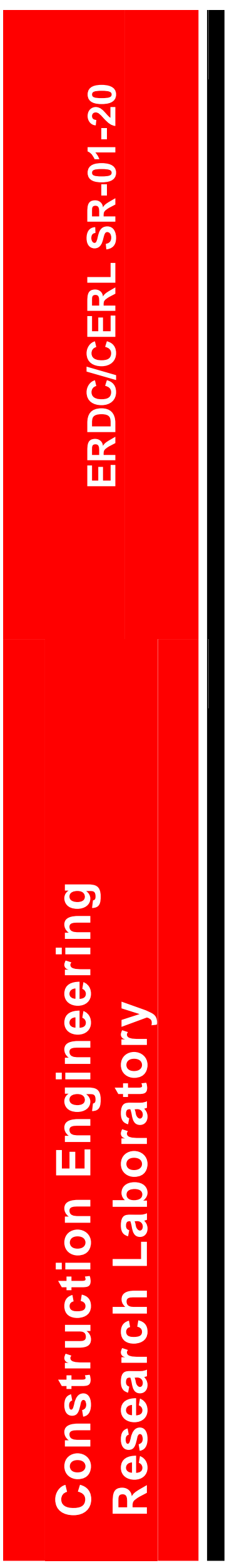

\title{
Design Review and Checking System (DrChecks)
}

E. William East, Jeffrey G. Kirby, and Jana Kelly 


\section{Foreword}

This study was conducted for the U.S. Army Corps of Engineers under Military Interdepartmental Purchase Request (MIPR) WX3JR902219476, "DrChecksFY01-Alaska." The technical monitor was Rick D. Dahnke, CECW-ET.

The work was performed by the Engineering Processes Branch (CF-N) of the Facilities Division (CF), Construction Engineering Research Laboratory (CERL). The CERL Principal Investigator was E. William East. Ms. Jana Kelly was the principal author at Research Center Enterprises, Inc. The technical editor was Linda L. Wheatley, Information Technology Laboratory - Champaign. Dr. Moonja Kim is Acting Chief, CF-N, and Michael Golish is Chief, CF. The associated Technical Director is Dr. Paul Howdyshell, CVZT. The Acting Director of CERL is Dr. Alan W. Moore.

CERL is an element of the U.S. Army Engineer Research and Development Center (ERDC), U.S. Army Corps of Engineers. The Commander and Executive Director of ERDC is COL John Morris III, EN and the Director of ERDC is Dr. James R. Houston.

DISCLAIMER: The contents of this report are not to be used for advertising, publication, or promotional purposes. Citation of trade names does not constitute an official endorsement or approval of the use of such commercial products. All product names and trademarks cited are the property of their respective owners. The findings of this report are not to be construed as an official Department of the Army position unless so designated by other authorized documents. 


\section{Contents}

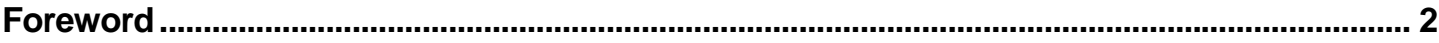

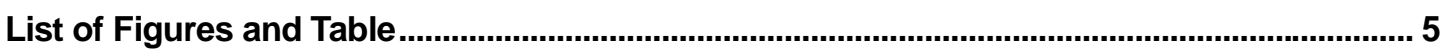

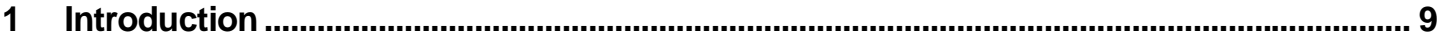

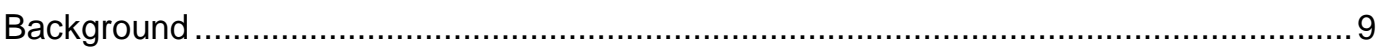

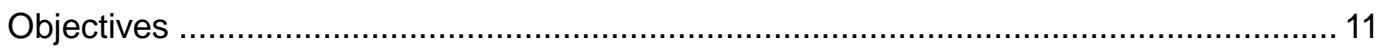

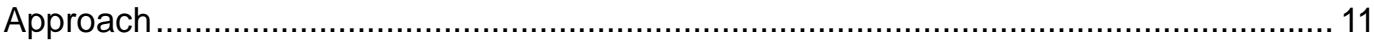

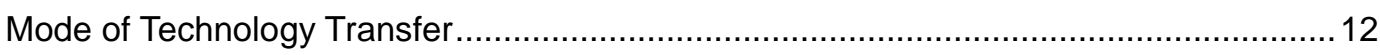

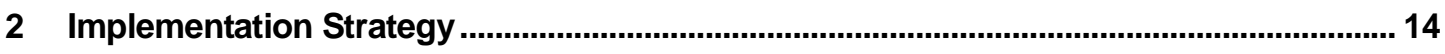

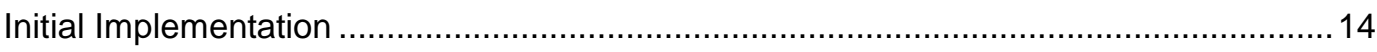

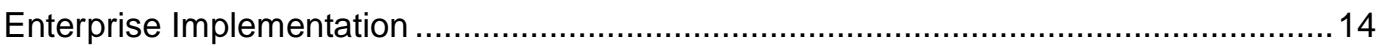

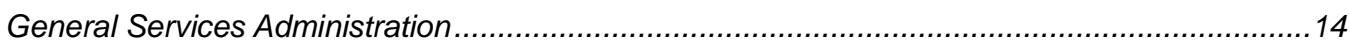

Naval Facilities Engineering Command ........................................................................ 14

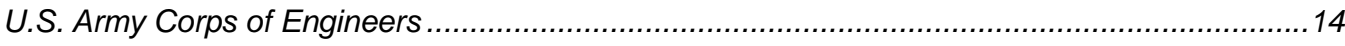

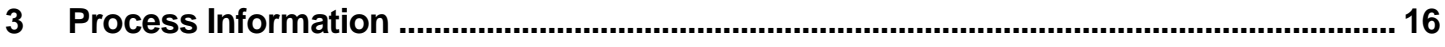

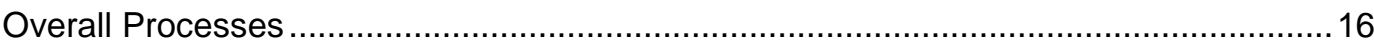

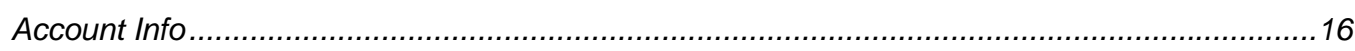

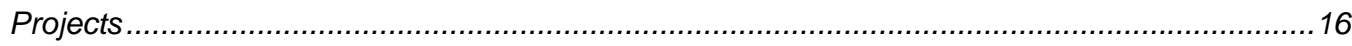

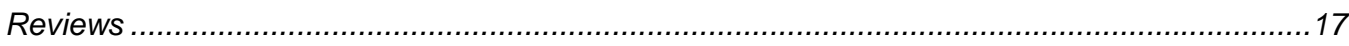

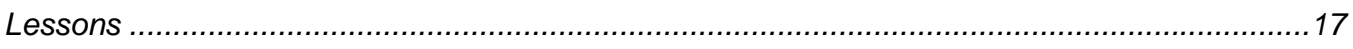

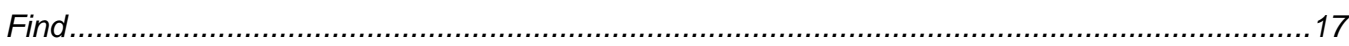

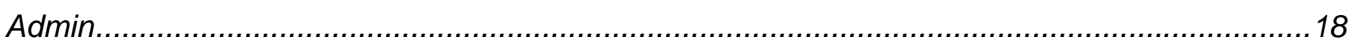

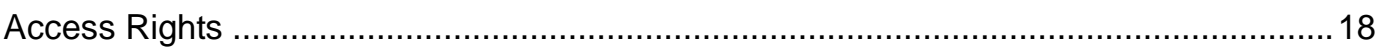

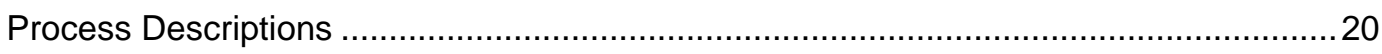

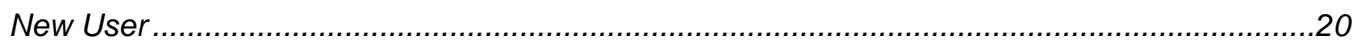

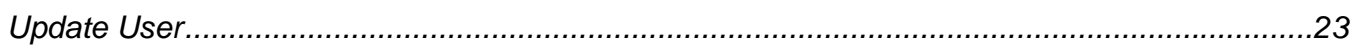

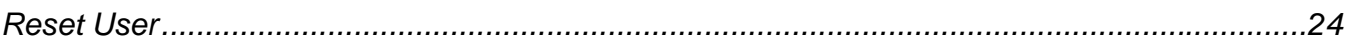

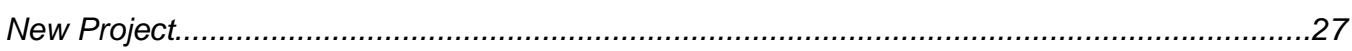

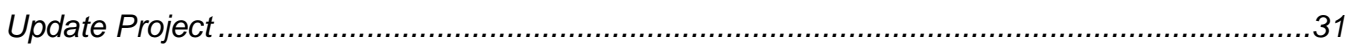

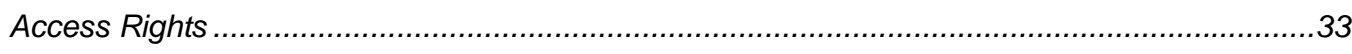

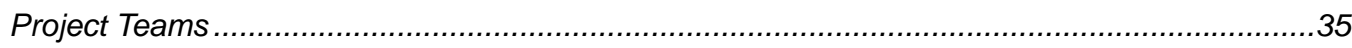

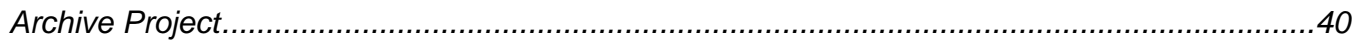

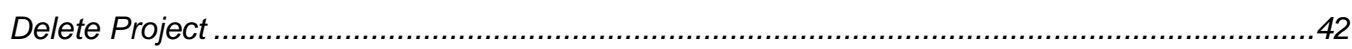




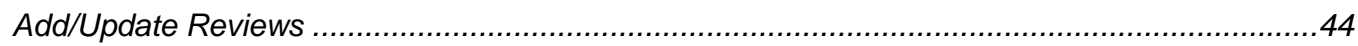

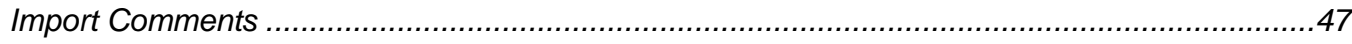

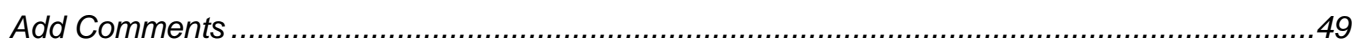

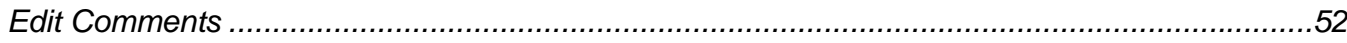

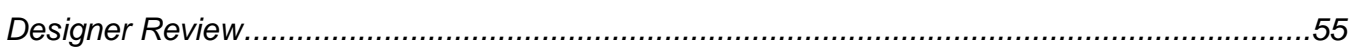

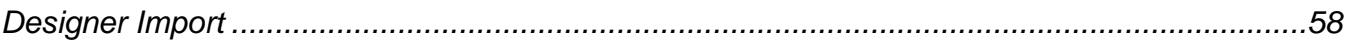

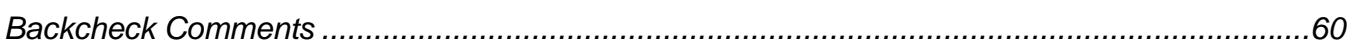

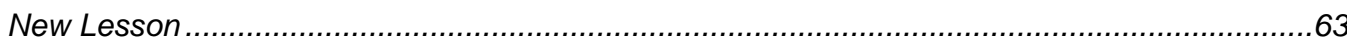

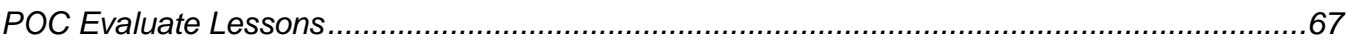

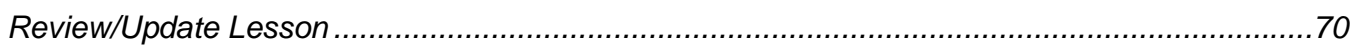

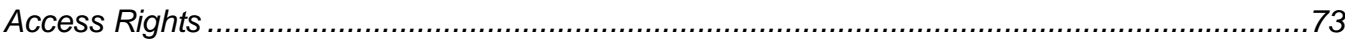

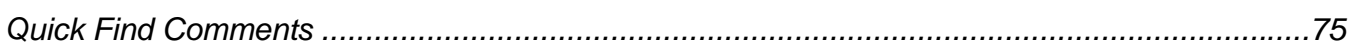

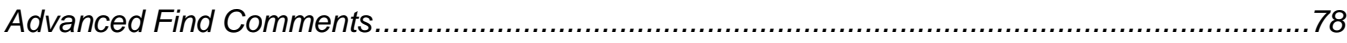

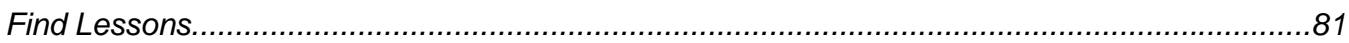

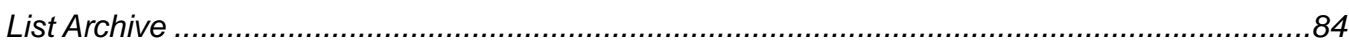

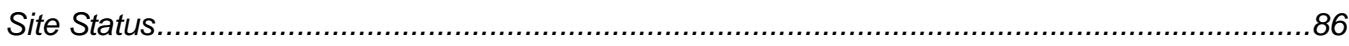

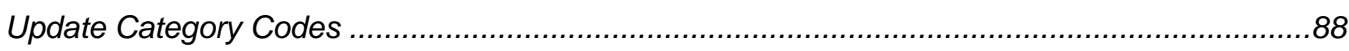

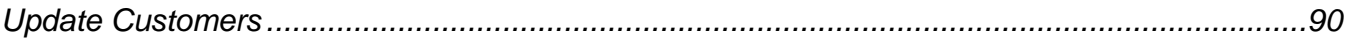

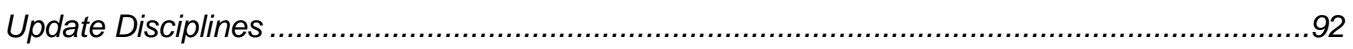

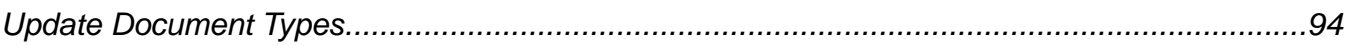

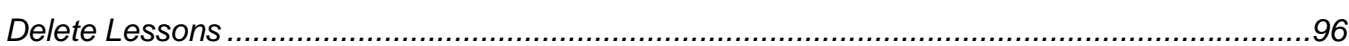

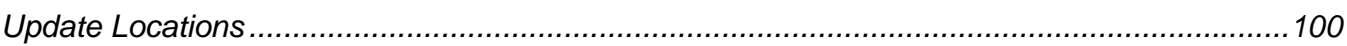

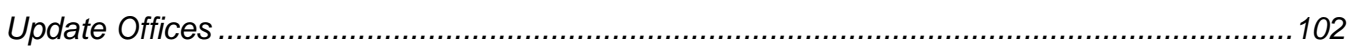

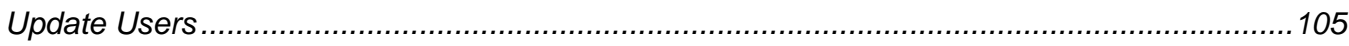

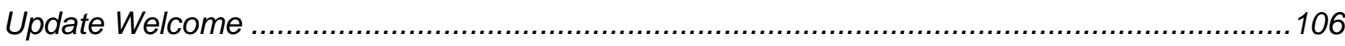

4 DrChecks Current Usage Statistics …........................................................................ 108

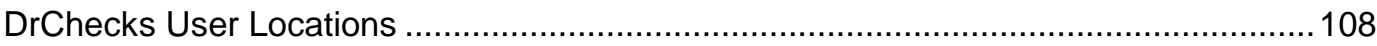

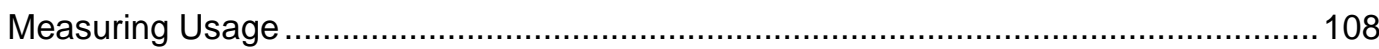

Examining Use Patterns for High-Use Subscribers ...................................... 109

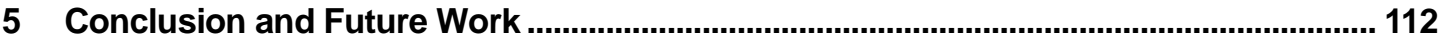

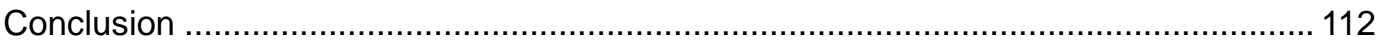

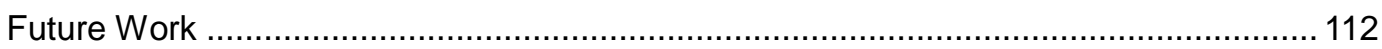

CERL Distribution................................................................................................................. 113

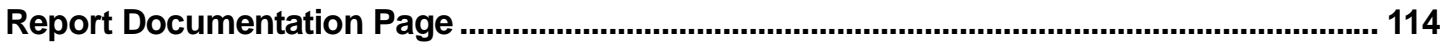




\section{List of Figures and Table}

\section{Figures}

\begin{tabular}{|c|c|}
\hline 1 & Process of adding a new user...................... \\
\hline 2 & New User Part $1 .$. \\
\hline 3 & Process of updating a user ......... \\
\hline 4 & Update User Part 1 .............. \\
\hline 5 & Process of resetting a user. \\
\hline 6 & Reset User Part $1 \ldots \ldots \ldots \ldots \ldots \ldots \ldots$ \\
\hline 7 & Process of creating a project \\
\hline 8 & New Project Part 1 . \\
\hline 9 & New Project Part 2 \\
\hline 10 & 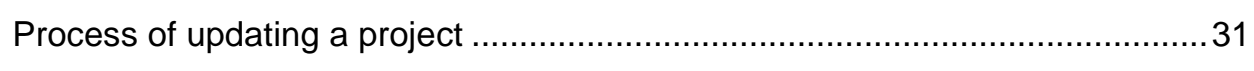 \\
\hline 11 & Update Project Part 2 \\
\hline 12 & 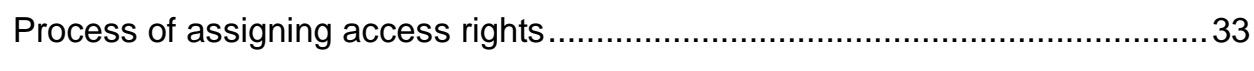 \\
\hline 13 & 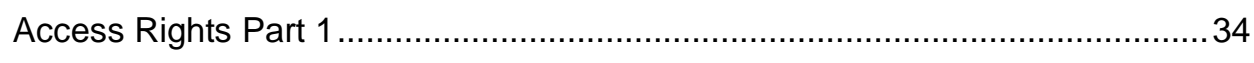 \\
\hline 14 & Access Rights Part $2 \ldots \ldots \ldots \ldots \ldots \ldots \ldots \ldots \ldots \ldots$ \\
\hline 15 & 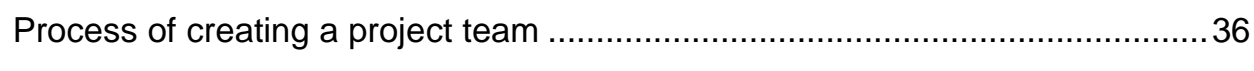 \\
\hline 16 & Project Teams Part $1 \ldots \ldots \ldots \ldots \ldots \ldots$ \\
\hline 17 & Project Teams Part 4 \\
\hline 18 & Process of archiving a project... \\
\hline 19 & Archive Project Part 2 .................... \\
\hline 20 & Process of deleting a project... \\
\hline 21 & Delete Project Part 2..... \\
\hline 22 & 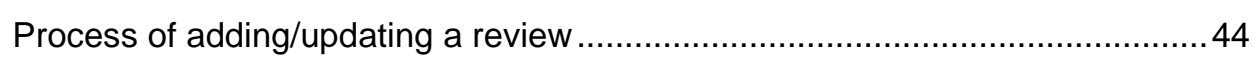 \\
\hline 23 & Add/Update Review Part 2 - Add New Review .. \\
\hline 24 & Add/Update Review Part 2 - Update Current Review......... \\
\hline 25 & Process of importing comments.... \\
\hline 26 & Import Comments Part 2 ............... \\
\hline 27 & Import Comments Part $3 \ldots \ldots \ldots . . .$. \\
\hline 28 & Process of adding comments............... \\
\hline & Add Comments Part 3.... \\
\hline
\end{tabular}




\begin{tabular}{|c|c|}
\hline 30 & Process of editing comments ................. \\
\hline 31 & Edit Comments Part $3 .$. \\
\hline 32 & Edit Comments Part 4 .. \\
\hline 33 & Process of design review ........... \\
\hline 3 & Designer Review Part 4 ................................. \\
\hline 3 & Design Review Part 4 (continued) ...................... \\
\hline 3 & 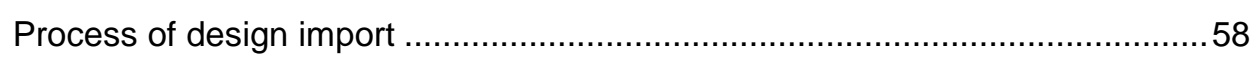 \\
\hline 37 & Designer Import Part $2 \ldots \ldots \ldots \ldots \ldots \ldots \ldots \ldots \ldots$ \\
\hline 38 & Process of backcheck comments ........................... \\
\hline 39 & Backcheck Comments Part $4 \ldots \ldots \ldots \ldots \ldots \ldots \ldots \ldots \ldots \ldots \ldots \ldots \ldots \ldots \ldots$ \\
\hline 4 & Backcheck Comments Part 4 (continued) .............. \\
\hline 41 & Process of adding a new lesson .............. \\
\hline 4 & New Lesson Part 1 .................................. \\
\hline 43 & New Lesson Part 1 (continued)..................... \\
\hline 4 & 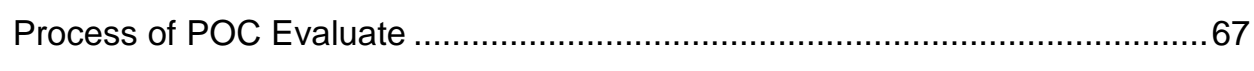 \\
\hline 45 & POC Evaluate Part $2 \ldots$. \\
\hline 46 & POC Evaluate Part 2 (continued) .............................. \\
\hline 47 & Process of review/updating a lesson ....................... \\
\hline 48 & Review/Update Lessons Part 2..... \\
\hline 49 & Process of assigning access rights to a lesson ....... \\
\hline 50 & Lesson Access Rights Part 1 ................. \\
\hline 5 & Process of quick find comments .................. \\
\hline 52 & Quick Find Comments Part 1 ................ \\
\hline 53 & Quick Find Comments Part $2 \ldots \ldots \ldots \ldots \ldots \ldots \ldots \ldots$ \\
\hline 54 & Process of advanced find comments .......................... \\
\hline 55 & Advanced Find Comments Part 1 .............................. \\
\hline 56 & Advanced Find Comments Part 2 ........... \\
\hline 57 & Process of finding lessons \\
\hline 58 & Find Lessons Part 1 ........................ \\
\hline 59 & Find Lessons Part 2 \\
\hline 6 & Process of listing an archive ............... \\
\hline 61 & View Archive Part 1 \\
\hline 6 & 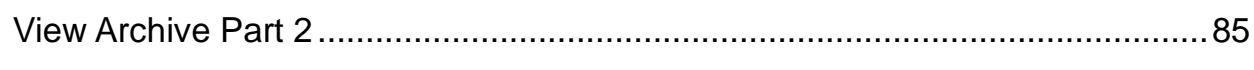 \\
\hline 63 & 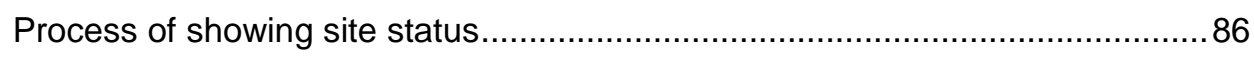 \\
\hline 6 & 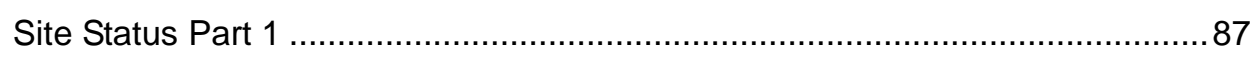 \\
\hline 65 & 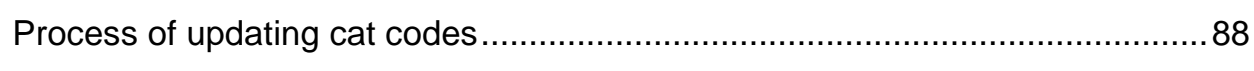 \\
\hline & pdate Cat Codes Part $1 \ldots \ldots \ldots \ldots . . .$. \\
\hline
\end{tabular}




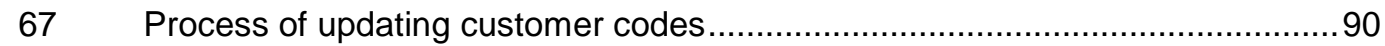

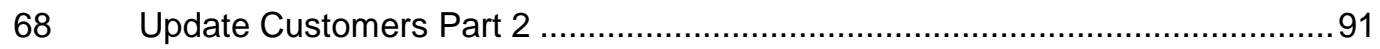

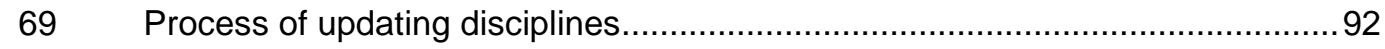

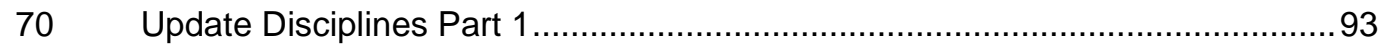

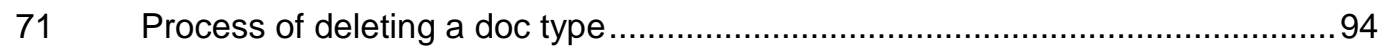

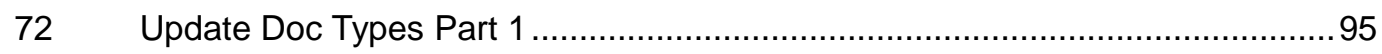

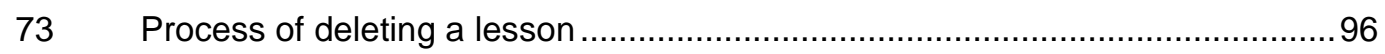

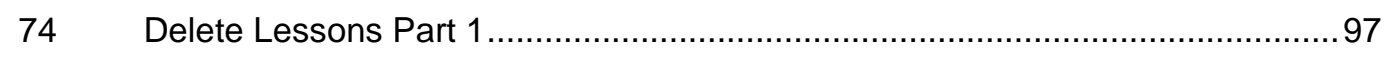

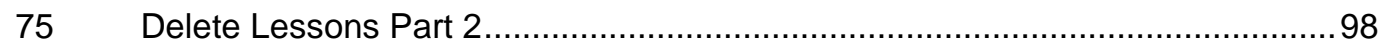

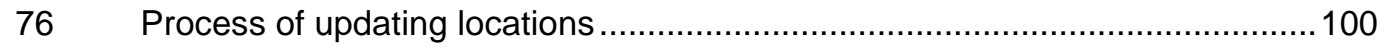

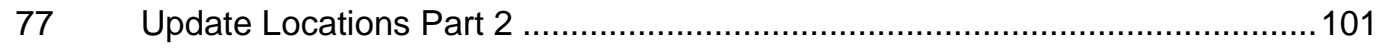

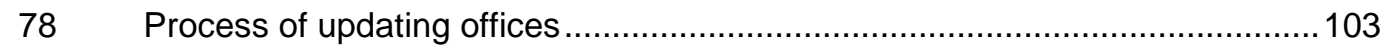

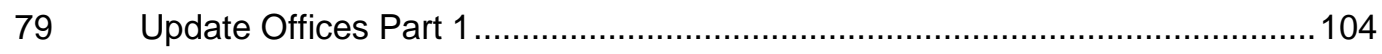

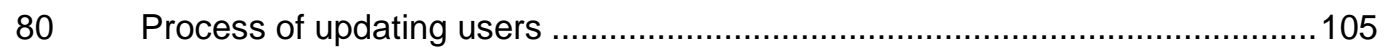

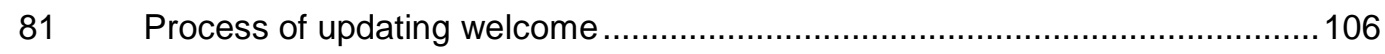

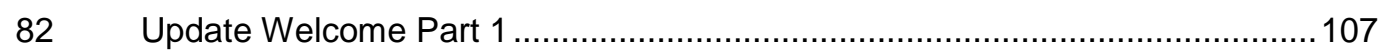

83 Total comments for 1999 and 2000 arranged by months ............................... 109

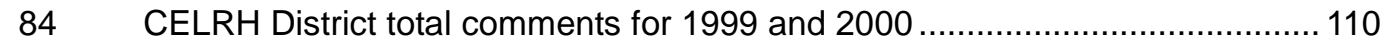

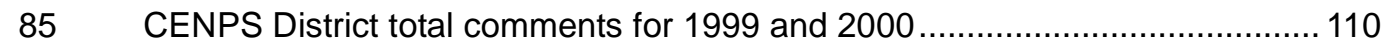

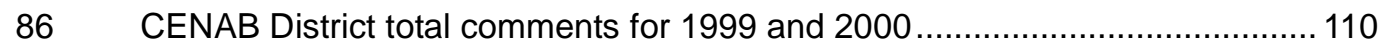

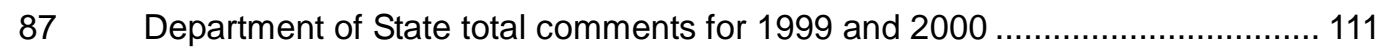

\section{Table}

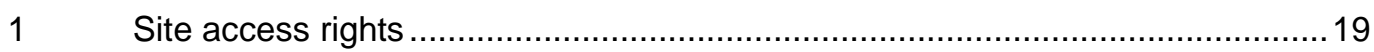





\section{Introduction}

\section{Background}

The U.S. Army Corps of Engineers (USACE) manages design and construction activities for Army, Air Force, and many other Federal and non-Federal agencies. Given the high turnover of experienced personnel throughout the Architect/Engineer/Contractor (A/E/C) community, the capture, evaluation, and use of organizational knowledge such as lessons learned, success stories, and good work practices are essential if the quality of Corps products is to continue to be high.

Past experience has shown that proprietary, stand-alone systems that capture and use lessons learned are too expensive to maintain over time. An integrated approach that uses commercially available software is needed. The intersection of the process whereby organizational knowledge can be captured and evaluated, and the process of design and Biddability, Constructability, and Operability (BCO) reviews provides one of the best points at which to develop an integrated method. Turning an individual's unique project learning into corporate knowledge is the essential core of the effort behind Design Review and Checking System (DrChecks) and its companion Corporate Lessons Learned (CLL).

In developing this capability, issues that needed to be addressed included: the requirement to match the type of review conducted with the nature of the project under design; the need for flexibility in defining how organizational knowledge is to be captured, reviewed, and reused; an investigation of communication techniques that would be as useful across town as they would be around the globe; the need for system security; the high cost of operating and maintaining current automated systems; the need to reduce the burden imposed on users who are forced to constantly upgrade and re-learn software systems; and the requirement to provide appropriate reference materials to personnel as needed.

DrChecks/CLL uses a secure, Internet-based, client-server system architecture. All users access the program using free, commercially available browser software. A 1-hour demonstration is all the training required. Long-term operations and maintenance costs of DrChecks/CLL are significantly less than traditional software because DrChecks/CLL is composed primarily of Commercial-Off- 
the-Shelf (COTS) components. There are no per-user fees or distribution charges.

DrChecks/CLL (hereafter referred to as DrChecks) has six different types of users: project managers, reviewers, customers, designers, lessons-learned points of contact (POCs), and administrators. Project managers create review phases for each project. Reviewers and customers conduct design reviews and submit potential lessons learned. The designer evaluates review comments that then become part of revised plans and specifications. Discipline-specific lessons-learned POCs determine if a pending item has a real impact on operations, is factually or technically correct, and has application to a specific process or component. Administrators are able to customize the DrChecks program, system title, search and indexing pick lists, and many other features, allowing the system to be customized for any site by someone with no computer programming knowledge.

The user-specific interface of DrChecks allows each user to see only those functions and information appropriate for the job at hand. A complete history of every comment and designer evaluation is provided with names, telephone numbers, and email addresses so that users can easily identify and follow-up on critical issues. With DrChecks, users can spend more time doing their jobs and less time learning software. One manager even joked, "DrChecks is too successful. Designers and reviewers are actually talking with one another."

Recognized as "Best of Breed" by a 1998 U.S. Army Corps of Engineers (USACE) Headquarters Lessons Learned task force, DrChecks was approved for operational testing by the USACE Board of Directors and designated an official USACE Automated Information System (AIS) in May 1998. DrChecks was recognized by the Office of the Secretary of Defense, Quality Management as a "Quality Management Best Practice" in 1999, and is now used throughout USACE and the Department of State's Office of Foreign Building Operations. In May 2001, Headquarters USACE mandated the use of DrChecks throughout the Corps in Fiscal Year (FY) 02.

Due to the flexibility of DrChecks, offices, large or small, can use this system. This flexibility is available due to the common business model used within DrChecks. So that offices of all sizes can use DrChecks, the personal settings can be customized. The overall site can be changed to include the office's name, a welcome message, and an information page footer. An office can also change codes within the program to meet its needs. These codes are disciplines, project category codes, customer codes, location codes, and document types. 


\section{Objectives}

DrChecks has four objectives:

1. Improve project quality - Project quality is improved by teams being allowed to identify issues before a project milestone is missed. Past comments and lessons are kept in the database and can be applied by reviewers when reviewing a comment or lesson. The program also uses a standardized process that helps the customers and designers to easily complete their reviews for a project.

2. Reduce construction change orders - DrChecks provides a reliable way for users to communicate with others. This communication increase allows users to inform others of problems immediately before decisions are made. In turn, the number of construction change orders is reduced.

3. Make small improvements in design that equal a large life-cycle return - When a change is made in the design, the whole project is affected. DrChecks will allow users to track those changes and make quick decisions about the affected project.

4. Improve satisfaction and usefulness of the facility - DrChecks has improved satisfaction and usefulness because it is easy to use. Users can enter comments either by file or directly on the site, and designers can review comments submitted. Users can also find the status of the site that includes comment summary information.

\section{Approach}

DrChecks is the latest in a series of products developed by the Engineer Research and Development Center's (ERDC's) Construction Engineering Research Laboratory (CERL) to enhance design quality. The detailed requirements for DrChecks were developed by the Design Review Tools Steering Committee in FY 96 and FY 97. The committee includes people from across USACE who conduct or manage design reviews and those people who develop design review products and set regional or national USACE policy regarding design reviews. Users from within and outside USACE tested DrChecks in FY 97. Based on those tests, the system revisions were implemented.

The World Wide Web (WWW) provides the communications backbone of DrChecks, which users access with commercially developed, free web browser software. Project participants without a permanent web connection can use commercial services for under $\$ 20$ per month. The hardware and software to operate a local DrChecks server are also very inexpensive commercial products. These products are either of the commercial-grade web server systems from 
Microsoft ${ }^{\circledast}$ and Netscape ${ }^{\circledast}$; the Cold Fusion ${ }^{\circledast}$ web-database query software; and the Microsoft ${ }^{\circledast}$ Access $^{\mathrm{TM}}$ database. The total cost of the DrChecks system for most offices will be under $\$ 600$. The use of such simple and inexpensive commercial software also means that personnel with limited software engineering knowledge can make local modifications to the system as needed.

DrChecks is a cost-effective, useful way to capture, manage, and use corporate knowledge in the context of a fully functional design review tool. Considering that current unrealized costs from a simple design review may reach 5 percent of the overall construction budget, the application of online organizational experience should double those customer savings. Customer satisfaction should also increase as the criteria used by various customers are documented in success stories and lessons learned. An even more important aspect of DrChecks is that the system can bring project stakeholders together to produce the best possible design given the variety of constraints that make each project unique. Finally, the overall cost of the design review features of DrChecks could be significantly lower than the cost of currently used methods and technology.

\section{Mode of Technology Transfer}

Potential users typically review and/or utilize the system on a trial basis before making a decision to adopt DrChecks organization-wide. The General Services Administration (GSA) has purchased one site license for the system and is currently determining whether to adopt it throughout all 11 of its regions. Naval Facilities Engineering Command (NAVFAC) on the other hand reviewed the system and decided to adopt it without a test period. The Federal Aviation Administration (FAA) is evaluating DrChecks as a potential Government-Off-the-Shelf (GOTS) software service provided by CERL. DrChecks is in use at one-third of the Corps Districts and is available for commercial use. Since the Corps has mandated the use of DrChecks by all Districts in FY 02, the economies of scale will reduce the effective site-license costs by one-third.

Currently, CERL is operating DrChecks project sites for a large number of Districts in the Continental United States (CONUS) and the Europe District. CERL also assists the Department of State and three Districts (Honolulu, Japan, and Korea) in the Pacific Ocean Division (CEPOD) that operate their own DrChecks servers. CERL support for DrChecks sites includes web server management, daily and weekly server backups, toll-free telephone support, and a technical support bulletin board for a per-project fee. Delivery of DrChecks to individual offices can be arranged depending on the specific requirements for a given office. 
Training and presentation materials are provided online. This report is accessible through the WWW at http://www.cecer.army.mil. 


\section{Implementation Strategy}

\section{Initial Implementation}

Initial fielding of DrChecks was on a voluntary annual license purchase basis. Beginning in FY 98 with 4 Corps of Engineer Districts, the number of subscribing users has steadily grown to 9 in FY 99, 13 in FY 00, and 16 in FY 01. During this period, other agencies such as the Department of State Foreign Building Office and GSA began to use DrChecks.

\section{Enterprise Implementation}

\section{General Services Administration}

GSA has indicated an interest in standardizing on the use of DrChecks for all of their 11 regions. Initial testing must be completed prior to an organization-wide implementation decision. The GSA POC has indicated a desire to include user training in their implementation at all regions.

\section{Naval Facilities Engineering Command}

While NAVFAC has agreed to implement DrChecks throughout the organization, initially they will purchase licenses for their four major Engineering Field Divisions (EFDs). Future additional licenses would be required for DrChecks to support each organization that actually runs (controls) the design review process.

\section{U.S. Army Corps of Engineers}

Successful completion of field testing of DrChecks with the CLL Module in Fall 1999 offered the possibility for integrating corporate lessons learned capabilities across a number of other key USACE business processes. During the 13-15 June 2000 Directors of Programs Management/Engineering Technical Services (DPM/DETS) Laydown, a decision was made to adopt DrChecks as the Corps' official design review, lessons learned, and feedback system. As a result of that meeting DrChecks was chosen to supersede the Automated Review Management System (ARMS) as the required repository for collating and transmitting project 
review comments. Consistent with this policy, Engineer Regulation (ER) 1110-18154 that mandated use of ARMS was rescinded by Engineer Circular (EC) 25-1292 dated 4 October 2000. A new ER 1110-1-8159 issued in May 2001 reflected this decision.

Along with the decision to standardize on DrChecks, enterprise-wide funding will be provided for all Districts. A phased-in approach will be followed so existing projects can be completed without converting to DrChecks mid-stream. Full implementation is expected by the FY 04 timeframe. 


\section{Process Information}

\section{Overall Processes}

Users will find many options in DrChecks to help them communicate with coworkers while keeping accurate records of activities that are being worked on or completed for a job. Options are divided according to access rights of each user and by type of activities to be performed. A brief description of these processes are listed below and categorized as they are in DrChecks. Further details on how these processes work and what information is collected in each process are discussed later in this chapter.

\section{Account Info}

The "New User" screen shows the registration form for users new to DrChecks. A user must have the office password to which they are associated. Once registered, the user receives a personal password. The "Update User" screen provides a form to change user information if needed. Information given during registration is automatically pre-filled. The "Reset User" screen allows a user to reset the user settings for DrChecks to their own settings. The password that should be used here is the personal password that was assigned after initial registration.

\section{Projects}

Activity details are stored in a project. When created in the "New Project" screen, a project should contain information concerning the type of project and its expected duration. Project managers use the "Update Project" screen to edit project details such as calendar dates and project categories. A project manager needs to use "Access Rights" to assign individuals or groups to a project. Access rights are required $\mathrm{k}$ on a project as one unit instead of assigning individual access rights to each person. Projects contain reviews that represent phases in a project. When a phase is complete and no longer active, a project manager can use the "Archive Project" screen to archive the review, making it read only. A project manager should use the "Delete Project" process if the project is complete and no longer needs to be accessed. It is advised, however, that the project be archived before deletion because the deletion is not reversible. 


\section{Reviews}

A review represents a phase in a project. A review can be created in "New/ Update" by identifying the name and expected duration. If a review is already created, a user can edit review details in this process as well. A review contains comments from users while communicating about a project. A user can use "Import Comments" to import a comment into a review when the comment is located in a different file. A review can also contain comments that are entered by users. If a user in DrChecks would like to enter a comment, the "Add Comments" process may be used. Once a comment is added, it is left pending until a designer reviews it. Pending comments are the only comments with fields that can still be edited in the "Edit Comment" process (if needed). A reviewer creates the comment and the designer reads the comment and replies in the "Designer Chk" process. The designer should specify concurrence or no concurrence and comment on why. A reviewer can use the "Designer Import" process to reply to pending comments when the reply is located in a different file. In "Backcheck," if a comment has been reviewed, a designer may close the comment or leave it open for further review.

\section{Lessons}

The "New Lesson" form is for reporting a problem or an idea that needs to be looked into further. A lesson is submitted to a POC who uses "POC Evaluate" to evaluate the lesson and determine if it is valuable. A pending lesson may be updated in the "Review/Update Lesson" screen. If a lesson is approved or disapproved, a user may review it. If disapproved, a user may also resubmit the lesson. Only certain people are POCs and allowed to review a lesson. If a user wants to assign POC rights to another, they may do so in the "Lesson Access Rights" process.

\section{Find}

The "Quick Find Comments" process allows a user to search for a comment in the database by specifying a keyword(s) or by searching all comments. The "Advanced Find Comments" process allows a user to narrow a search for a comment by providing various fields to search. "Find Lessons" allows a user to identify search criteria to find a specific lesson. After a review has been archived, a user will be able to view the archive address and have the opportunity to see the archive in the "View Archive" process. The "Site Status" screen shows summaries of activities on a site or reports on category information. 


\section{Admin}

The "Update Cat Codes" process allows a user to either add or update category code information. The "Update Customers" process allows a user to either add or update customer information. Customer information represents the agency an office is listed under. The "Update Disciplines" process allows a user to either add or update discipline information. The "Update Doc Types" process allows a user to either add or update document type information. The "Delete Lessons" process allows a user to search for and delete a specific lesson by identifying criteria. Deleting a lesson is not reversible. The "Update Locations" process allows a user to either add or update location information. The "Update Offices" process allows a user to either add or update office information. The "Update Users" process allows a user to either add or update user information. An information list for each employee within the District can also be retrieved. The "Update Welcome" process allows a user to update what others see on the screen. The screen consists of the header, body, and footer, which are all required.

\section{Access Rights}

Activities in DrChecks are categorized by the type of users who use them. Access rights allow users to work with these specific activities. The grid in Table 1 shows access rights for the different types of users. The ' $\mathrm{X}$ ' indicates an access right that is given to a user classified as that type. If access has not been assigned, the user receives an error message. A user can be more than one type of user at the same time. He/she may be a reviewer, designer, and manager and have all of the access rights that go with each type. Another user may be a designer only. Table 1 shows a grid that represents users assigned to one user type only. 
Table 1. Site access rights.

\begin{tabular}{|c|c|c|c|c|c|}
\hline & Managers & Designers & Reviewers & Customers & Administrators \\
\hline \multicolumn{6}{|l|}{ Account Info } \\
\hline New User & $x$ & $x$ & $x$ & $X$ & $X$ \\
\hline Reset User & $x$ & $x$ & $X$ & $X$ & $x$ \\
\hline Update User & $x$ & $x$ & $x$ & $x$ & $x$ \\
\hline \multicolumn{6}{|l|}{ Project } \\
\hline New Project & $\mathrm{X}$ & & & & $\mathrm{X}$ \\
\hline Update Project & $x$ & & & & $x$ \\
\hline Access Rights & $\mathrm{X}$ & & & & $X$ \\
\hline Project Teams & $x$ & $x$ & $x$ & $X$ & $x$ \\
\hline Archive Project & $\mathrm{X}$ & & & & $X$ \\
\hline Delete Project & $X$ & & & & $X$ \\
\hline \multicolumn{6}{|l|}{ Reviews } \\
\hline New/Update Review & $x$ & & & & $x$ \\
\hline Import Comments & $\mathrm{X}$ & & & & $X$ \\
\hline Add Comments & $x$ & & $x$ & $x$ & $x$ \\
\hline Edit Comments & $x$ & & $x$ & $x$ & $x$ \\
\hline Designer Chk & & $x$ & & & $x$ \\
\hline Designer Import & $x$ & & & & $x$ \\
\hline Backcheck & $x$ & & $x$ & $X$ & $x$ \\
\hline \multicolumn{6}{|l|}{ Lessons } \\
\hline New Lesson & $\mathrm{X}$ & $\mathrm{X}$ & $\mathrm{X}$ & $\mathrm{X}$ & $X$ \\
\hline POC Evaluate & & & & & $x$ \\
\hline Review/Update Lesson & $\mathrm{X}$ & $\mathrm{X}$ & $\mathrm{X}$ & $\mathrm{X}$ & $X$ \\
\hline Access Rights & & & & & $x$ \\
\hline \multicolumn{6}{|l|}{ Find } \\
\hline Quick Find Comments & $x$ & $x$ & $X$ & $X$ & $x$ \\
\hline Advanced Find Comments & $X$ & $X$ & $\mathrm{X}$ & $\mathrm{X}$ & $X$ \\
\hline Find Lessons & $X$ & $x$ & $X$ & $X$ & $x$ \\
\hline View Archive & $\mathrm{X}$ & $\mathrm{X}$ & $\mathrm{X}$ & $\mathrm{X}$ & $\mathrm{X}$ \\
\hline Site Status & $x$ & $x$ & $x$ & $X$ & $x$ \\
\hline \multicolumn{6}{|l|}{ Admin } \\
\hline Update Cat Code & & & & & $x$ \\
\hline Update Customers & & & & & $X$ \\
\hline Update Disciplines & & & & & $X$ \\
\hline Update Doc Types & & & & & $x$ \\
\hline Delete Lessons & & & & & $x$ \\
\hline Update Locations & & & & & $\mathrm{X}$ \\
\hline Update Offices & & & & & $X$ \\
\hline Update Users & & & & & $x$ \\
\hline Update Welcome & & & & & $x$ \\
\hline
\end{tabular}




\section{Process Descriptions}

New User

This section explains how new users enter information about themselves and their offices. It is not possible to execute this sequence without access to the company password, so new users should already have that password when starting. Registered users may enter other users into the system with this page. Figure 1 shows the process steps.

In Part 1 (Figure 2) a user will need to enter items such as first and last names, email address, his/ her office, and the discipline he/ she participates in the most. Part 2 shows all information about that user including the office address and phone number. Once the user has confirmed the information is correct, Part 3 will show the permissions that have been assigned and other rules and regulations that should be observed while using DrChecks.

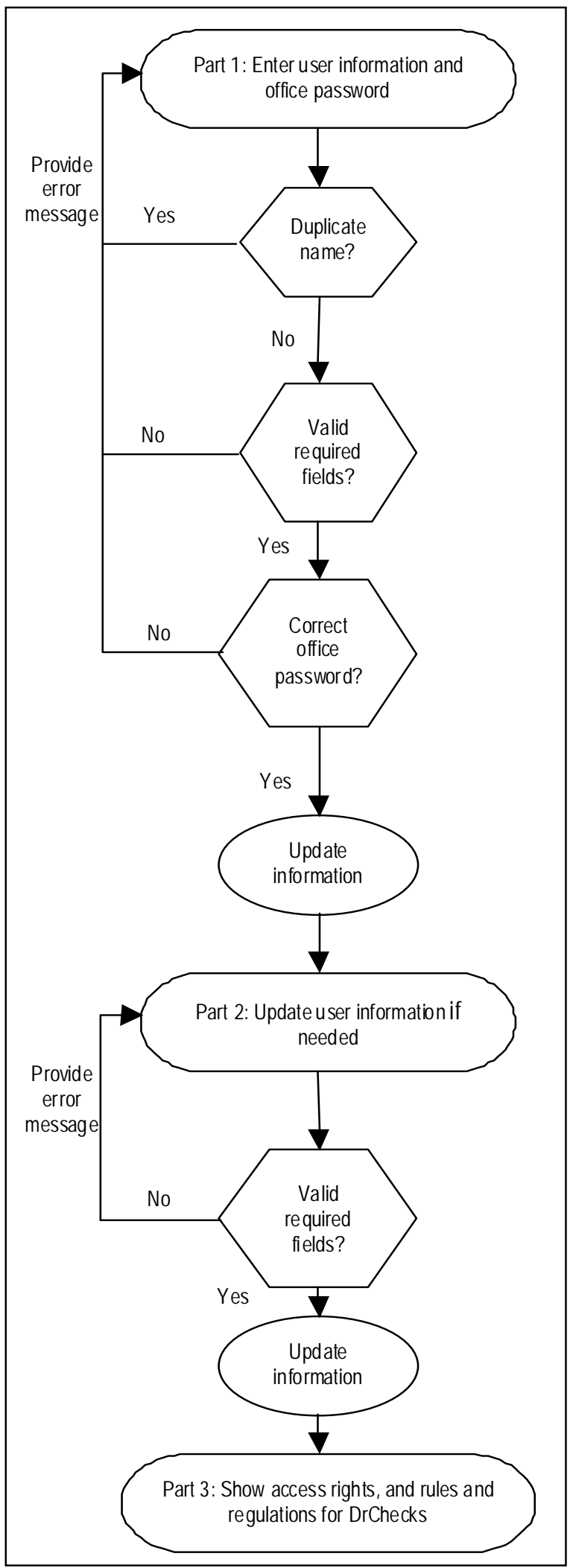

Figure 1. Process of adding a new user. 


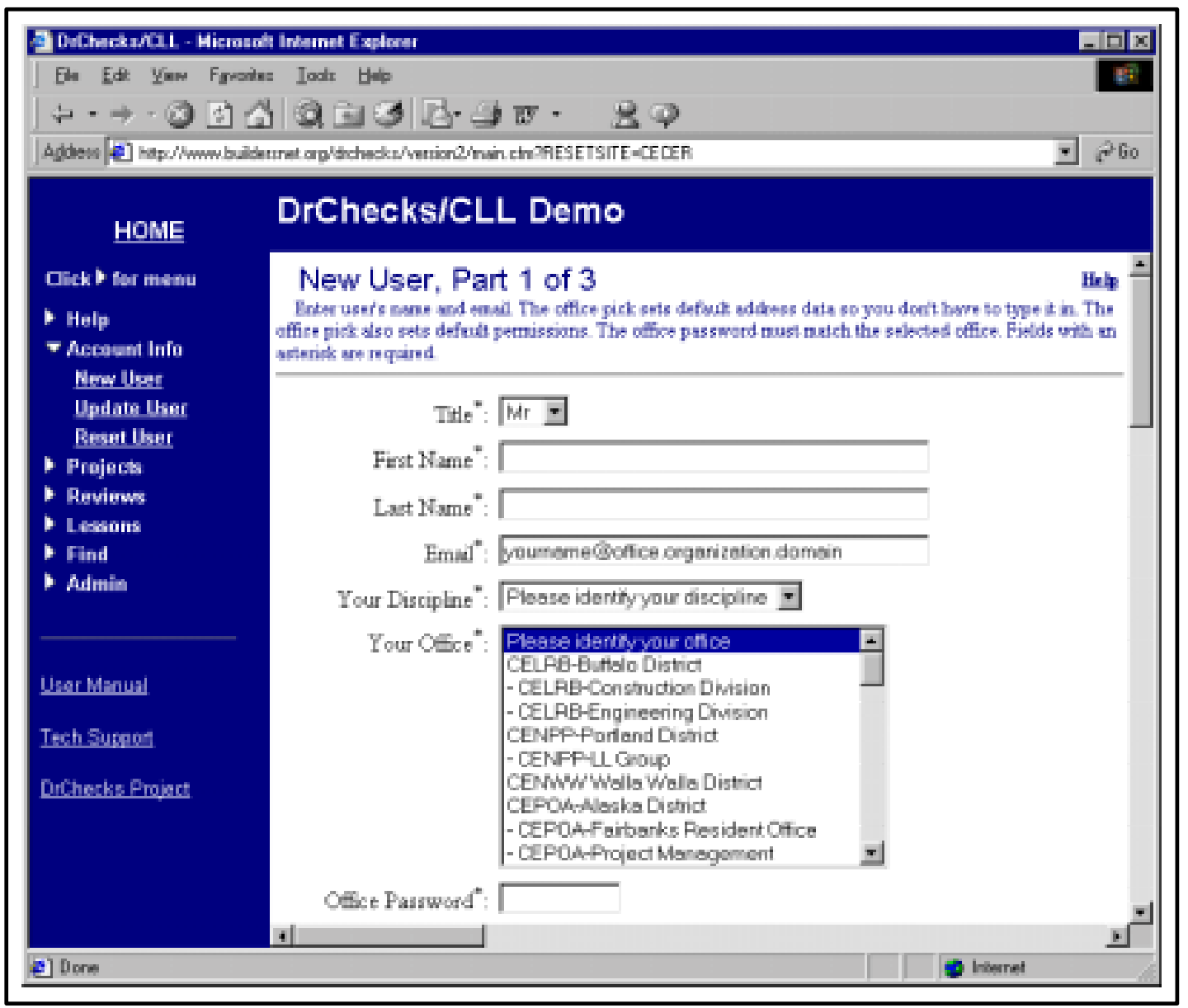

Figure 2. New User Part 1.

Title: The title refers to a person's marital status, education, and gender. Men should use either "Mr." or "Dr." and women should use "Mrs.," "Ms.," or "Dr." A married woman without a doctorate degree is indicated by "Mrs." or "Ms." "Mr." or "Ms." can indicate either single or married status without a doctorate degree. The "Dr." title should be used only for a person who has obtained a doctorate degree regardless of marital status and gender. This field is required.

Name: First and last names legally given to a user. These are required fields.

Phone: The telephone number should be where a user can be contacted regarding DrChecks questions or concerns. The default telephone number is that of the user's office. A user can keep this number or change it to a direct telephone number that can also be reached for DrChecks questions or concerns.

Your Discipline: The discipline is the specialization of the user. A dropdown list of disciplines to choose from is provided. If there is not a distinct discipline a 
user is involved in or the correct discipline is not on the list, he/she should choose "Other" for the discipline. This field is required.

Your Office: A person completes work for the office in which they are employed. Offices are divided into Divisions, Districts, or offices under Divisions or Districts. If the specific office is not listed, he/she should contact the office or Division they are completing work for to find out the correct listing.

Address: The address consists of the street, post office box, city, state, zip code, and mail stop. The default address is that of the user's specified office. These address fields can be revised.

FAX: The fax number is where a copy of a document can be sent electronically without using a computer.

Email: Messages may be sent electronically to this address via computer workstations. This address will be used to mark materials a user submits and to communicate with other users while using DrChecks. It is important to enter the correct email address. This field is required. 


\section{Update User}

User information can be updated here as needed. Data listed in the system for the individual are presented and may be edited as desired. If the information is incorrect, another user may be registered on the workstation. In this case, the user will first need to go to the "Reset the User" section, which is discussed in the next section. Figure 3 shows the process steps. User information on "Update User" Part 1 (Figure 4) can be edited, but no changes will be made until the proper password is entered and the [Continue] button pressed.

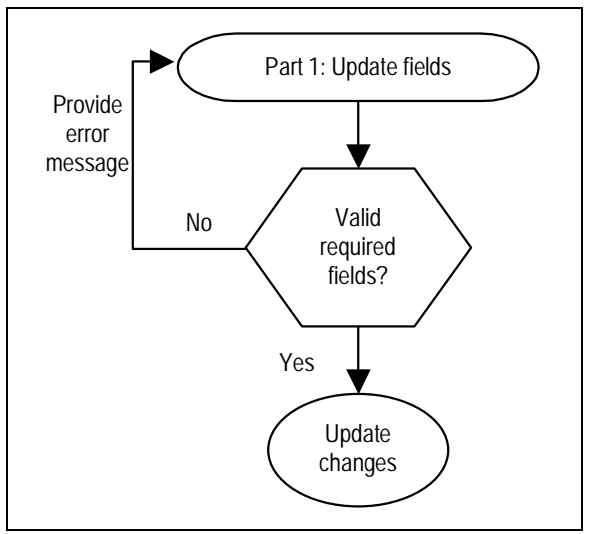

Figure 3. Process of updating a user.

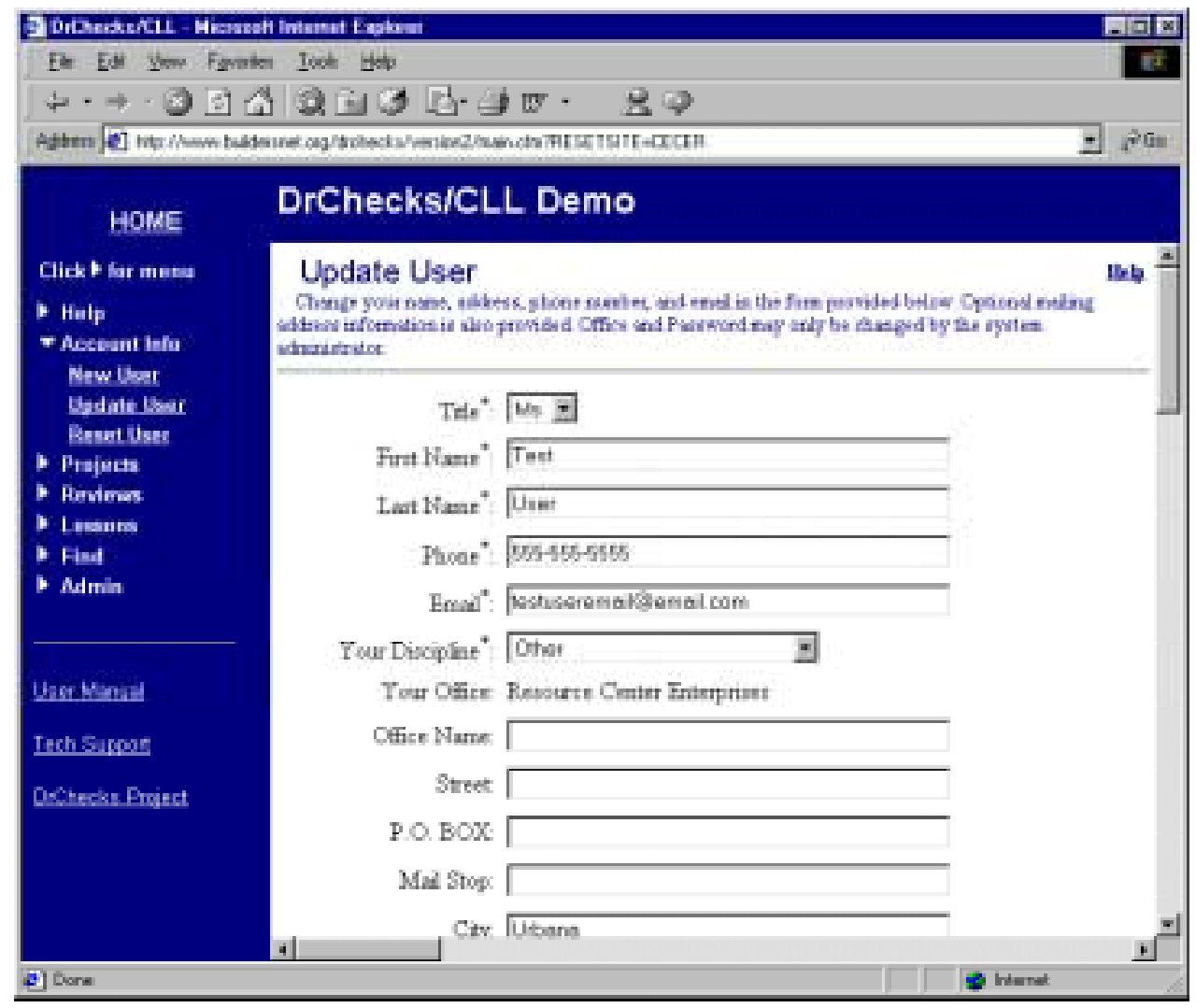

Figure 4. Update User Part 1. 


\section{Reset User}

This section is for current users to reset their security key and simultaneously update user information stored in DrChecks databases. It is not possible to execute this sequence without access to the personal password. Registered users may enter other users into the system with this page. Figure 5 shows the process steps.

To reset the user information, the name of the user and the user's personal password should be entered in the fields in Part 1 (Figure 6) before proceeding to Part 2. The personal password is automatically assigned to a user when his/her account is created. To clear a user account, click on the [Clear Account] button located on Part 1 of "Reset User."

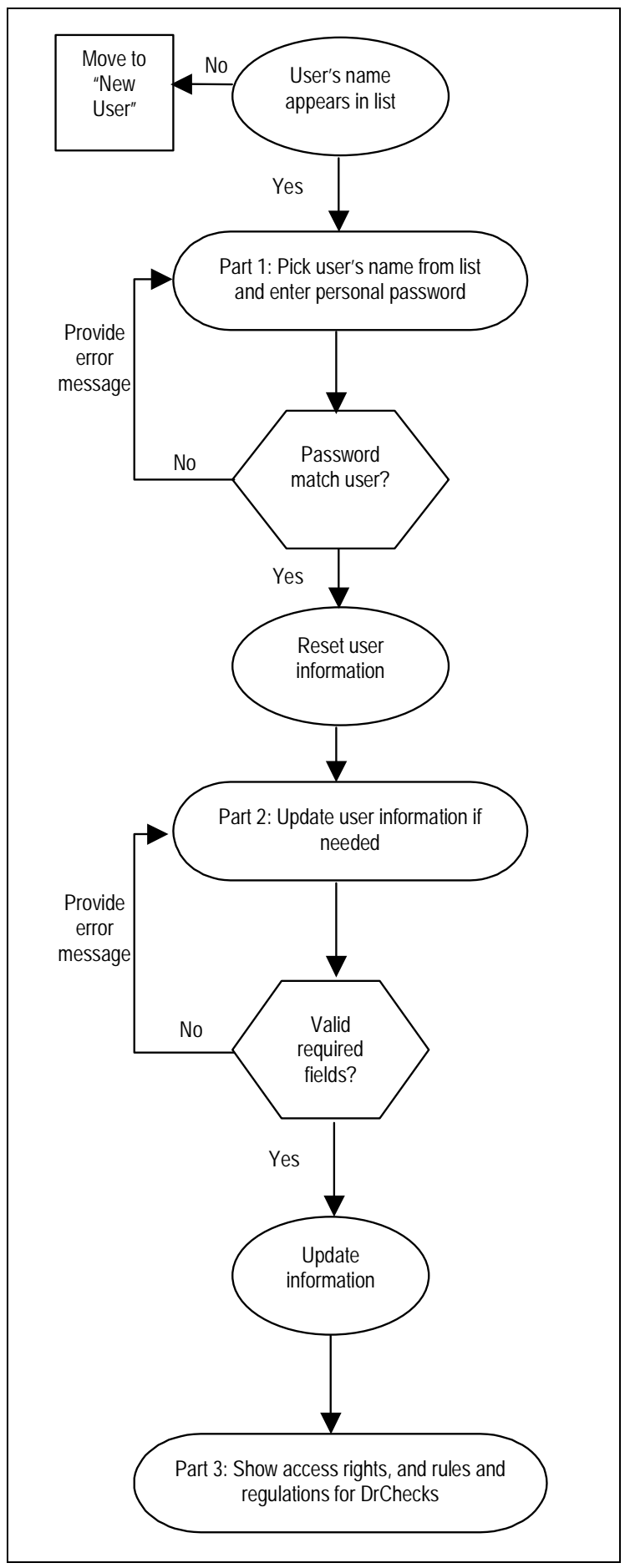

Figure 5. Process of resetting a user. 


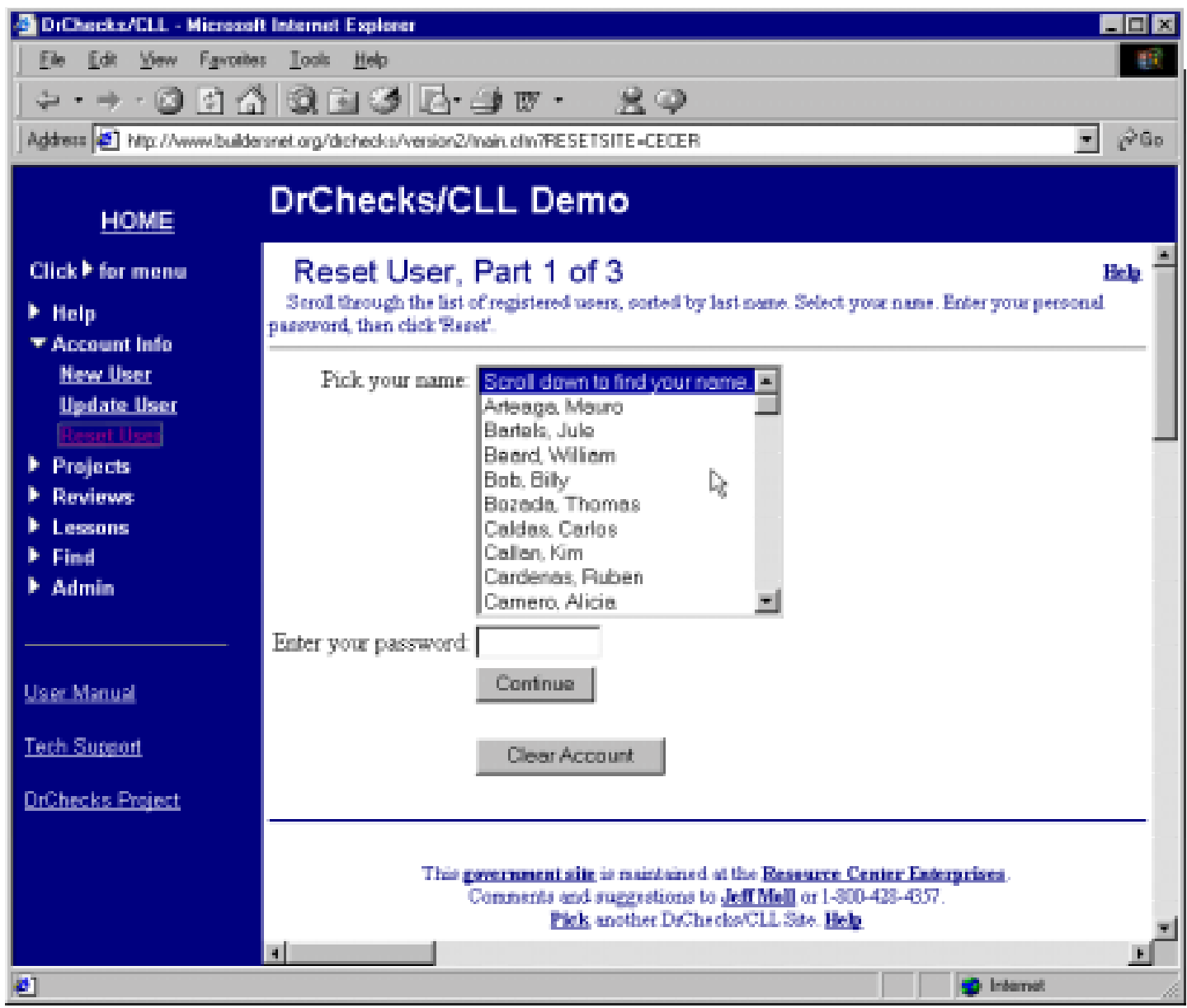

Figure 6. Reset User Part 1.

In Part 2 the user can confirm and/or edit the fields. After account data are entered, the default permissions for the company are assigned to the user. Based on the permissions a user has been assigned, each activity a user is allowed to work on in DrChecks is listed in Part 3.

Title: The title refers to a person's marital status, education, and gender. Men should use either "Mr." or "Dr.," and women should use "Mrs.," "Ms.," or "Dr." A married woman without a doctorate degree is indicated by "Mrs." or "Ms." "Mr." and "Ms." indicate either single or married status without a doctorate degree. The "Dr." title should be used only for a person who has obtained a doctorate degree regardless of marital status and gender. This field is required.

Name: First and last names legally given to a user. These fields are required.

Phone: The telephone number should be where a user can be contacted regarding DrChecks questions or concerns. The default telephone number is that of the user's office. A user can keep this number or change it to a direct telephone 
number that can also be reached for DrChecks questions or concerns. This field is required.

Your Discipline: The discipline is the specialization of a user. A dropdown list of disciplines to choose from is provided. If there is not a distinct discipline a user is involved in or the correct discipline is not on the list, he/she should choose "Other" for the discipline. This field is required.

Your Office: A person completes work for the office in which they are employed. Offices are divided into Divisions, Districts, or offices under Divisions or Districts. If the specific office is not listed, he/she should contact the office or Division they are completing work for to find out the correct listing.

Address: The address consists of the street, post office box, city, state, zip code, and mail stop. The default address is that of the user's specified office. These address fields can be revised.

FAX: The fax number is where a copy of a document can be sent electronically without using a computer.

Email: Messages may be sent electronically to this address via computer workstations. This address will be used to mark materials a user submits and to communicate with other users while using DrChecks. It is important to enter the correct email address. This field is required. 


\section{New Project}

This section of DrChecks is used to create a new project. A project contains reviews and comments about the uncompleted task. The person who creates the project will be the project manager who can assign access rights for the project to other individuals. Figure 7 shows the process steps. In Part 1 (Figure 8), the category code, customer category, and location category need to be chosen from the options listed in the boxes. After clicking on the [Continue] button, the user will proceed to Part 2 (Figure 9).

In Part 2 the project name and the start and end dates should be specified. Also on this screen, the category code, customer category, and location category choices made in Part 1 need to be "narrowed down." All fields must be filled or selected in order to create the project. After a user clicks on [Continue], the new project is in the listing of all other projects for the site.

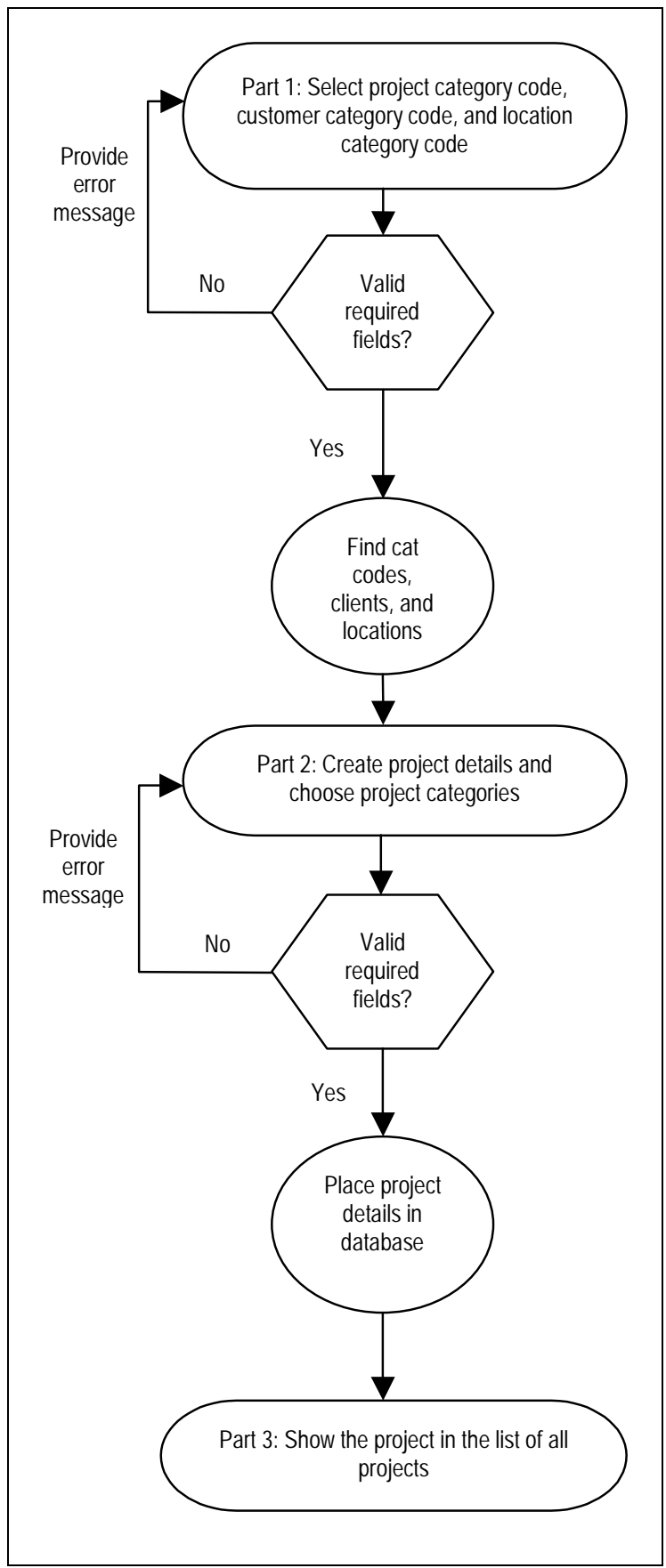

Figure 7. Process of creating a project. 


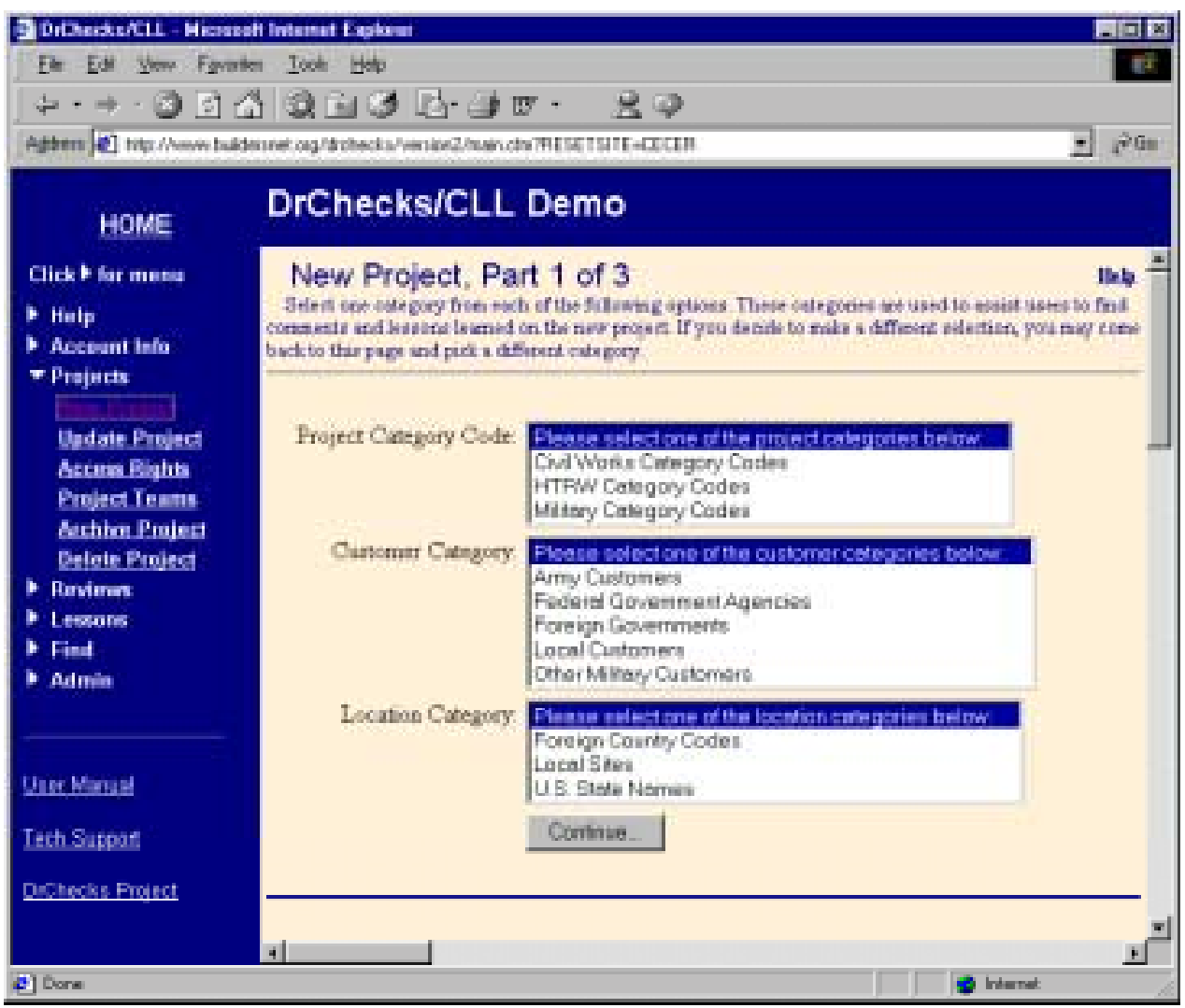

Figure 8. New Project Part 1.

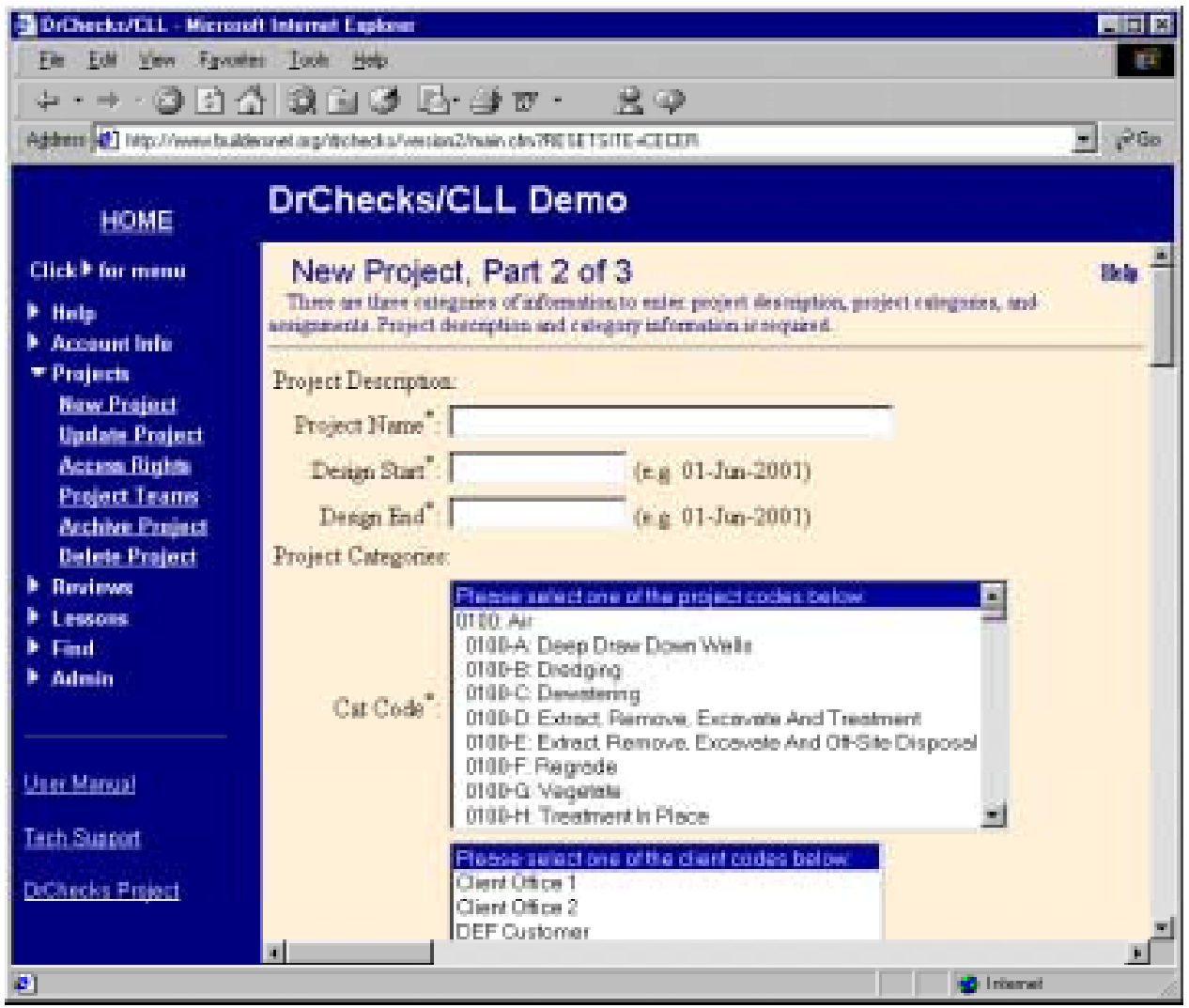

Figure 9. New Project Part 2. 
Project Category Code: The project category code will show what the project activities involve. The code can be one of three types: (1) The Civil Works category code shows activities not broken down into specific facilities or tasks, (2) the HTRW (Hazardous, Toxic, or Radioactive Waste programs) category code shows task-specific activities that may include handling dangerous materials, and (3) military codes show tasks needed for a specific facility. This field is required.

Customer Category Code: The customer category code will show to whom the project pertains. Army customers are the branches of the U.S. Army. Federal Government Agencies are customers that work for the U.S. Government and are not included in the military. Foreign Governments are non-U.S. governments doing business with the DrChecks agency. Local customers are not U.S. Government or military specific. Other Military Customers are the branches of the military not included under the Army Customers. This field is required.

Location Category Code: The location category code shows where the project is located. Foreign Country Codes shows the names of various foreign countries. Local Sites shows nearby locations. U.S. State Names lists all U.S. states. This field is required.

Project Name: The project name is the standard project reference name. The name should be meaningful and typed in correctly because it will be shown on various reports. It is useful to include one keyword that allows unique identification for searching. This field is required.

Design Calendar: The design calendar is for the "Design Start" and "Design End" dates for a project. The design start date should be greater than the design end date. Dates need to be entered in the dd-Mmm-yy format (e.g., 10-Oct-00). This field is required.

Cat Code: The Cat Code is a more specific Civil Works, HTRW, or Military category depending on what Project Category Code was chosen. If the category was Civil Works, a user can choose an activity not meant for specific facilities or tasks. If the category was HTRW, a user can choose a task-specific activity that may include handling dangerous materials. If the category was Military, a user can choose a task needed for a specific facility. This field is required.

Customer: The customer is a more specific customer category code. It refers to the group or organization requesting the project. Army customers are the branches of the U.S. Army. Federal Government Agencies are customers that work for the U.S. Government and are not included in the military. Foreign Governments are non-U.S. governments doing business with the DrChecks 
agency. Local Customers are not U.S. Government or military specific. Other Military Customers are the branches of the military that cannot be included under Army Customers. This field is required.

Location: Location targets the specific area where the project is taking place. After a customer has chosen a larger area such as a foreign site, a local site, or a U.S. state, a site within that larger area needs to be chosen. This field is required. 


\section{Update Project}

A user can update various project specifications in "Update Project." Project managers and administrators are the only users with access to update a project. Figure 10 shows the process steps.

On Part 1 of the "Update Project" screen, the manager selects a project to update. Clicking on the project name takes the user to Part 2 (Figure 11).

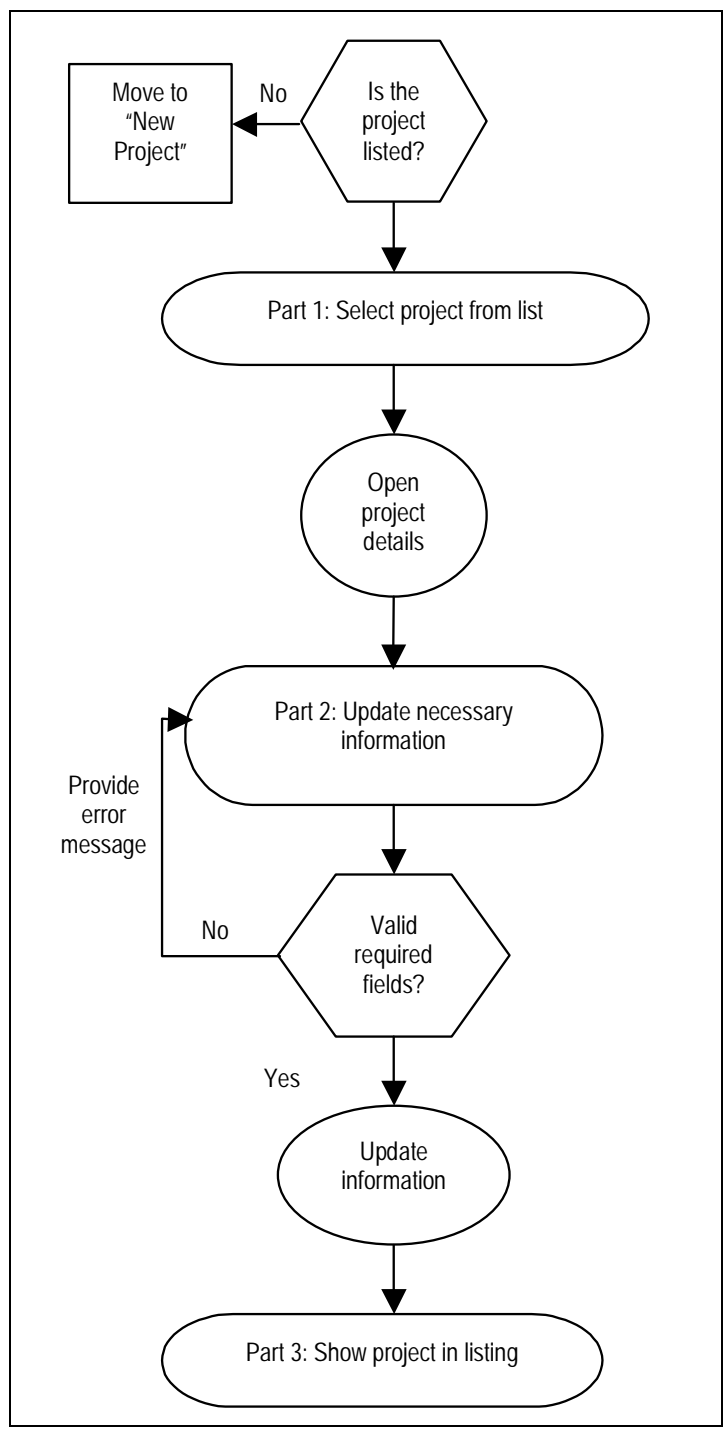

Figure 10. Process of updating a project.
Part 2 is where the project name, design start and end, cat code, location code, and customer code may be changed. All fields are required and overall project categories cannot be changed, because these categories are carried along with all current and future comments and lessons learned. After making the necessary changes, the user should click on the [Update Project] button to finish the update, which automatically returns the user to the main screen.

Project Name: The project name is the standard project reference name, which should have been given when the project was created in DrChecks. A user can change the project name in "Update Project." It is useful to include one keyword that allows unique identification for searching. This field is required.

Design Calendar: The design calendar is for the "Design Start" and "Design End" dates for a project. The design start date should be greater than the design end date. Dates need to be entered in the ddMmm-yy format (e.g., 10-Oct-00). This field is required.

Cat Code: The Cat Code is a more specific Civil Works, HTRW, or Military category, depending on what Project Category Code was chosen. If the category was Civil Works, a user can choose an activity not meant for specific facilities or tasks. If the category was HTRW, a user can choose a task-specific activity 


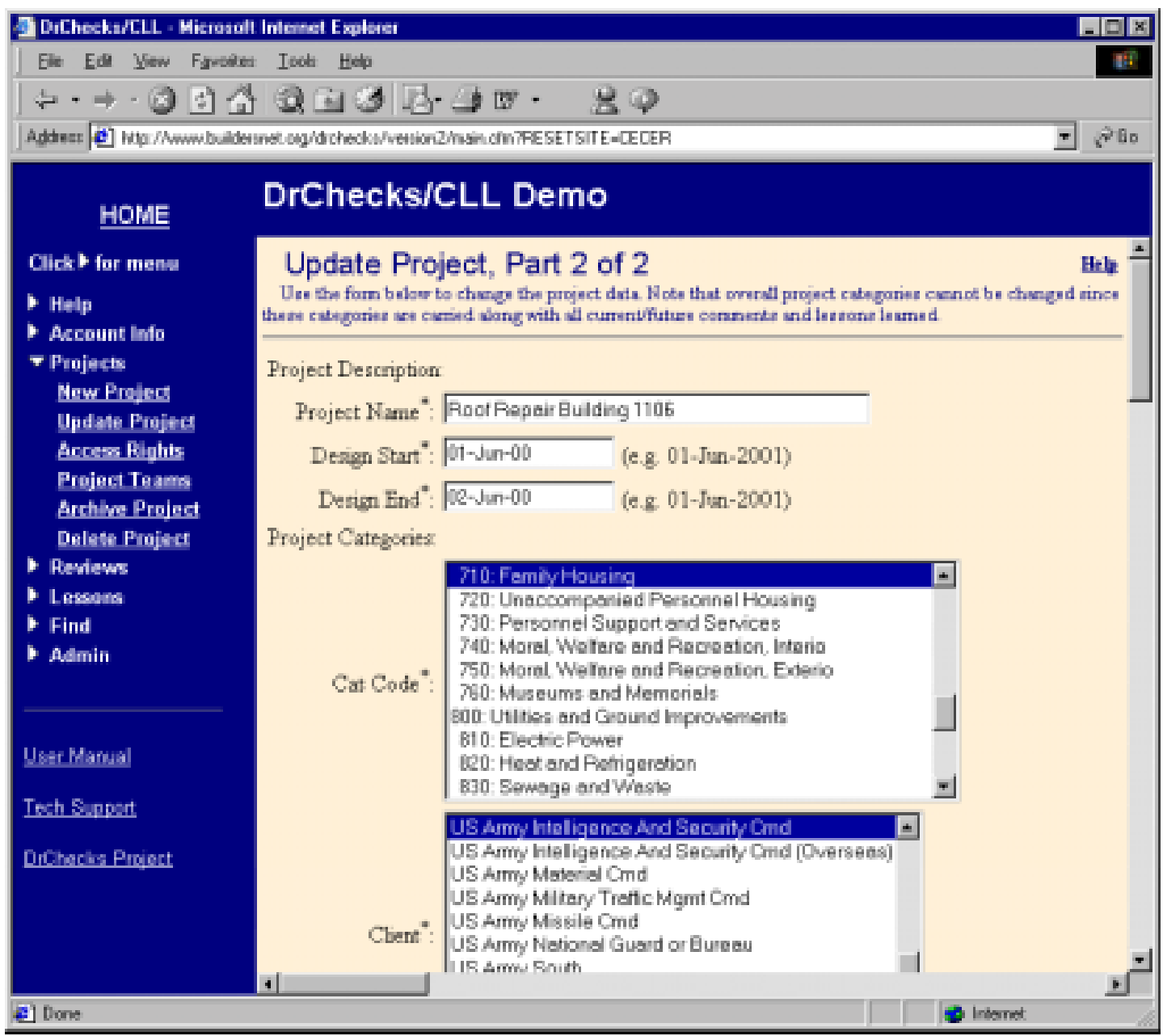

Figure 11. Update Project Part 2.

that may include handling dangerous materials. If the category was Military, a user can choose a task needed for a specific facility. This field is required.

Customer: The Customer is a more specific customer category code that refers to the group or organization requesting the project. Army customers are the branches of the U.S. Army. Federal Government Agencies are customers that work for the U.S. Government and are not included in the military. Foreign Governments are non-U.S. governments doing business with the DrChecks agency. Local customers are not U.S. Government or military specific. Other Military Customers are the branches of the military not included under Army Customers. This field is required.

Location: The location targets the specific area where the project is taking place. After a customer has chosen a larger area such as a foreign site, a local site, or a U.S. state, a site within that larger area needs to be chosen. This field is required. 


\section{Access Rights}

For a user to access a project, he/she needs to have access rights. The project manager can assign these rights by going into "Access Rights" and selecting the project and the type of users to which he/she wishes to assign rights. Figure 12 shows the process steps.

Part 1 of assigning access rights (Figure 13) is selecting the project and the type of users to which he/she wishes to assign rights. Once these two selections are made, the user clicks on the [Continue] button.

The boxes shown in Part 2 (Figure 14) contain names of all users on that site. From these boxes, the user selects names to assign to a project and then clicks on the [Add] button. $\mathrm{He} / \mathrm{she}$ should keep in mind that each category of user is going to be assigned different rights. The permissions granted to a user indicate which activities from the left-side menu are available to him/her. If permission has not been given to a user for an activity and it is selected, an error message will be posted to the browser indicating an attempt to access a page to which access has not been given. Access to specific projects or reviews may be limited by the user's office. A user cannot access a project until rights have been assigned.

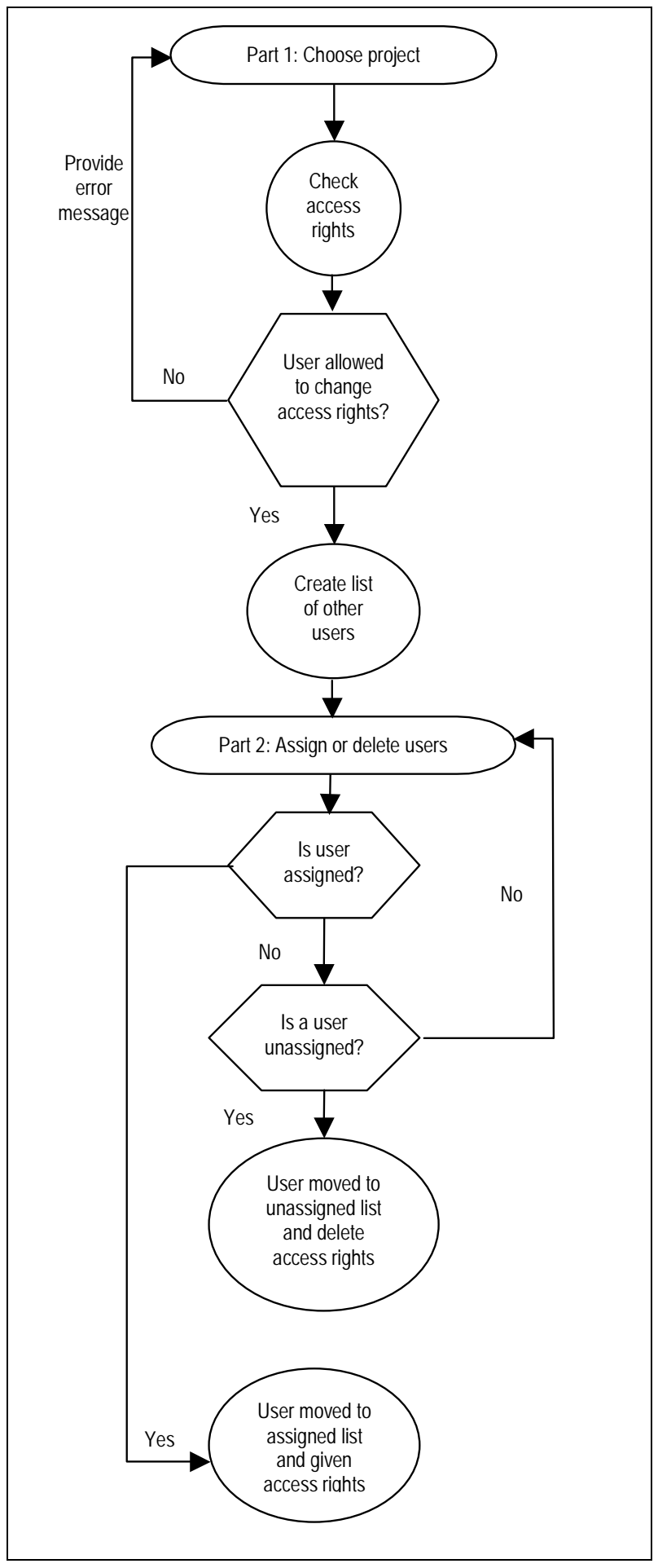

Figure 12. Process of assigning access rights. 


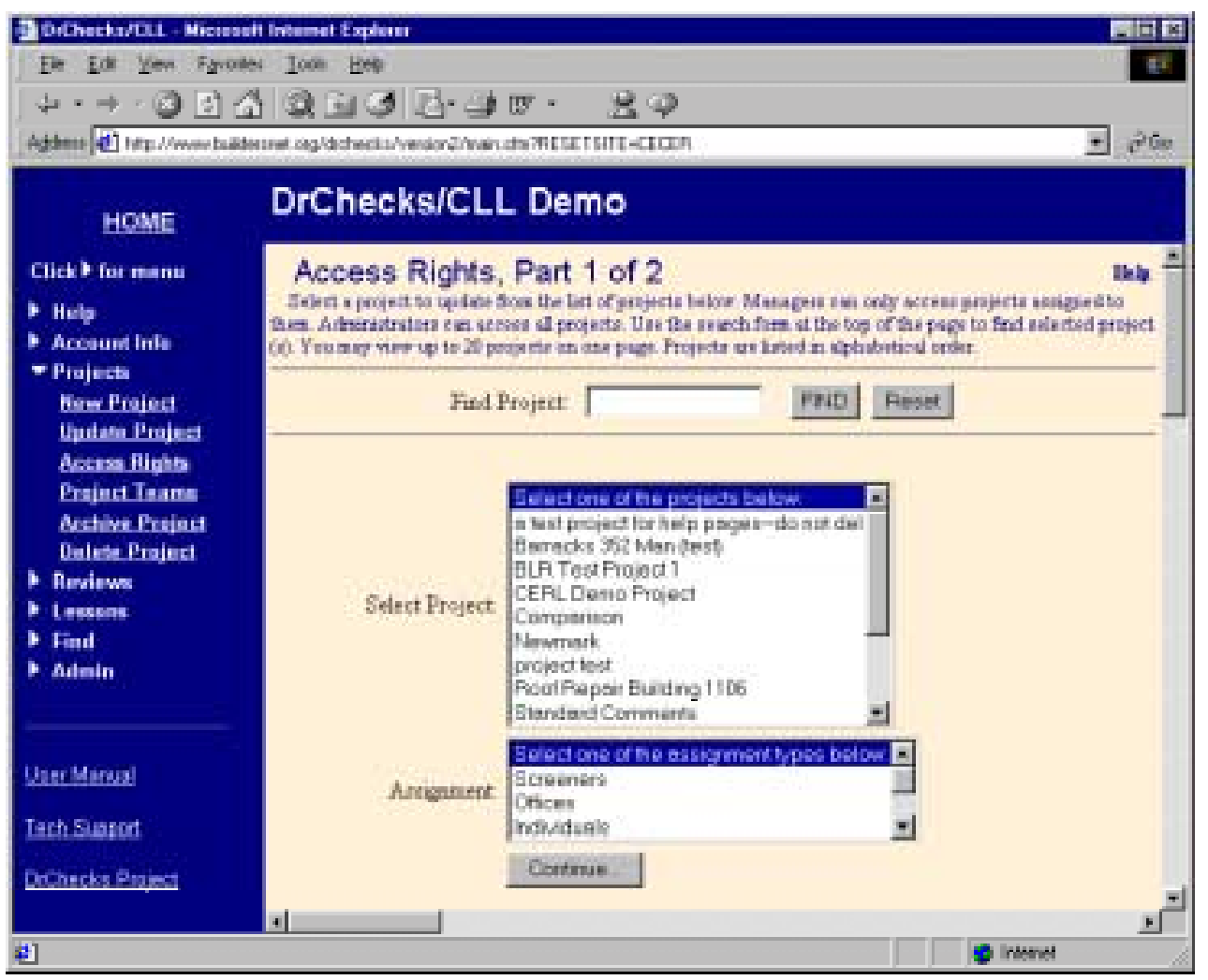

Figure 13. Access Rights Part 1.

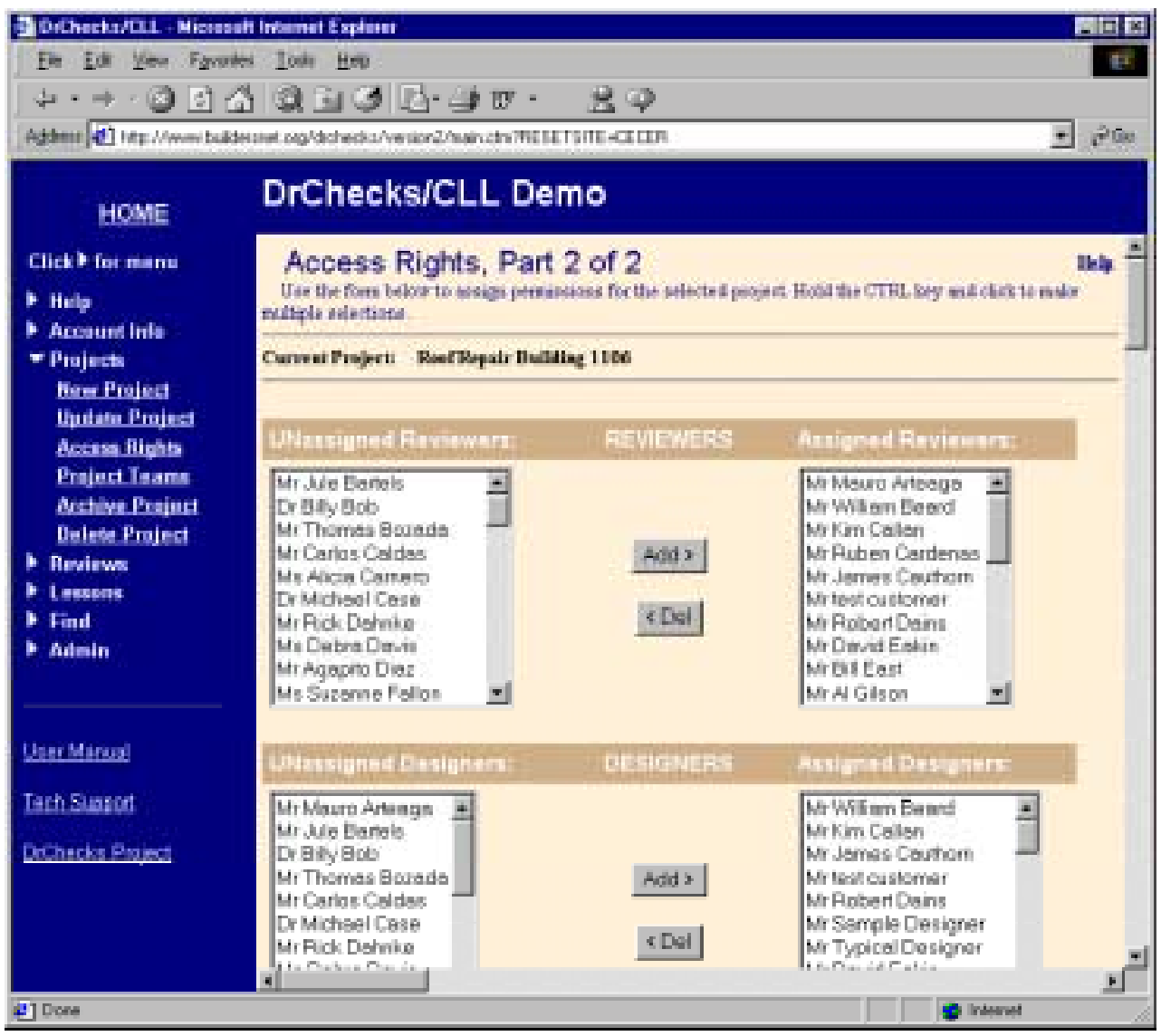

Figure 14. Access Rights Part 2. 
Project Name: The project name is how the project is referenced. In "Access Rights" the project name is the project a user can access if the correct rights are assigned. This field is required.

Assignment Types: When a user wishes to assign access rights, he/she must decide to assign an individual or a group of people. For example, if "Offices" were selected, he/she would be able to assign a whole office and not just an individual from that office. If he/she chooses to assign individuals they may do so. This field is required.

Unassigned Users: A person is placed into the default unassigned box until he/she has been given certain access rights. Each box of unassigned users are teams or individuals that meet the criteria of the assignment type chosen. These individuals or groups are also divided into reviewers, designers, managers, and customers.

Assigned Users: An assigned user has access rights to a certain project. Each type for which a user's name appears in the assigned box will give access rights in that division. For example, if a user is assigned as a reviewer and designer, the only access rights the user has are reviewer and designer rights.

\section{Project Teams}

A project team is a group of individuals assigned access rights as a team. The names of these individuals will be listed when it is time to assign individual access rights for a project. Figure 15 shows the process steps. To create a team, the user needs to choose how to organize the team in Part 1 (Figure 16). The user can organize by location, customer type, category code, or standard screeners. After each selection is made, the user needs to click on [Continue] to proceed to Part 2.

Once the team organization has been chosen, the type of location, customer, or category code depending on what was chosen in Part 1 should be selected in Part 2. If "Standard Screener" was chosen in Part 1, "Current Screeners" should be chosen from the "All Reviewers" box. Once the team is created, the user clicks on the [Assign] button to move to Part 3. 


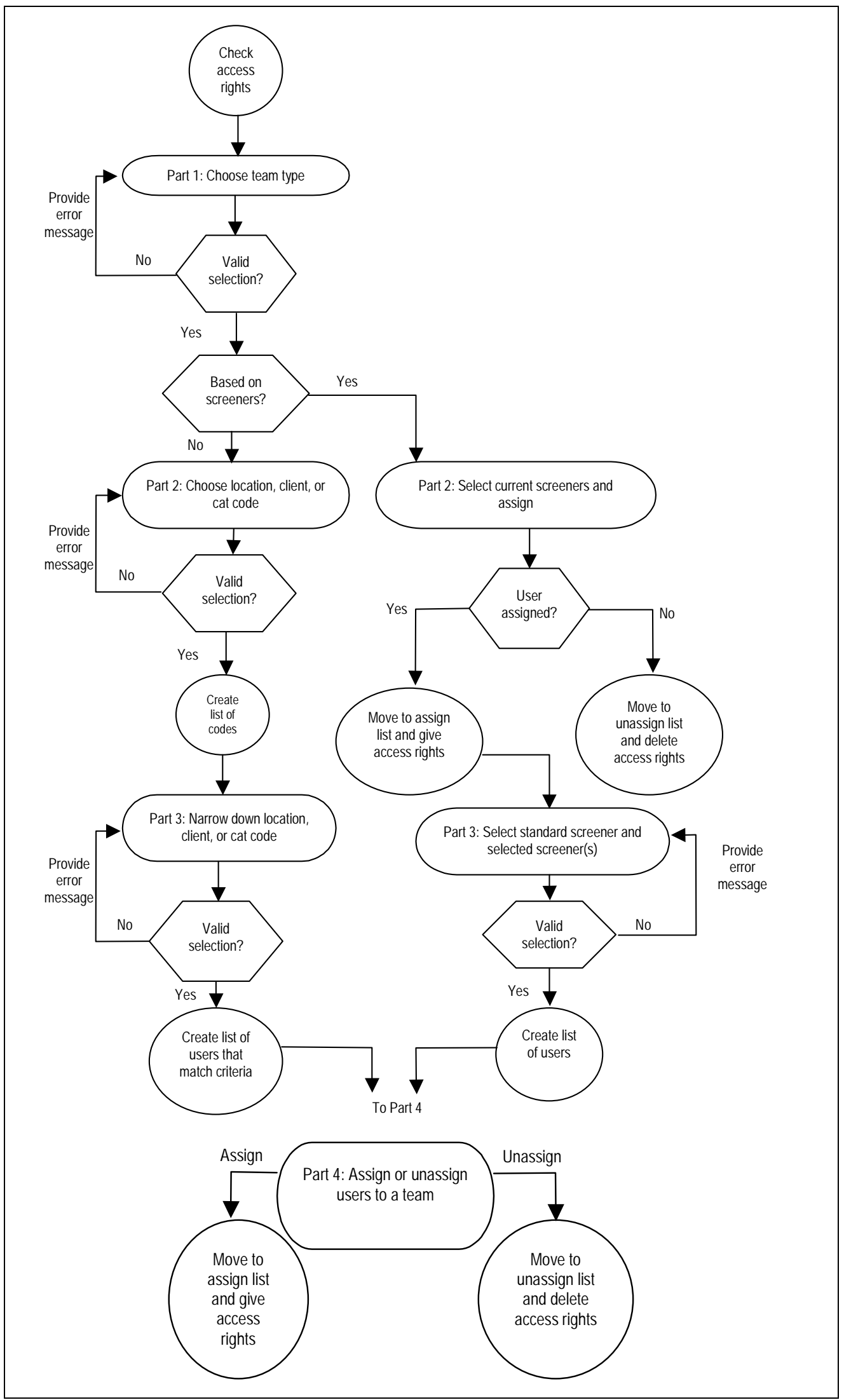

Figure 15. Process of creating a project team. 


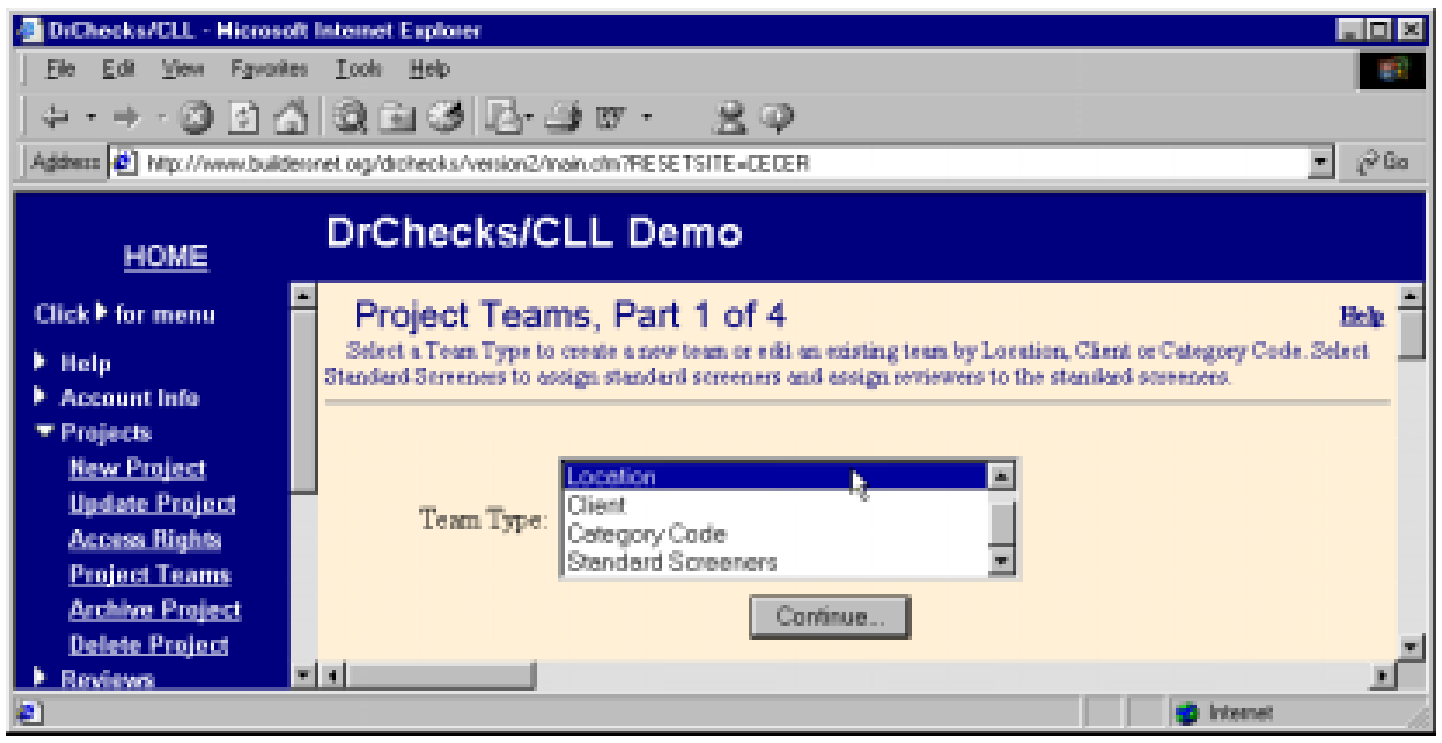

Figure 16. Project Teams Part 1.

If location, customer, or category code was chosen in Part 2, the user will need to make those selections more specific in Part 3. If grouping teams by selecting screeners, one standard screener must be chosen in Part 3 from the list of assigned screeners created in Part 2. Reviewers must be chosen for the selected screener by holding down the Ctrl key while pointing the cursor and clicking on each name to be assigned. This allows a user to select multiple users not in consecutive order in the list. To save the list, click the [Save Now] button. In Part 4 (Figure 17), boxes on the left contain names not assigned to a team. Those on the right are already on the team. To add a team member, the user should highlight that person's name and click on [Add]. The name should then appear in the box on the right side of the screen. To delete a person from a team, the user should highlight that person's name and click on the [Del] button. Deleting moves the name from the assigned list to the unassigned list. If "Standard Screeners" was chosen in Part 1, the user needs to choose the names to assign in Part 2 by clicking on the names and clicking on the [Add] button to move the name to the righthand box where the assigned screeners are.

Team Type: The team type is a general category of users based on certain criteria. The four types of criteria for teams are: location, customer, category code, and screeners. This field is required.

Location Type: If a user chooses the team type based on location, he/she will need to choose the location type to show the location of the project. Foreign Country Codes will show the names of various foreign countries. Local Sites will show nearby locations. U.S. State Names will list names of all U.S. states. This field is required. 


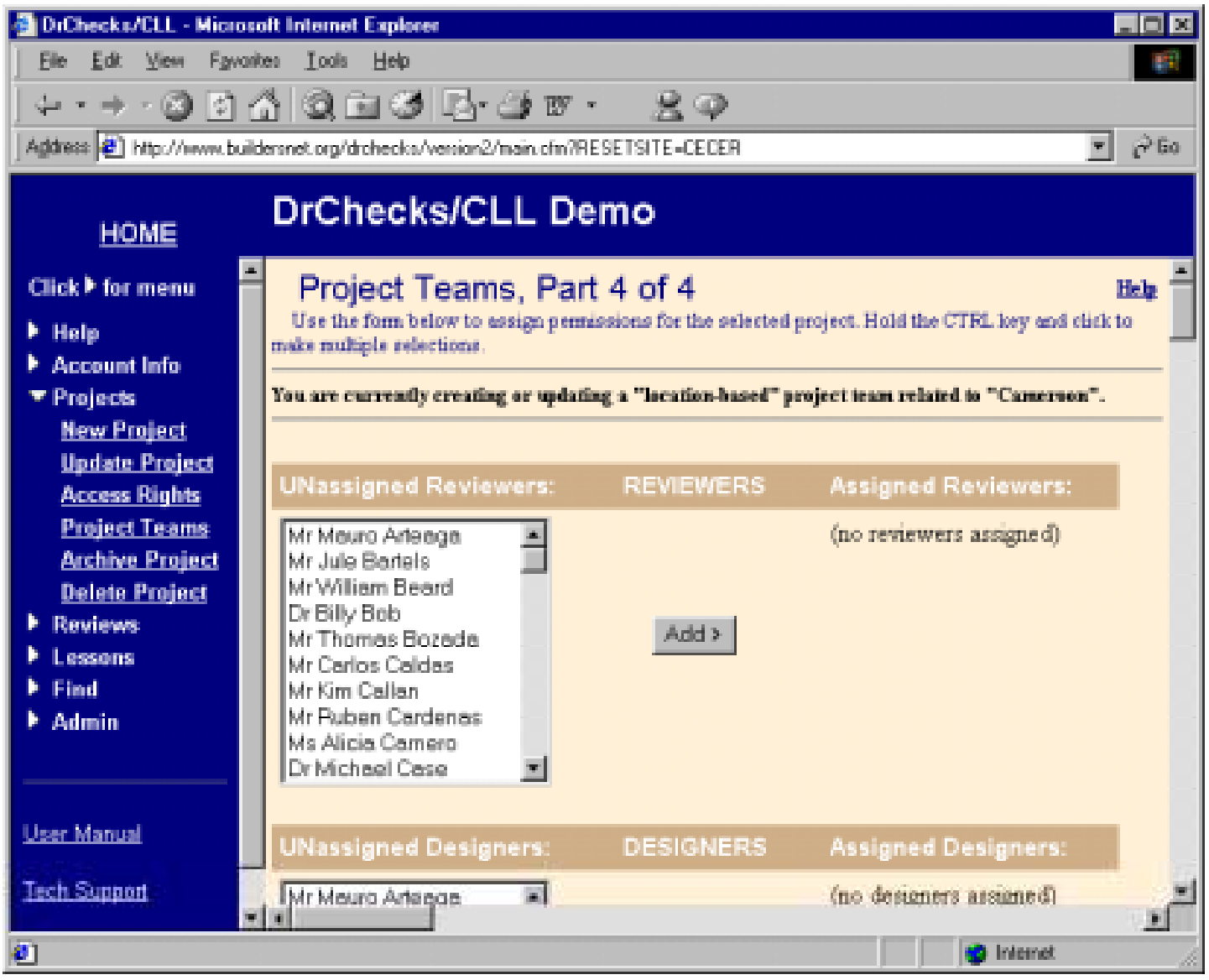

Figure 17. Project Teams Part 4.

Customer Type: If the user chooses the team type based on customer, he/she will need to choose the customer type that shows to whom the project pertains. Army customers are the branches of the U.S. Army. Non-Army Military Customers are the branches of the military not included under Army Customers. Other Government Agencies are customers that work for the U.S. Government and are not included in the military. Foreign Governments are non-U.S. governments doing business with the DrChecks agency. Other customers are not U.S. Government or military specific. This field is required.

Category Code Type: If the user chooses the team type based on Category Code, he/she needs to choose the category code type that shows what project activities are involved. Military Construction (MILCON) codes show the tasks needed for a specific facility. The Civil Works category code shows activities not broken down into specific facilities or tasks. The HTRW category code shows task-specific activities that may include handling dangerous materials. Other codes show activities for local facilities. This field is required. 
All Reviewers: If the user chooses to create the team by standard screeners, he/she chooses from the list of reviewers to create screeners. "All Reviewers" is a list of users that have access rights as reviewers. This field is required.

Current Screeners: Once a reviewer is picked from the "All Reviewers" list, the reviewer then becomes a current screener. A screener looks at comments before they are sent to a designer. This field is required.

Location: Location targets the specific area where the project is taking place. After a customer chooses a larger area such as a foreign site, a local site, or a U.S. state, a site within that larger area needs to be chosen. This field is required.

Customer: The customer is a more specific customer category code that refers to the group or organization requesting the project. Army customers are the branches of the U.S. Army. Federal Government Agencies are customers that work for the U.S. Government and are not included in the military. Foreign Governments are non-U.S. governments doing business with the DrChecks agency. Local Customers are not U.S. Government or military specific. Other Military Customers are the branches of the military that cannot be included under Army Customers. This field is required.

Cat Code: The Cat Code is a more specific Civil Works, HTRW, or Military category depending on what Project Category Code was chosen. If the category was Civil Works, a user can choose an activity not meant for specific facilities or tasks. If the category was HTRW, a user can choose a task-specific activity that may include handling dangerous materials. If the category was Military, a user can choose a task needed for a specific facility. This field is required.

Standard Screener: The standard screener should be chosen out of the list of "Current Screeners." Only one name can be chosen; however, selected screeners can be chosen from the reviewer list. This field is required.

Unassigned Users: A person is placed into the default unassigned box until he/she has been given certain access rights. Each box of unassigned users are teams or individuals who meet the criteria of the assignment type chosen. Also, these individuals or groups are divided into reviewers, designers, managers, and customers. This field is required.

Assigned Users: An assigned user has access rights to a certain project. Each time a user's name appears in the assigned box gives access rights in that divi- 
sion. For example, if a user is assigned as a reviewer and designer, the only access rights the user has are reviewer and designer rights. This field is required.

\section{Archive Project}

To keep a copy of the review in another place, a user may choose to archive the project. This does not mean the review will no longer be accessible or will be deleted, but rather the review will be copied to another location and formatted as a Hypertext Markup Language (HTML) document. The review will still be there to access. Figure 18 shows the process steps.

To archive a review, a user first needs to select the project containing the comment review. This is done in "Archive Project" Part 1. The review to archive needs to be specified in Part 2 (Figure 19). Only one review can be chosen at a time, but many reviews from the same project can be archived. To archive this review, the user clicks the [Archive Now] button.

In Part 3, the discipline, count of archives for review, and the location of the archive is displayed. To view the archive, the address shown in blue should be selected. Once it is selected, the locations of the project archive directory and the review archive directory are displayed.

Project Name: The project name is the standard project reference name. In "Archive Project," the project name contains reviews to archive. This field is required.

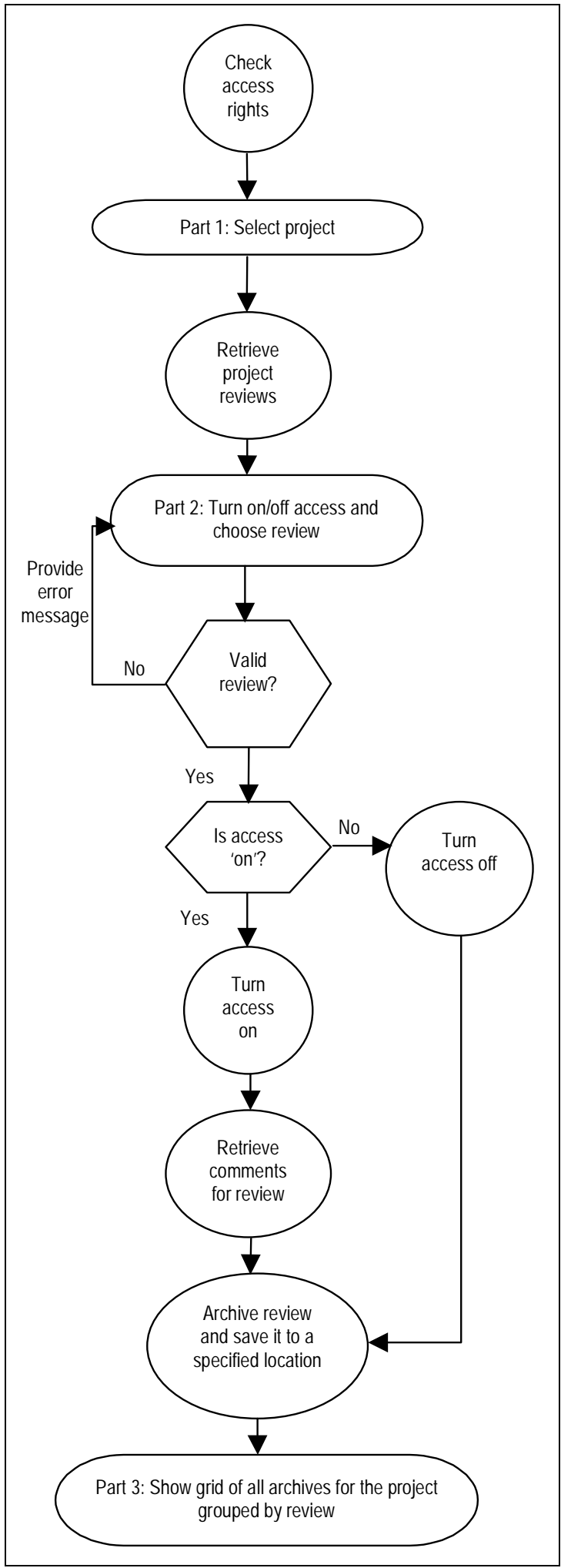

Figure 18. Process of archiving a project. 
Review Phase: A review is a representation of the project stage. To archive a project, the user needs to select the name of the review he/she wishes to copy. This field is required.

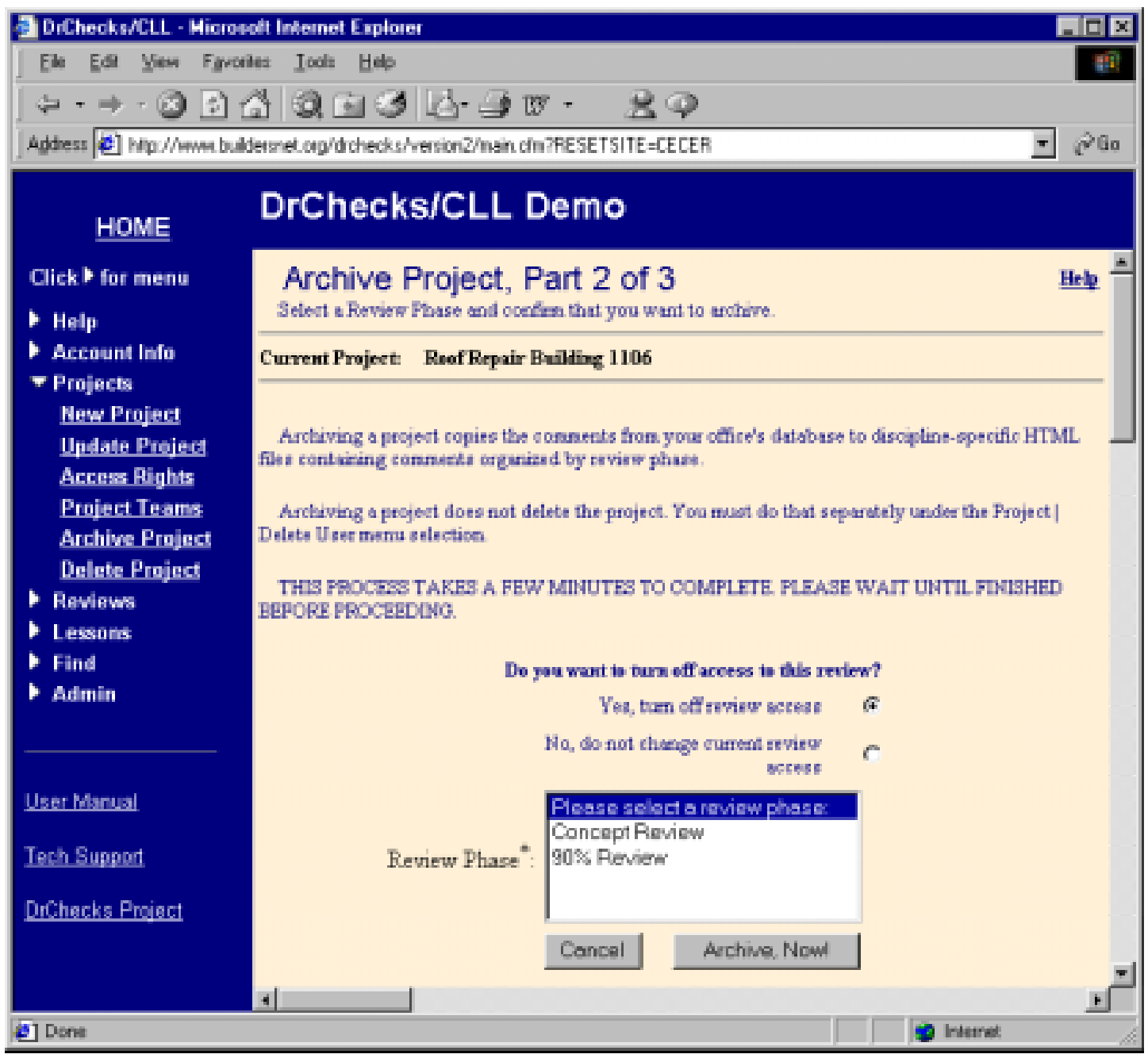

Figure 19. Archive Project Part 2. 


\section{Delete Project}

A user may need or want to delete a project in DrChecks. This simple process is for managers and administrators only and takes just two steps to do. Keep in mind that the delete operation cannot be undone. Figure 20 shows the process steps. To delete a project, it needs to be selected from the list of projects in Part 1.

In Part 2 (Figure 21), DrChecks warns that not only will the selected project be deleted, but all items associated with it will be deleted as well. If the user decides to delete it anyway, the [Delete, Now!] button should be clicked; otherwise, the user should click on [Cancel] to move back to Part 1 of "Delete Project."

Project Name: The project name is the standard project reference name. In "Delete Project," the project is the one the user will be deleting. When a project is deleted, only the archive remains. This field is required.

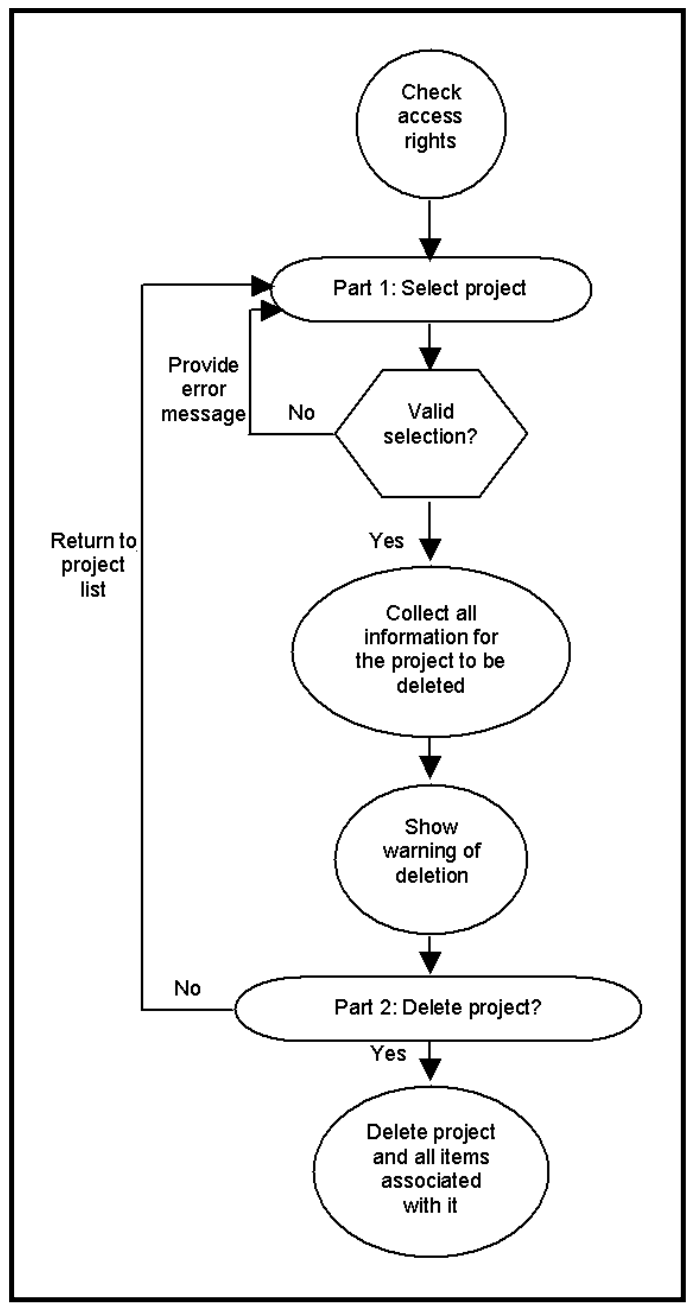

Figure 20. Process of deleting a project. 


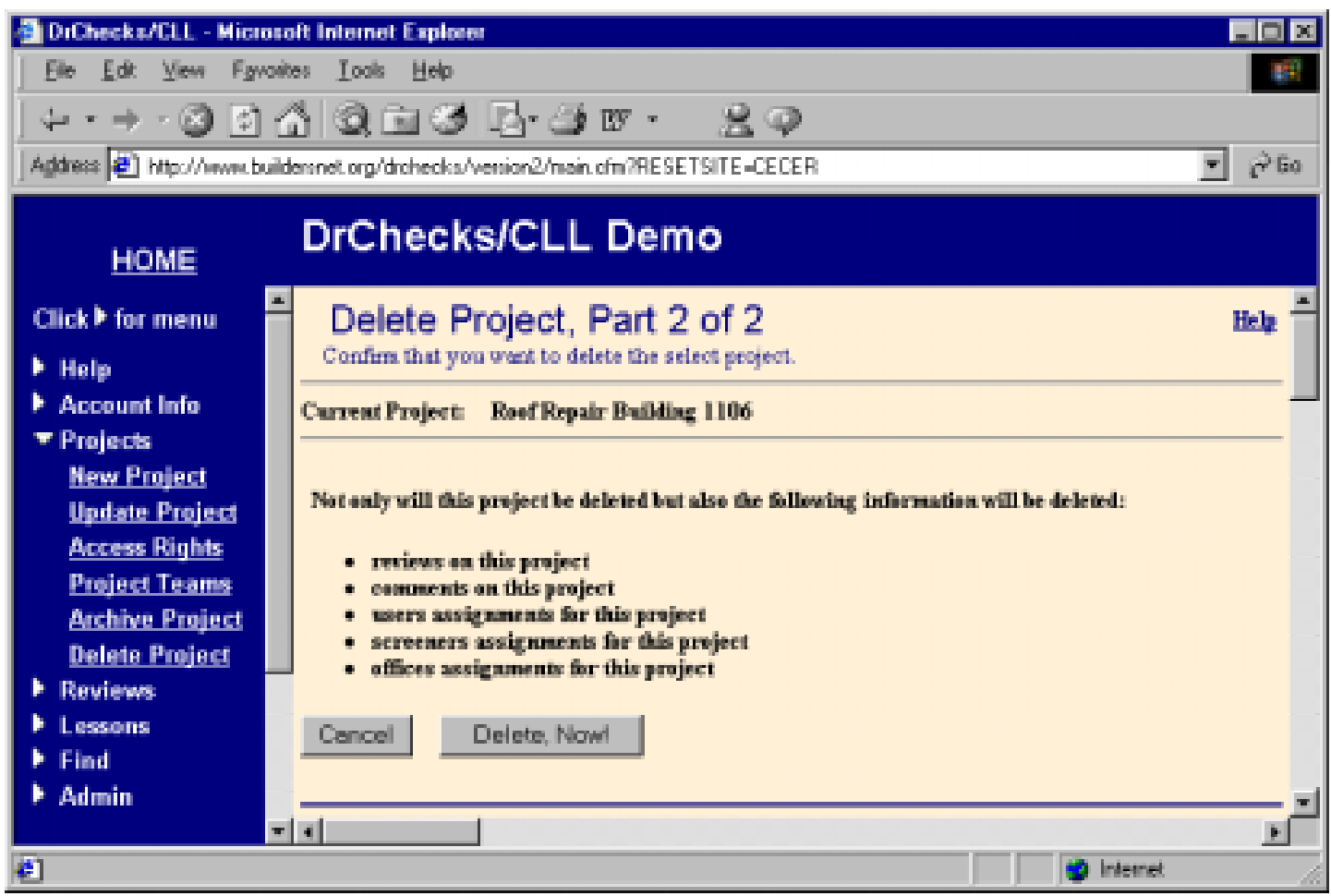

Figure 21. Delete Project Part 2. 


\section{Add/Update Reviews}

Reviews are where collections of comments about a project are stored. After a project is created, reviews can be added. To update a review, a user can follow the same directions for adding a review. Figure 22 shows the process steps.

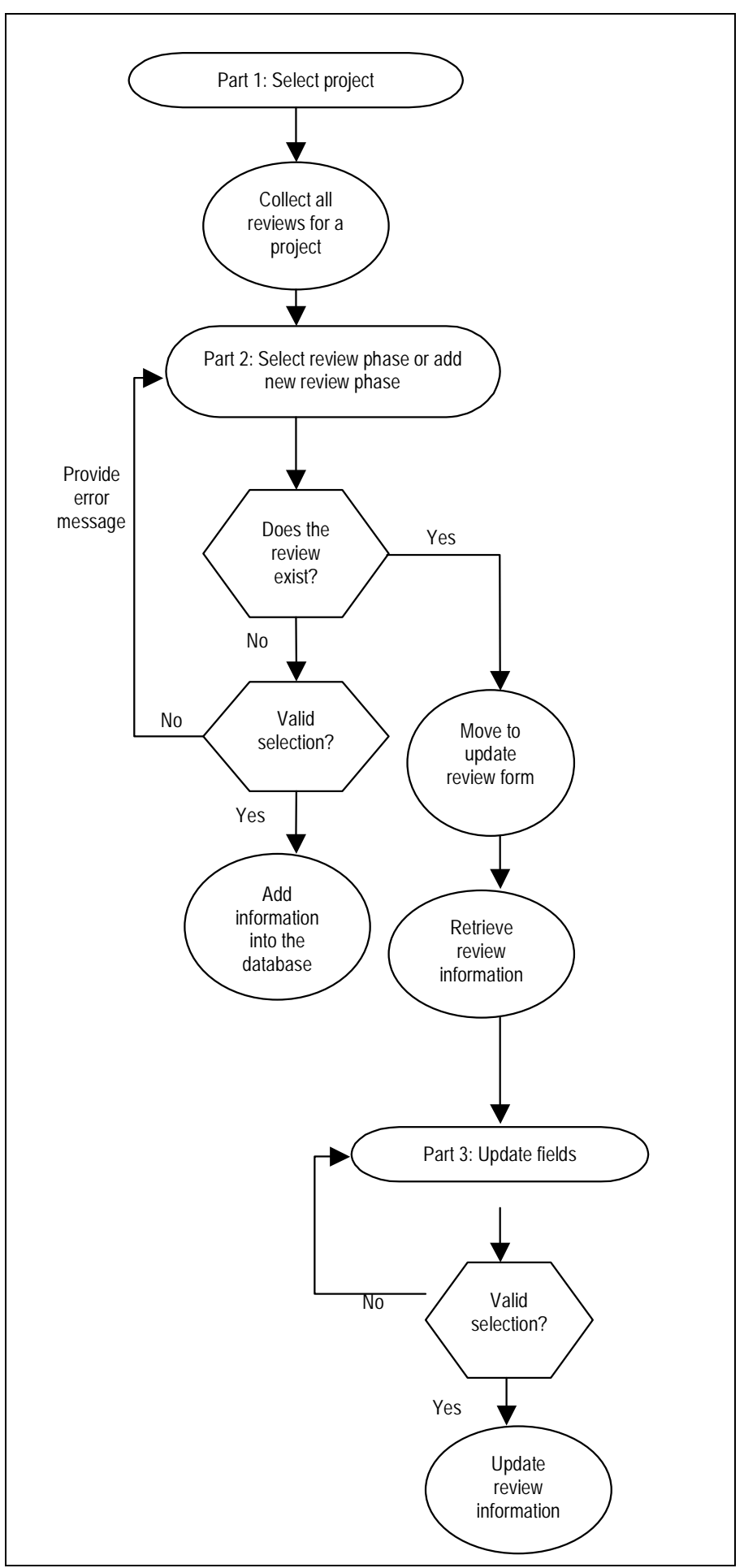

Figure 22. Process of adding/updating a review. 
In Part 1 of "Add/Update Reviews," the project for which to add or edit a review needs to be specified by clicking on the name of the project. Once the project name has been chosen, three required data elements need to be collected in Part 2 if adding a review or displayed if editing a review. These elements include the review name and the start and end dates for the review. After these three are filled in, the [Add New] button should be selected to add a review (Figure 23). Otherwise, the [Update] button should be selected (Figure 24).

Project Name: The project name is the standard project reference name. In "New/Update Review" the project name is the project where the review is located or needs to be added. This field is required.

Reviews: "Reviews" contains the name of the review a user wishes to update or add. Choose a descriptive name (e.g., 90\% Complete). This field is required.

Review Date: The review date is the start and end dates of the review and is open for revision. The start date should be greater than the end date. Dates need to be entered in the dd-Mmm-yy format (e.g., 10-Oct-00). This field is required.

Control Number: The control number is a number specifically assigned to a review for internal review management for an office. This field is optional.

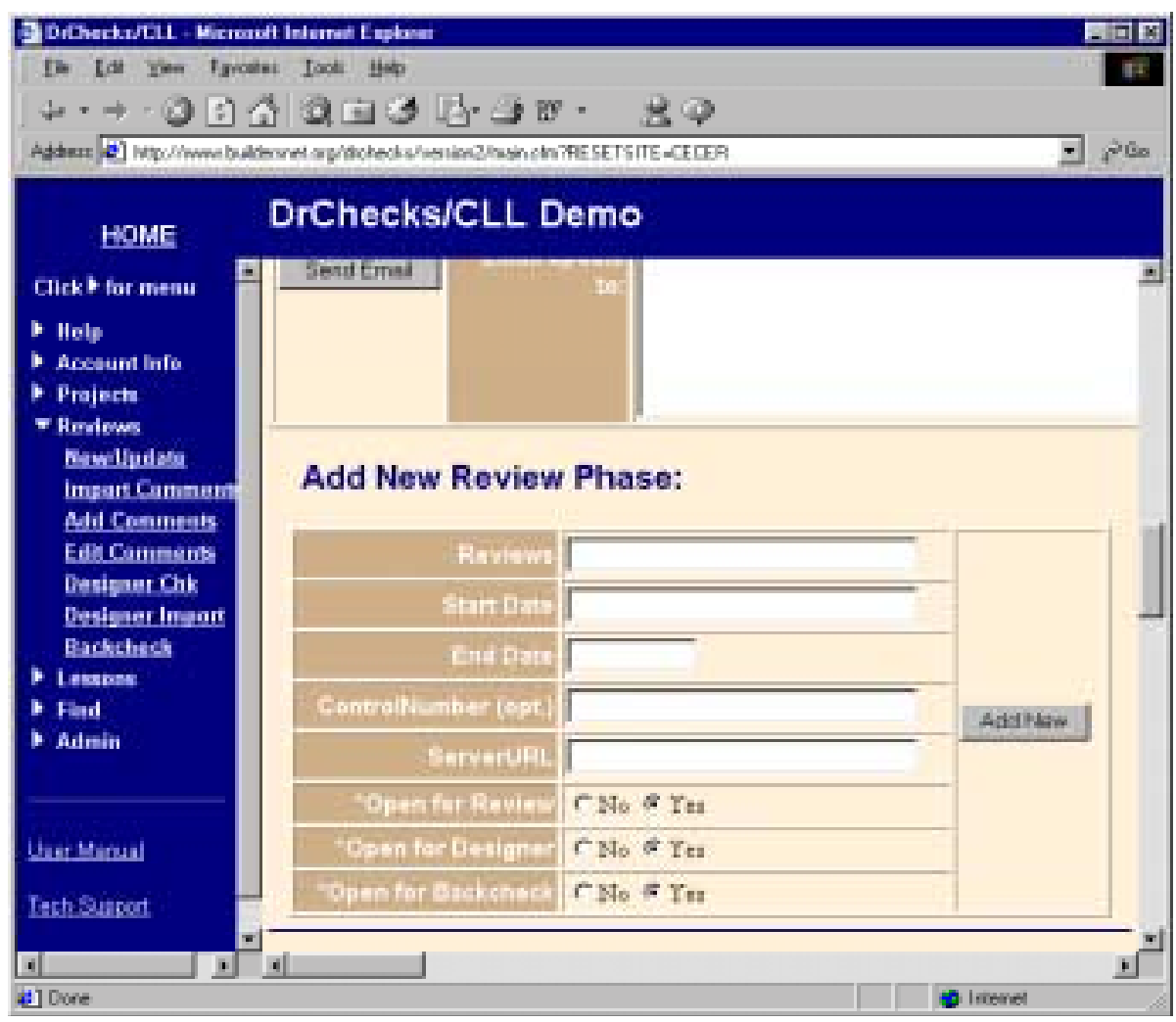

Figure 23. Add/Update Review Part 2 - Add New Review. 


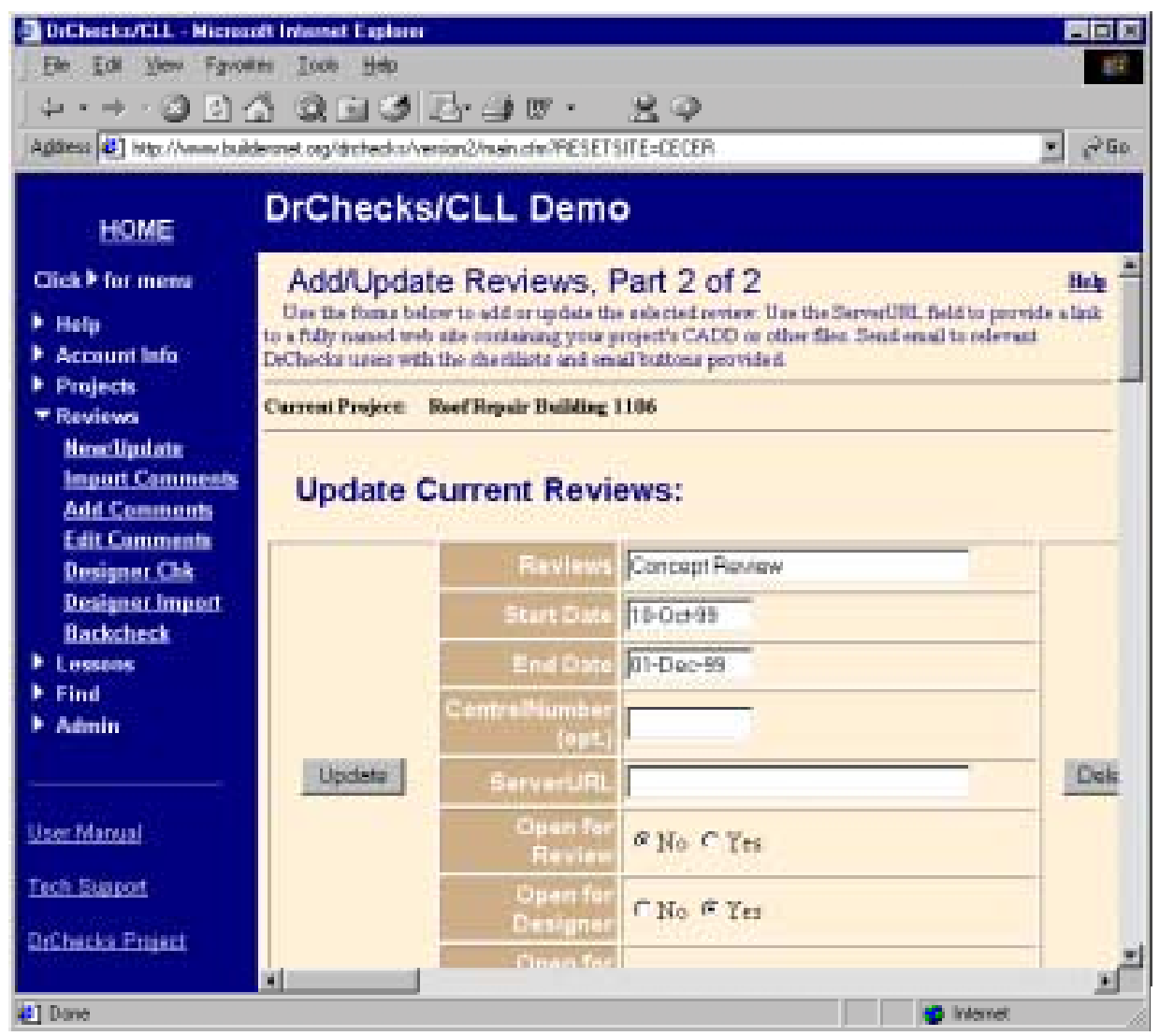

Figure 24. Add/Update Review Part 2 - Update Current Review.

ServerURL: The ServerURL is the address where all reviews can be found. This field is not yet implemented.

“Open" Buttons: The three different "Open" fields are: open for review, open for design, and open for backchecking. When one of these options is selected "yes," the review can, depending on the selection, have comments inserted by a reviewer or a designer, or be backchecked. The default for these buttons is "yes." This field is required.

Email Update: When updating the review, a user can send the review update to all reviewers, customers, or designers by clicking on the appropriate check box. A box is provided for entering email addresses and additional comments that the recipients might need to know about the update. 


\section{Import Comments}

If a user wants to enter comments located in a different file, it is possible to import those comments to any available review in a project. To see all comments for a review, the user clicks the [View all comments...] button. Figure 25 shows the process steps.

When importing comments, the project to import to must be selected by clicking on the project name in Part 1. This brings up Part 2 (Figure 26), where the review into which the comment is to be imported should be selected. Clicking on the review name brings up Part 3 (Figure 27). The file path the comment is located in should be specified as well as one reviewer for the comment. A confirmation message will be displayed in Part 4 explaining that the import was successful.

Project Name: "Import Comments" uses the project name to identify the location of the review to which comments are to be imported. This field is required.

Review Name: To import a comment to a review, a user selects the name of the review that he/she wishes to receive the comments. Comments can be imported to any available review. This field is required.

Comment File: When importing a comment, which means it is stored in a different file, the file path needs to be located and entered into the "Comment File" field. The [Browse] button can be used to ease the location process. This field is required.

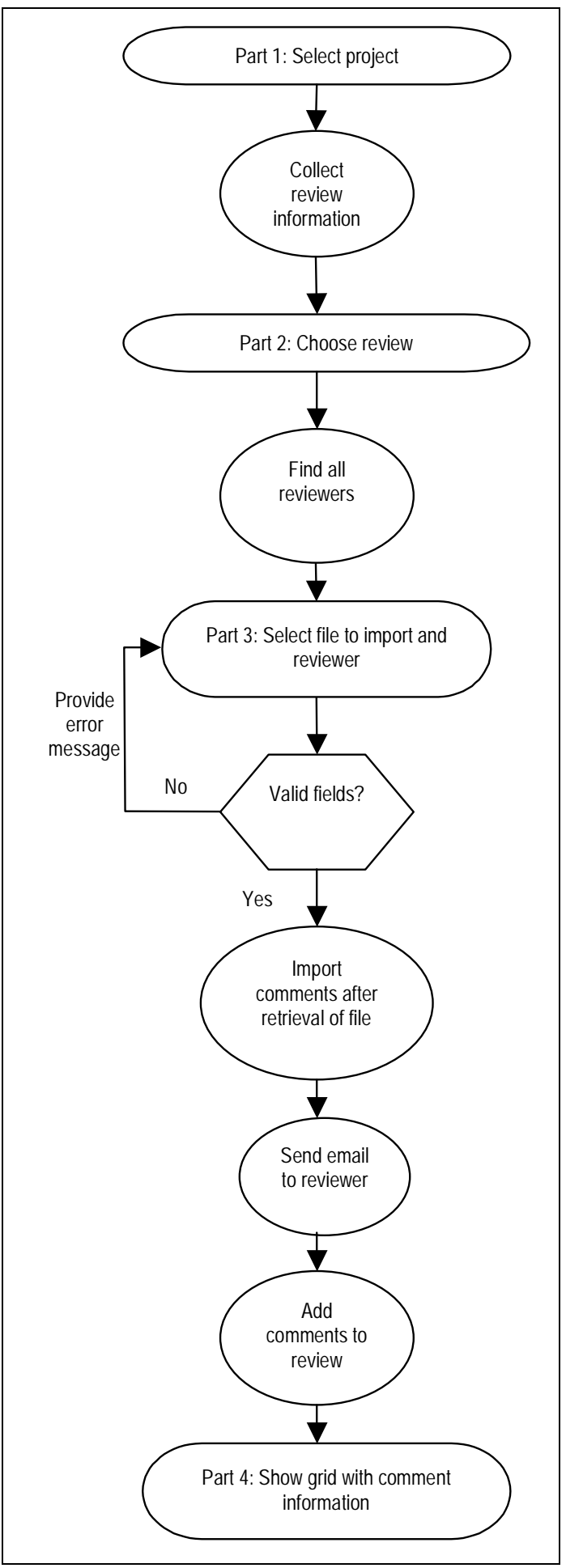

Figure 25. Process of importing comments. 
Reviewer Select: Once a user has imported a comment, he/she needs to select a reviewer to review the comment. The list contains names of all assigned reviewers for the project. This field is required.

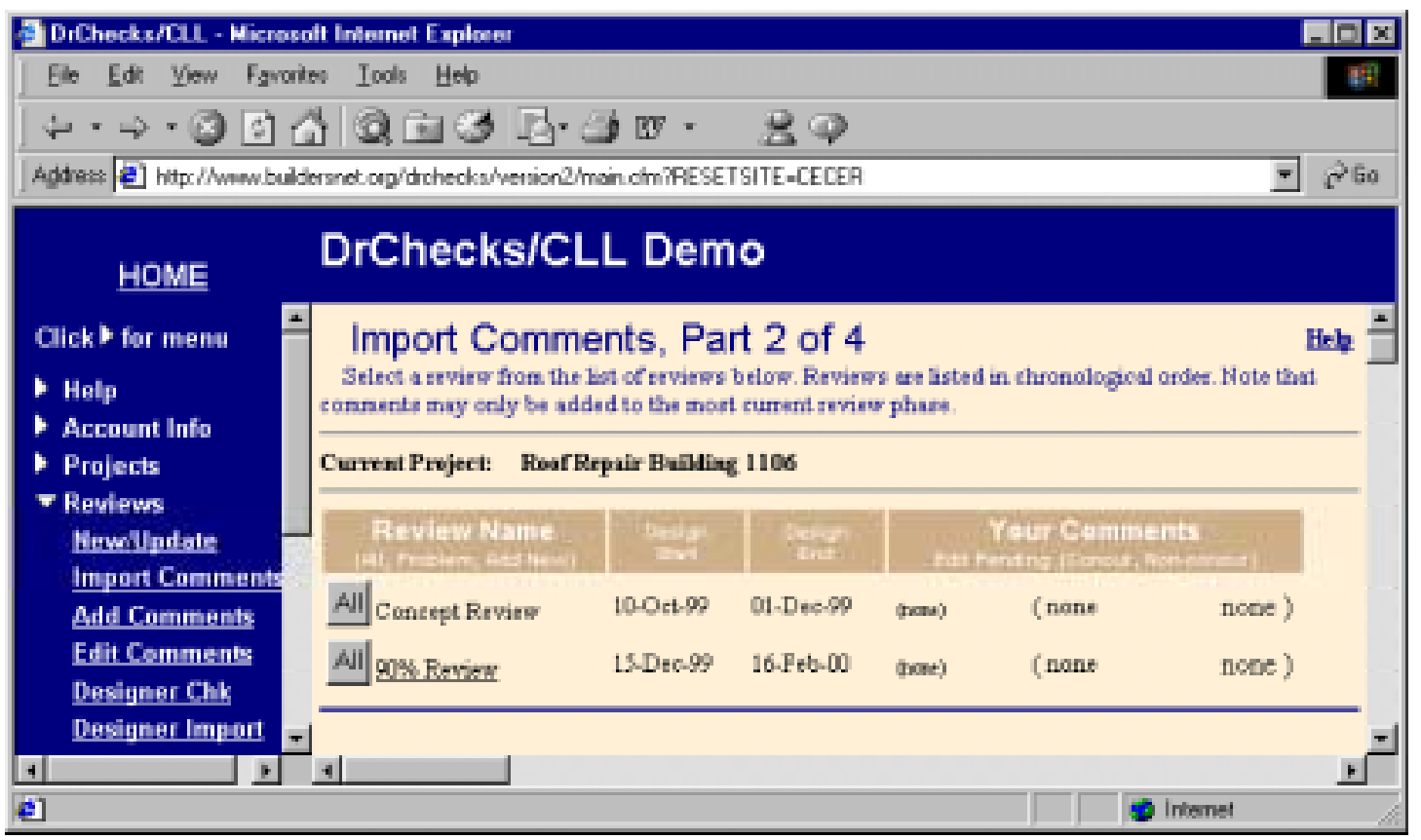

Figure 26. Import Comments Part 2.

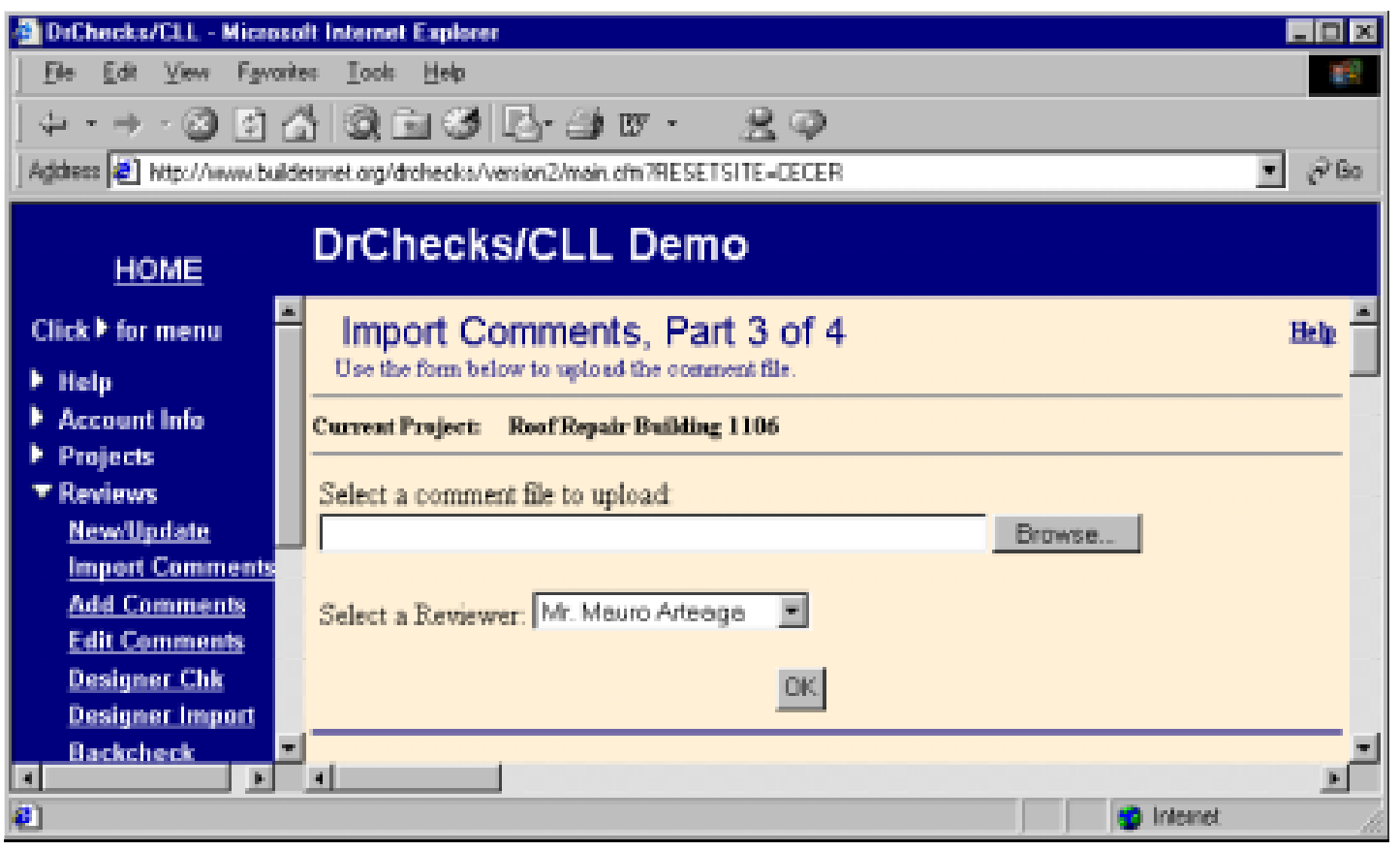

Figure 27. Import Comments Part 3. 


\section{Add Comments}

To communicate to coworkers and other users about a project, a user must add a comment to the project. A collection of these comments is grouped into a review that represents a stage of the project. Figure 28 shows the process steps.

Before adding a comment, the project and the review should be specified. The project name can be selected on Part 1 of "Add Comments."

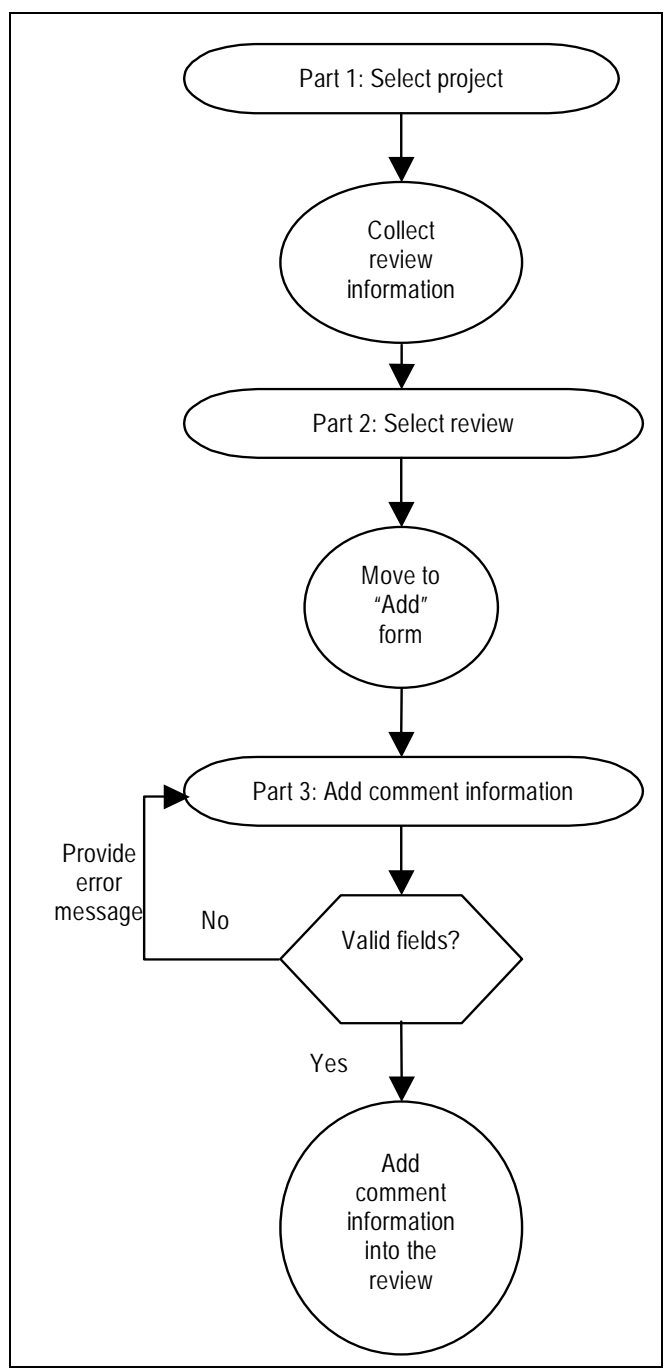

Figure 28. Process of adding comments.
In Part 2 the user selects the review to receive the comment. From this page it is also possible to see any pending comments or unaccepted comments in the "Your Comments" column.

After the review is selected, the "Add Comment" form is displayed in Part 3 (Figure 29). The fields presented are: document type, comment's discipline, spec section, drawing sheet, drawing detail, code reference, document reference, attachment, and review comment. Required fields are indicated by the (*) beside the field prompt. When all required fields and desired optional fields are complete, clicking on the "Add Comment" button will complete the addition process.

Once the comment is added in Part 4 , the user will then be returned to Part 3 of "Add Comments" in order to enter any additional comments for the same project.

Project Name: The project name is the standard project reference name. In "Add Comment" the project contains the review to which comments will be added. This field is required.

Review Name: To add a comment to a review, the user needs to select the name of the review where the comment should be placed. This field is required. 


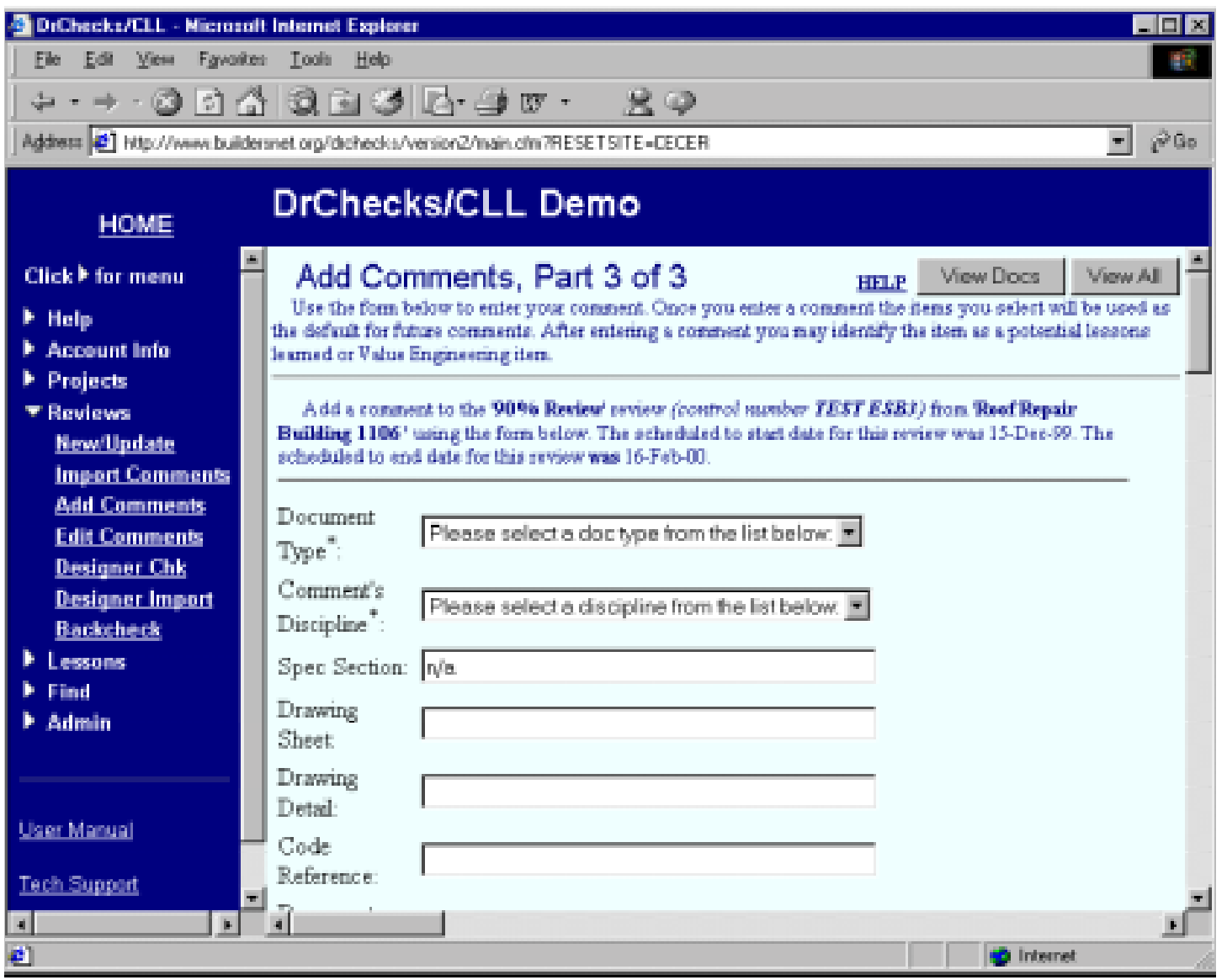

Figure 29. Add Comments Part 3.

Document Type: The document type is the part of the project that the added comment affects. For example, if a user wanted to add a comment to say "the specifications were incorrect," he/she would choose "Specifications" from the dropdown list. If the correct document type is not listed, the user should choose "Other." This field is required.

Comment's Discipline: The comment discipline defines the area of the task. For example, if the user's comment was that more outlets are needed, the comment discipline would be "Electrical." If a certain discipline cannot be found in the list, the user needs to choose "Other." It is reasonable to assume one user can use more than one discipline during a review. This field is required.

Spec Section: When a user needs to refer to the project, he/she can enter a specification reference. The specification reference helps the reviewer identify the individual project specification of the comment.

Drawing Sheet: The "Drawing Sheet" field is a reference to an architectural drawing. For example, if a user wanted to show all outlets in a building, the drawing sheet could reference the drawing that shows the outlets. 
Drawing Detail: The "Drawing Detail" field is a reference to a collection of architectural drawings. If a user wants a reviewer to see a certain sheet in a collection, he/she can reference the collection containing the sheet.

Code Reference: Federal laws or regulations may be referenced in the "Code Reference" field if necessary. For example, if a user wants to reference the law that specifies how many fire extinguishers are required, the code reference would show where to find the law.

Document Reference: If the user references a document either for a code or specification detail, this field provides a place to store the reference.

Attachment: When adding a comment, the user can use this field to add supplemental comments or pictures to support the comment. To use this field, click on the "Browse" button to find the path for the file the supplement is in and select the file. It will be moved to the server.

Review Comment: Comments are entered into this field. Text can be copied from a word processor and pasted into the comment. The recommended upper level for this field is approximately 1,000 characters. This field is required.

Lessons Learned: If the comment was a problem or discovery that needs to be shared with others, the user may make the comment a Lesson Learned. If the Lessons Learned value is set to "yes," an intermediate form is displayed to collect Lessons Learned information. The details for submitting a Lessons Learned form are given later in this chapter.

Value Engineering: If the Value Engineer Item value is set to "yes," the comment is automatically mailed to the person indicated as the Value Engineer for the project. Unlike the Lessons Learned option, no additional comments or forms are required prior to the submittal. 


\section{Edit Comments}

Editing comments in DrChecks allows a user to make changes to any open comment that has not been reviewed by a designer. Figure 30 shows the process steps. When editing a comment, the project name must first be chosen by clicking on the project name in Part 1.

In Part 2 the review containing the comment must be chosen. If the user is unsure which review the comment is in, he/she can look to the right of the grid where it shows the number of comments pending. If a number other than zero is in the pending column, the review contains revisable comment(s). After the review has been chosen, a user will then proceed to Part 3 (Figure 31) to view all revisable comments located in the review.

In Part 4 (Figure 32), changes to the comment can be made or the comment can be deleted completely. To update a comment only, the "No, Do NOT Delete" option needs to be selected. In Part 5 a user receives confirmation of the update.

Project Name: The project name is the standard project reference name. In "Edit Comment" the project contains the review where comments will be edited. This field is required.

Review Name: To edit a comment in a review, the user needs to select the name of the review that contains the comment to be edited. This field is required.

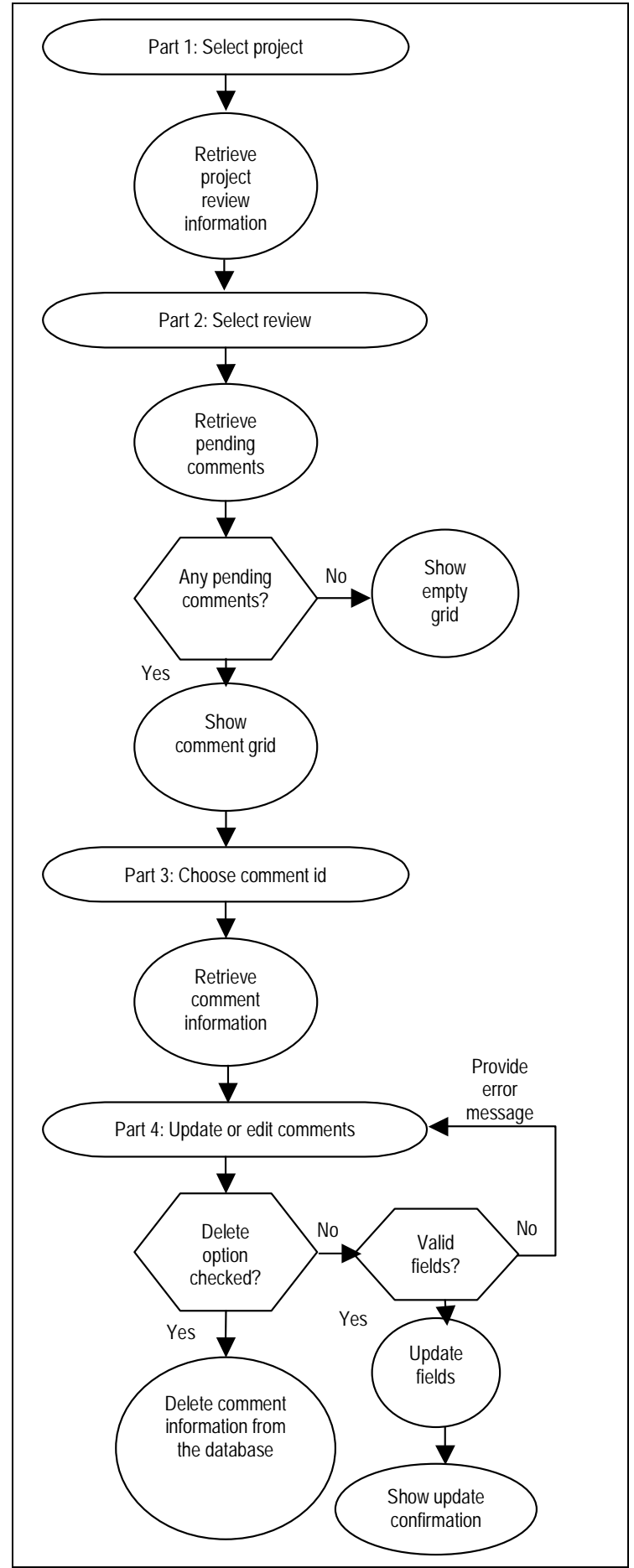

Figure 30. Process of editing comments. 


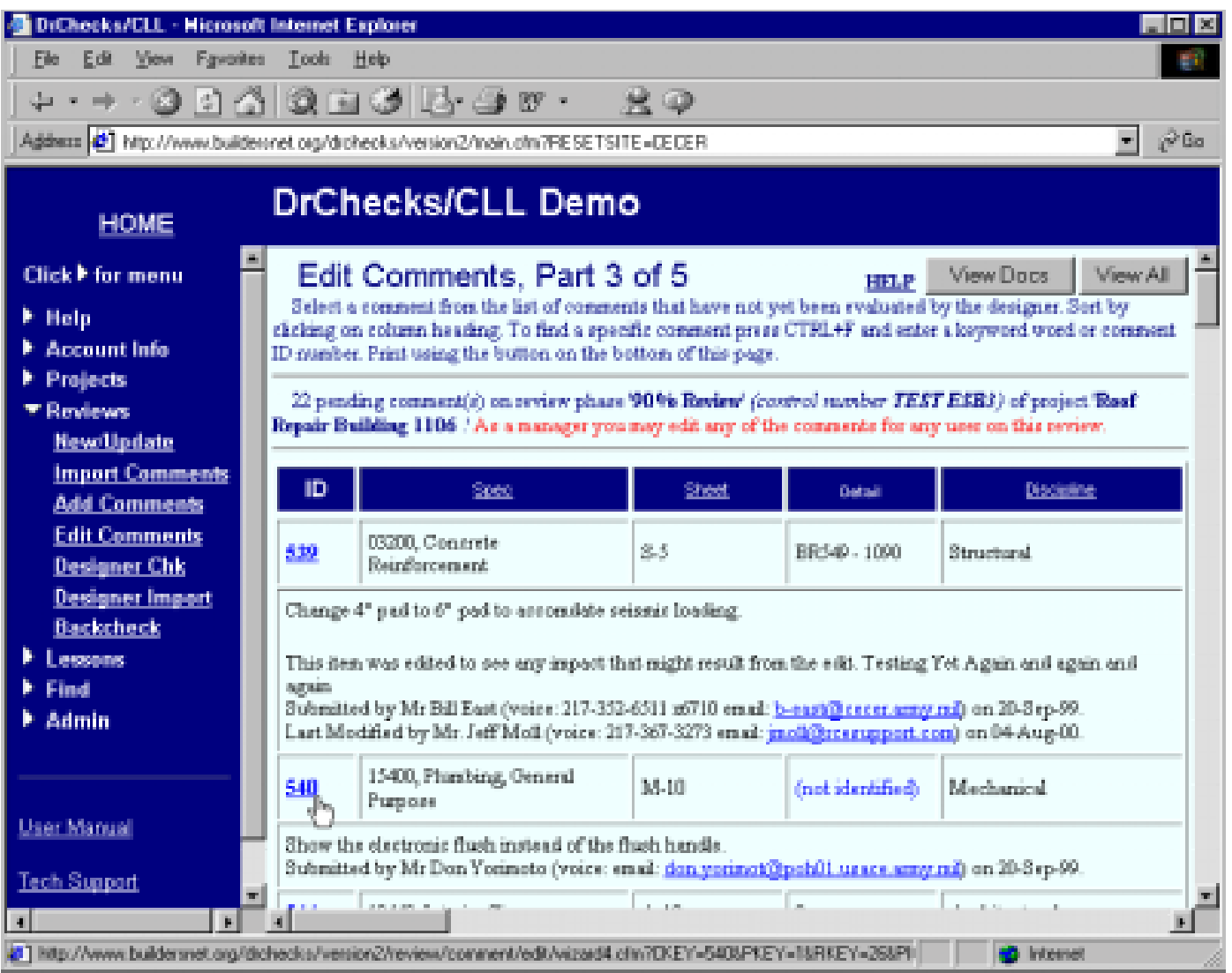

Figure 31. Edit Comments Part 3.

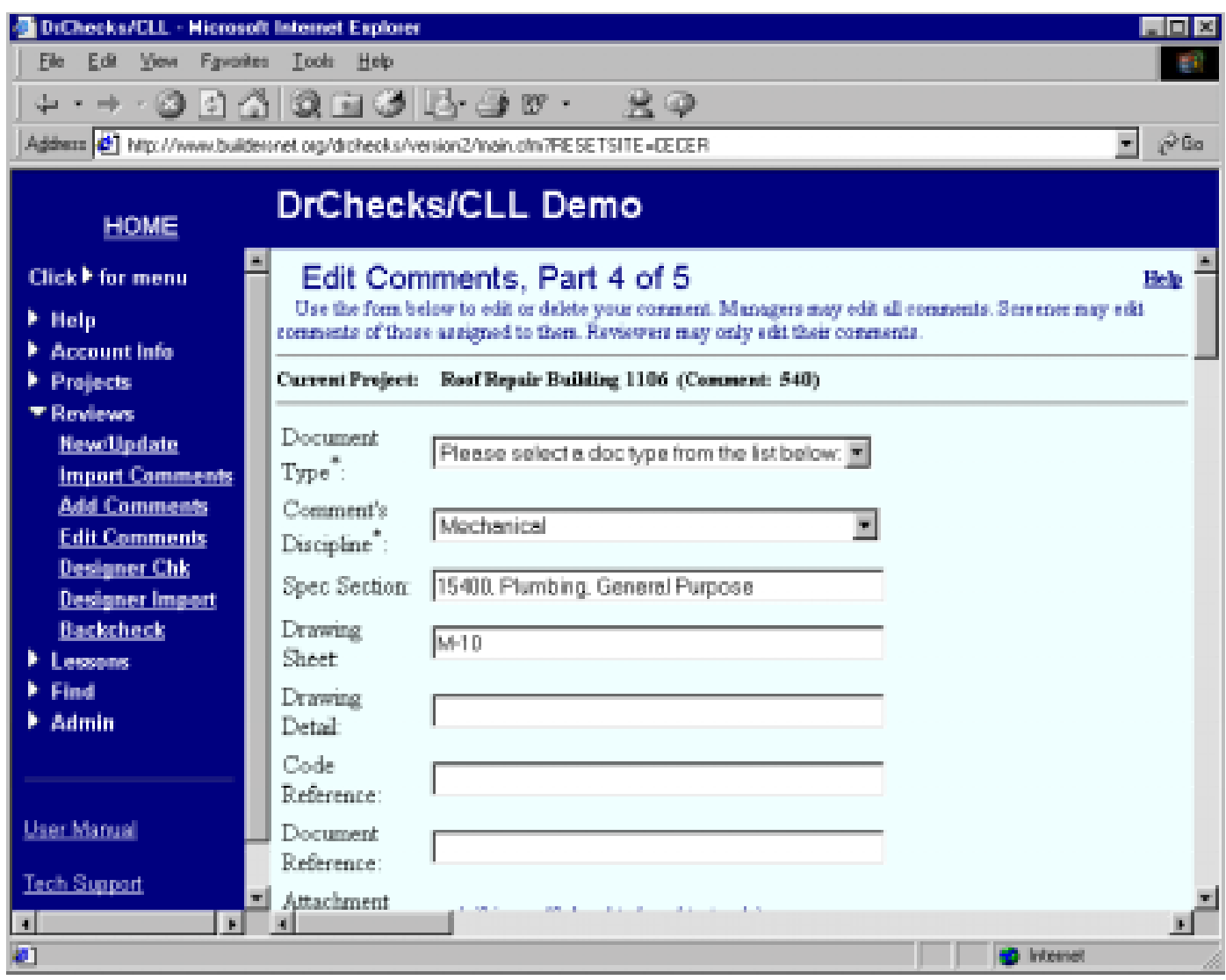

Figure 32. Edit Comments Part 4. 
Document Type: The document type can be defined as the part of the project the added comment affects. For example, if a user wants to add a comment to say "the specifications were incorrect," he/she would choose "Specifications" from the dropdown list. If the correct document type is not listed, the user needs to choose "Other." This field is required.

Comment's Discipline: The comment discipline defines the area of the task. For example, if the user's comment was that more outlets are needed, the comment discipline would be "Electrical." If a certain discipline cannot be found in the list, the user needs to choose "Other." It is reasonable to assume one user can use more than one discipline during a review. This field is required.

Spec Section: When the user needs to refer to the project, he/she can enter a specification reference. The specification reference helps the reviewer identify the individual project specification of the comment.

Drawing Sheet: The "Drawing Sheet" field is a reference to an architectural drawing. For example, if a user wanted to show all outlets in a building, the drawing sheet could reference the drawing that shows the outlets.

Drawing Detail: The "Drawing Detail" field is a reference to a collection of architectural drawings. If the user wants a reviewer to see a certain sheet in a collection, he/she can reference the collection containing the sheet.

Code Reference: Federal laws or regulations may be referenced in the "Code Reference" field is necessary. For example, if a user wants to reference the law that specifies how many fire extinguishers are required, the code reference would show where to find the law.

Document Reference: If the user references a document either for a code or specification detail, this field provides a place to store the reference.

Attachment: When adding a comment, a user can use this field to add supplemental comments or pictures to support the comment. To use this field, click on the "Browse" button to find the path for the file the supplement is in and select the file. It will be moved to the server.

Review Comment: Comments are entered into this field. Text can be copied from a word processor and pasted into the comment. The recommended upper level for this field is approximately 1,000 characters. This field is required. 


\section{Designer Review}

Once a comment has been entered, a designer needs to review it and add his/her own comments. This occurs on the "Designer Chk" screen. Figure 33 shows the process steps.

In Part 1, the user should click on the name of the project that contains comments to be reviewed. After clicking on the project name, the user chooses the review, comment type, and discipline in Part 2.

In Part 3, the user will be presented with a report that shows comment information. Clicking on the "ID" number to the left of the comment will take the user to Part 4, which shows where the comments will be placed (Figures 34 and 35). Concurrence/no concurrence with the comment should also be specified.

After receiving a confirmation screen in Part 5, the user needs to click on the [OK] button to go back to Part 3 and add additional comments.

Project Name: The project name is the standard project reference name. In "Designer Chk" the project named contains the review where comments will be reviewed. This field is required.

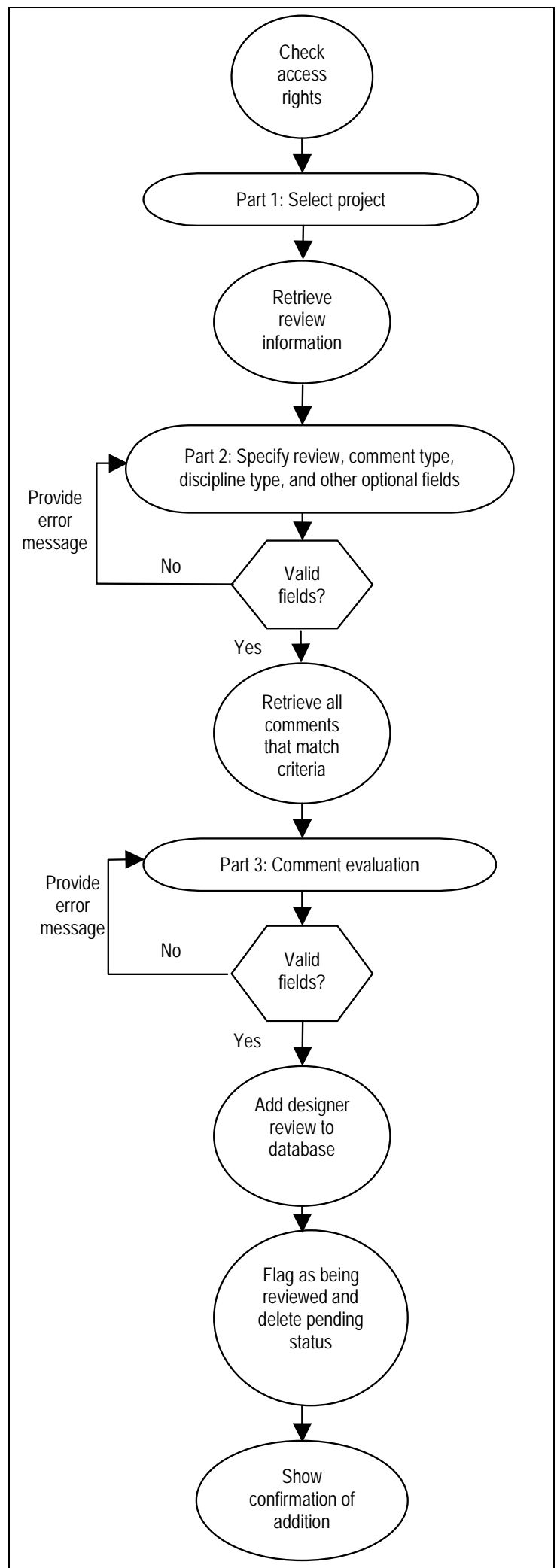

Figure 33. Process of design review. 


\begin{tabular}{|c|c|c|c|}
\hline \multicolumn{3}{|c|}{ 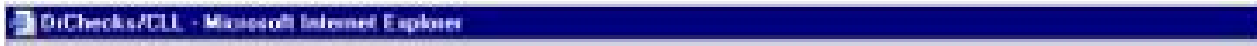 } & Ela \\
\hline \multicolumn{3}{|c|}{ 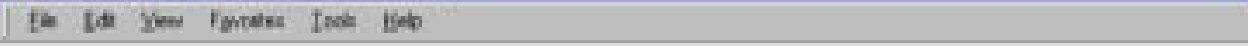 } & A \\
\hline \multicolumn{4}{|c|}{ 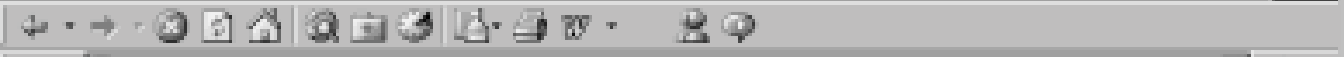 } \\
\hline \multicolumn{3}{|c|}{ 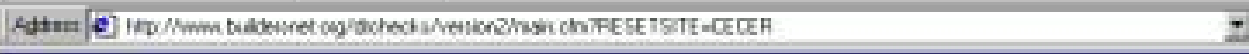 } & से०0 \\
\hline \multirow{4}{*}{\multicolumn{4}{|c|}{ 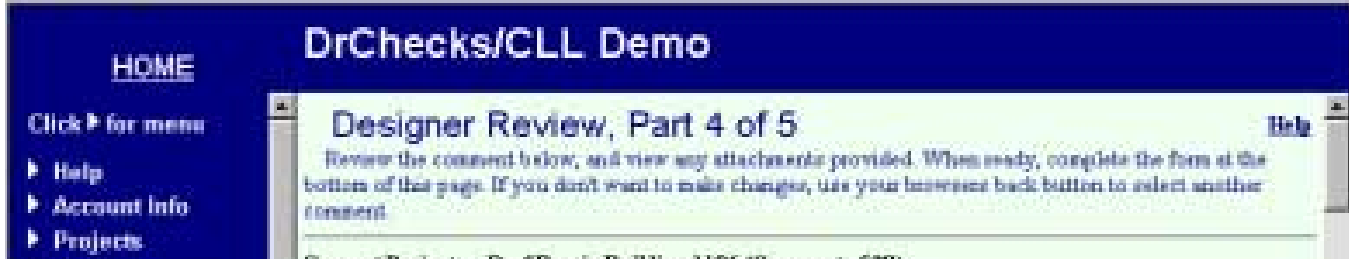 }} \\
\hline & & & \\
\hline & & & \\
\hline & & & \\
\hline \multirow{2}{*}{$\begin{array}{l}\text { - Pavieras } \\
\text { MeranUpidate } \\
\text { Impart Comments }\end{array}$} & \multicolumn{3}{|c|}{ 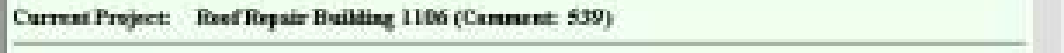 } \\
\hline & \multicolumn{3}{|l|}{ Review Camuent: } \\
\hline \multirow{5}{*}{ 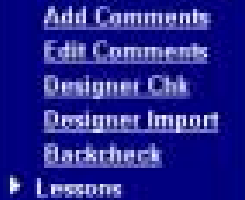 } & Docament Type: & (thet identaind) & \\
\hline & Diutiples: & Structural & \\
\hline & Spet Sectoon & 03200. Conctete Rentortement & \\
\hline & Drawng Seet: & s-5 & \\
\hline & Dramang Detsil & $B R 549-1090$ & \\
\hline $\begin{array}{l}\text { Lessons } \\
\text { Find }\end{array}$ & Code Reference: & (bot iderified) & \\
\hline \multirow[t]{2}{*}{ Admin } & Docoment Fieference: & (tont identaind) & \\
\hline & Revien Cuement & & \\
\hline Wuer Maned & \multicolumn{3}{|c|}{ "Change 4" pad to $6 "$ pail to acromidate serismie lnailing. } \\
\hline Ierch Susout & \multicolumn{2}{|c|}{$\begin{array}{l}\text { This item was edited to see any impart that might result from the edit. Testing Yet } \\
\text { Again and again and again" }\end{array}$} & \\
\hline 4 & st & & 5 \\
\hline \multicolumn{4}{|l|}{ elone } \\
\hline
\end{tabular}

Figure 34. Designer Review Part 4.

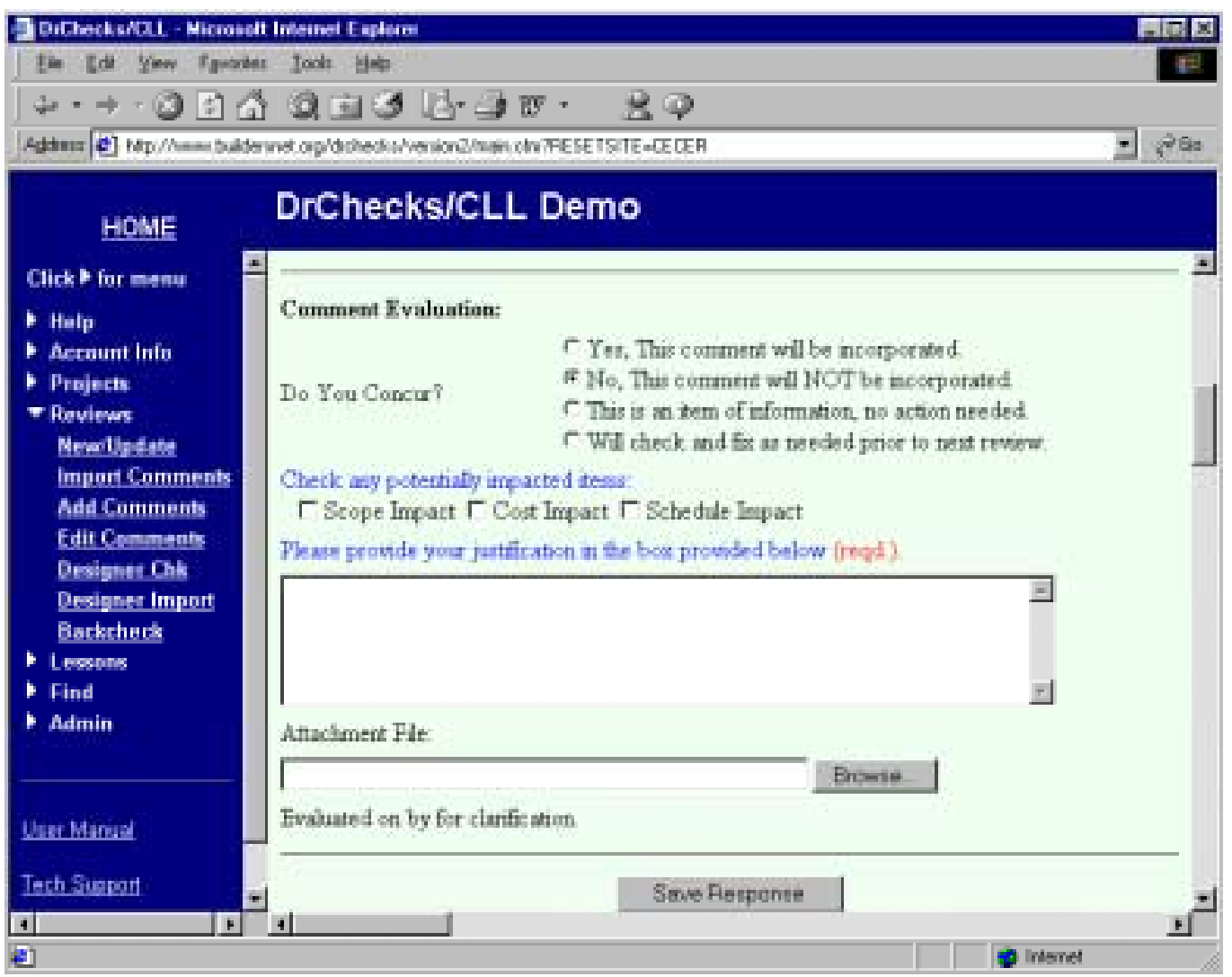

Figure 35. Design Review Part 4 (continued). 
Review Phase: To review a comment, the user selects the name of the review for which he/she wishes to review a comment. This field is required.

Comment Type: The comment type describes the stage of the comment. For example, a new comment is considered "pending," but another reviewer might want to see pending comments. Instead of the new reviewer viewing all comments, he/she can choose to view all pending comments in the comment type list box. This is a required field.

Specific Discipline: The specific discipline defines the area of the task. For example, if the user's comment was about needing more outlets added, the comment discipline would be "Electrical." If a certain discipline cannot be found in the list, he/she will need to choose "Other." This field is required.

Spec Section: When the user needs to refer to the project, he/she can enter a specification reference. The specification reference helps the reviewer identify the individual project specification of the comment.

Specific Sheet: The "Specific Sheet" field is a reference to an architectural drawing. This field is not a required, but it is the equivalent of the "Drawing Sheet" in "Add Comment."

Specific Detail: The "Drawing Sheet" field is a reference to a collection of architectural drawings. For example, if the user wanted to show all outlets in a building, the drawing sheet could reference the drawing that shows the outlets.

Comment Evaluation: In the comment evaluation area there are three parts. First, the user needs to specify if he/she agrees or disagrees with the comment. If no action is required, he/she could mark the comment as information only. Second, the user needs to specify how the project scope is affected; however, this is an optional field. Third, the user comments on why he/she agrees or disagrees. This field is required.

Attachment File: When adding a comment, the user can use this field to add supplemental comments or pictures to explain the comment better. To use this field, click on the "Browse" button to find the path for the file the supplement is in. The attachment of the file will be moved to the server. 


\section{Designer Import}

A designer can import a comment in the "Designer Import" screen. If a user wants to enter comments located in a different file, it is possible to import those comments to any available review in a project. If a user wants to see all comments for a review, the [View all comments...] button should be clicked. Figure 36 shows the process steps. To import a comment, the project name needs to be specified by clicking on the project name in Part 1.

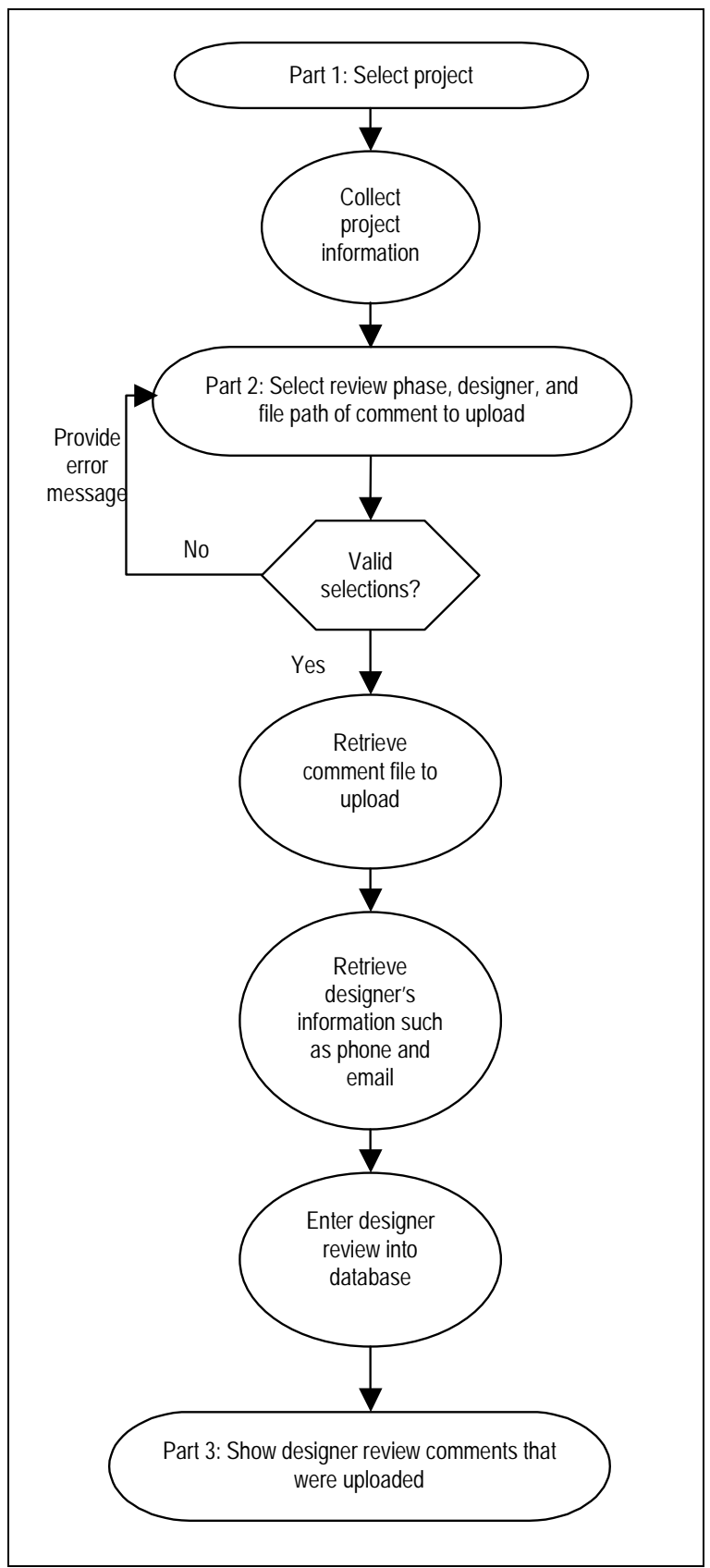

Figure 36. Process of design import. 
Once the project is selected and the user has proceeded to Part 2 (Figure 37), the review phase, the designer to review the comment, and the file path where the comment is located should all be specified.

If the file path is correct, the upload will be confirmed in Part 3.

Project Name: The project name is the standard project reference name. In "Designer Import" the project name is the project that contains the review from which comments will be imported. This field is required.

Review Phase: To import a comment, a user selects the name of the review where the imported comment will be placed. This field is required.

File Upload: To import a file, the designer will need to specify the path for the file where the comment can be found. A designer import can be uploaded to any review phase, unlike "Import Comment" where comments can be imported only to the last review. This field is required.

Designer Select: The user selects a designer name from the dropdown list. Names located in the list are designers assigned for the project. This field is required.

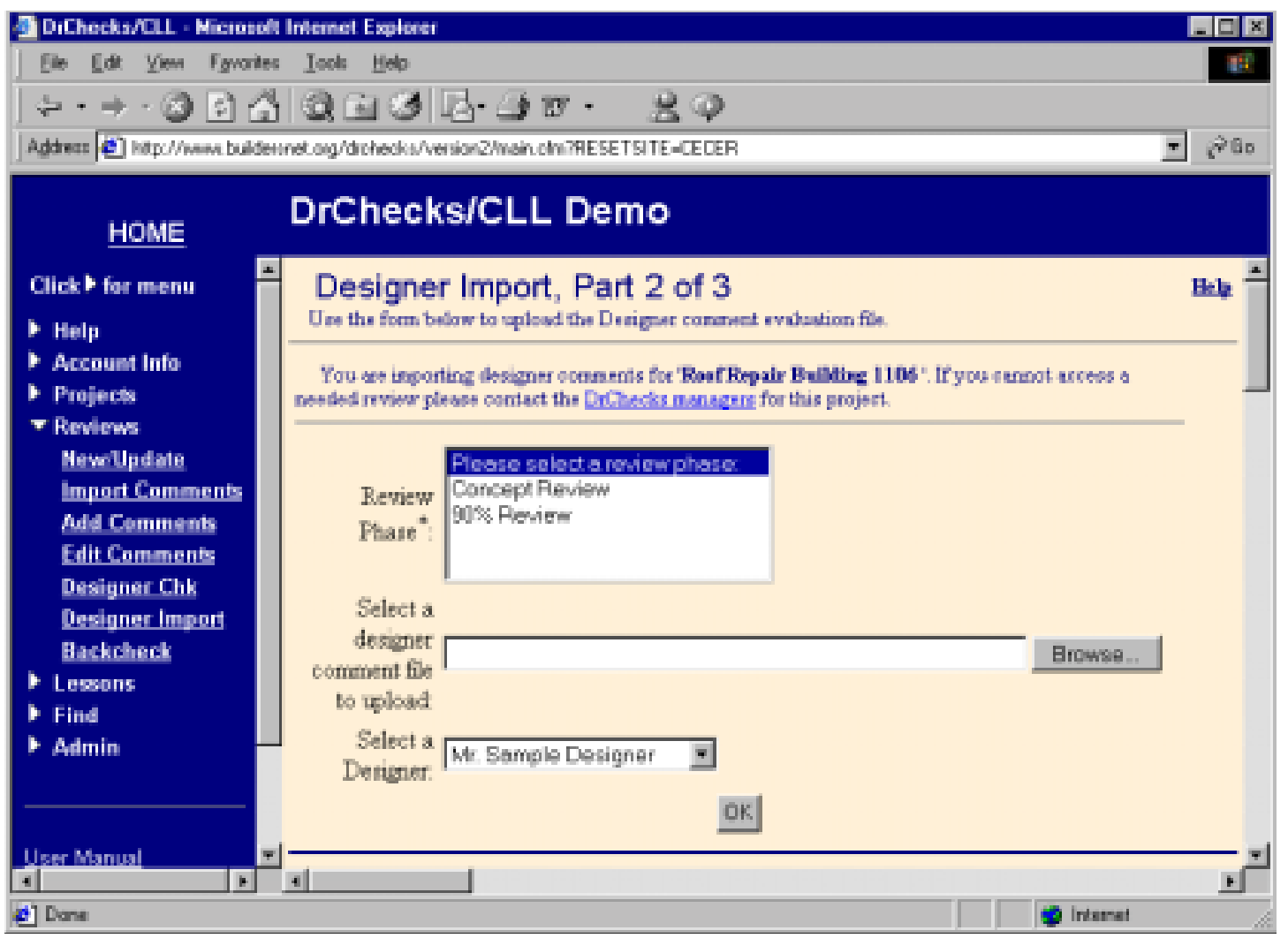

Figure 37. Designer Import Part 2. 


\section{Backcheck Comments}

Once a designer has reviewed a comment, it needs to be backchecked. Backchecking allows updating a comment status to closed or open, or to withdraw the comment altogether. Figure 38 shows the process steps. In Part 1 of the "Backcheck" screen, the user chooses the project to backcheck. The review in which a comment is located must be chosen by clicking on the review name in Part 2. A graph that holds the comment information is presented in Part 3. This shows various details about the comment. Part 4 (Figures 39 and 40) is where the backcheck is entered. The user clicks on the "ID" number of the comment to be taken to the backcheck screen. In Part 5 the user clicks the [OK] button to confirm the backcheck.

Project Name: The project name is the standard project reference name. In "Backcheck Comments," the project name is the project that contains the review where comments will be backchecked. This field is required.

Review Phase: To backcheck a comment, the user selects the name of the review containing the comment. This is a required field.

Comment Status: When backchecking a comment, the user specifies whether the comment is still open, closed, or will be amended and reviewed again. This field is required and defaults to "item open."

Comment: If the item is still open or needs to be amended, the user may want to provide an explanation for the open status. The comment is an optional field and is not required. 


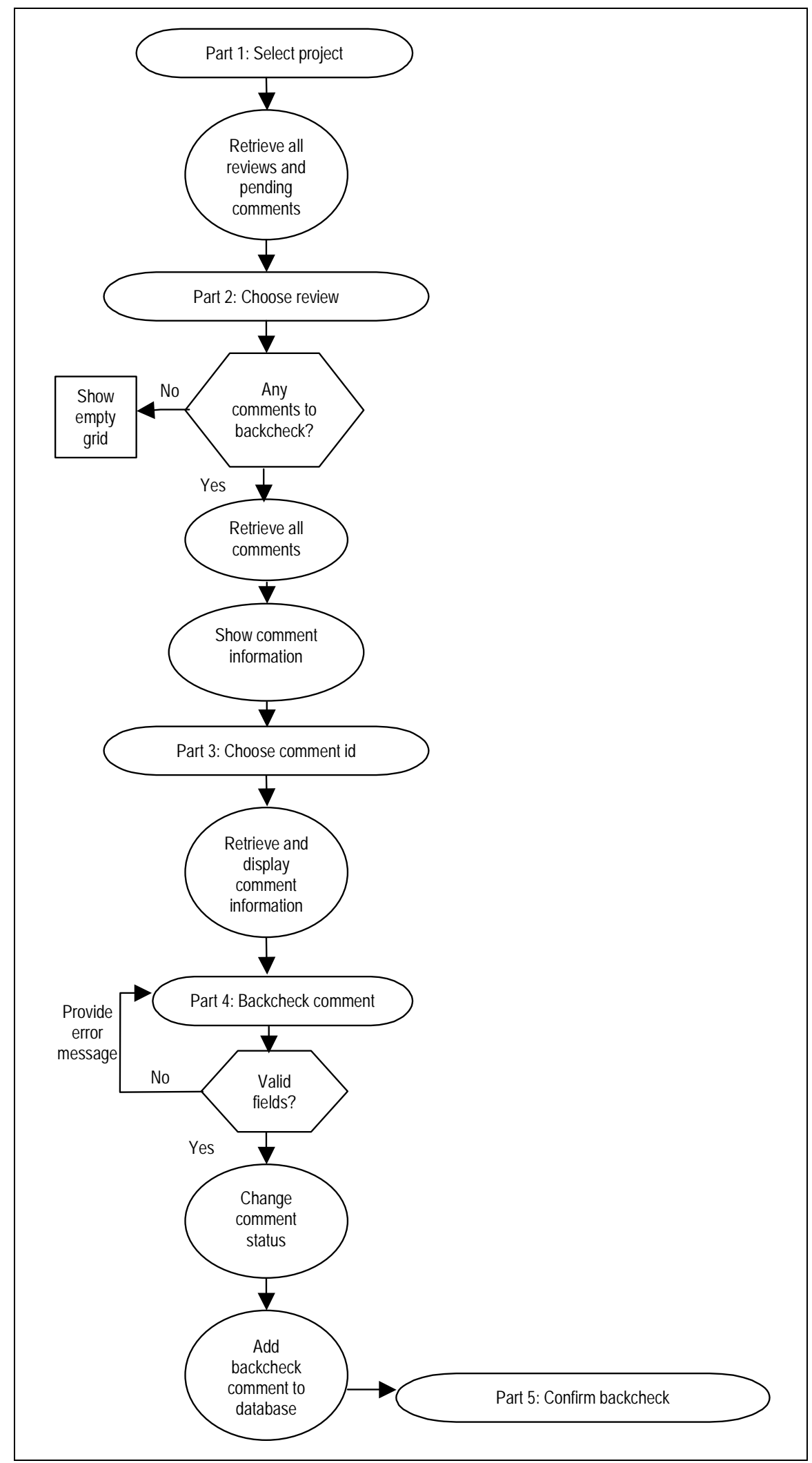

Figure 38. Process of backcheck comments. 


\begin{tabular}{|c|c|c|}
\hline \multicolumn{3}{|c|}{ 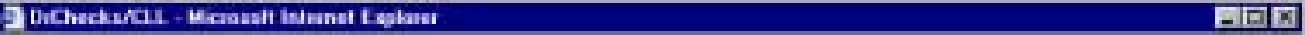 } \\
\hline \multicolumn{3}{|c|}{ 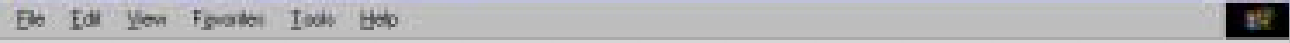 } \\
\hline \multicolumn{3}{|c|}{ 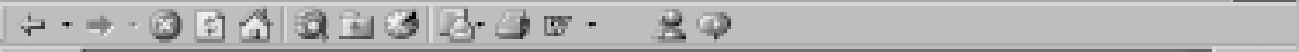 } \\
\hline \multicolumn{3}{|c|}{ 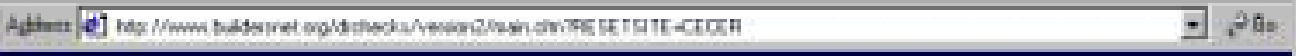 } \\
\hline \multicolumn{3}{|c|}{ Home DrChecks/CLL Demo } \\
\hline \multirow{2}{*}{\multicolumn{3}{|c|}{ 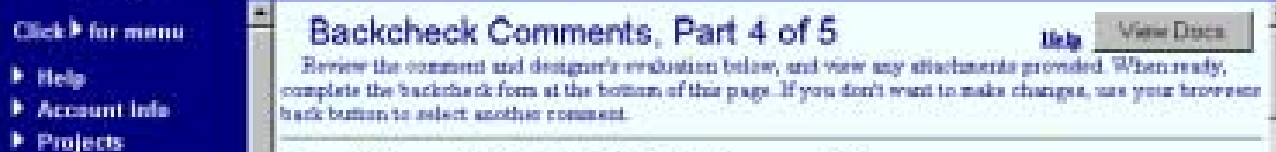 }} \\
\hline & & \\
\hline \multirow{3}{*}{ 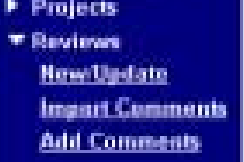 } & \multicolumn{2}{|c|}{ 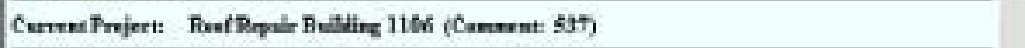 } \\
\hline & \multicolumn{2}{|l|}{ Review Comment: } \\
\hline & Dociment Typt: & Plass \& Specificatical \\
\hline \multirow{3}{*}{ 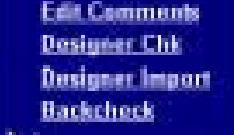 } & Disciples: & Conl \\
\hline & Spet Sectice: & $00000,5 e$ Work \\
\hline & Drawing Sbeet: & C-1 \\
\hline \multirow{2}{*}{ Find } & Drawng Detail & $1 \mathrm{C} \cdot 1 \mathrm{C} \cdot \mathrm{C}$ \\
\hline & Code Finference: & $A W W A$ \\
\hline \multirow[t]{2}{*}{ D Admin } & Dostantrt Rerfinmet & DA-Eappliatile \\
\hline & Renew Cotuntut & \\
\hline \multirow{2}{*}{\multicolumn{3}{|c|}{ Medifly depth ar }} \\
\hline & & \\
\hline$\cdot$ & .1 & 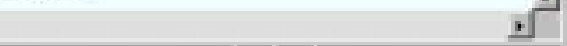 \\
\hline \multicolumn{3}{|r|}{ Dinener } \\
\hline
\end{tabular}

Figure 39. Backcheck Comments Part 4.

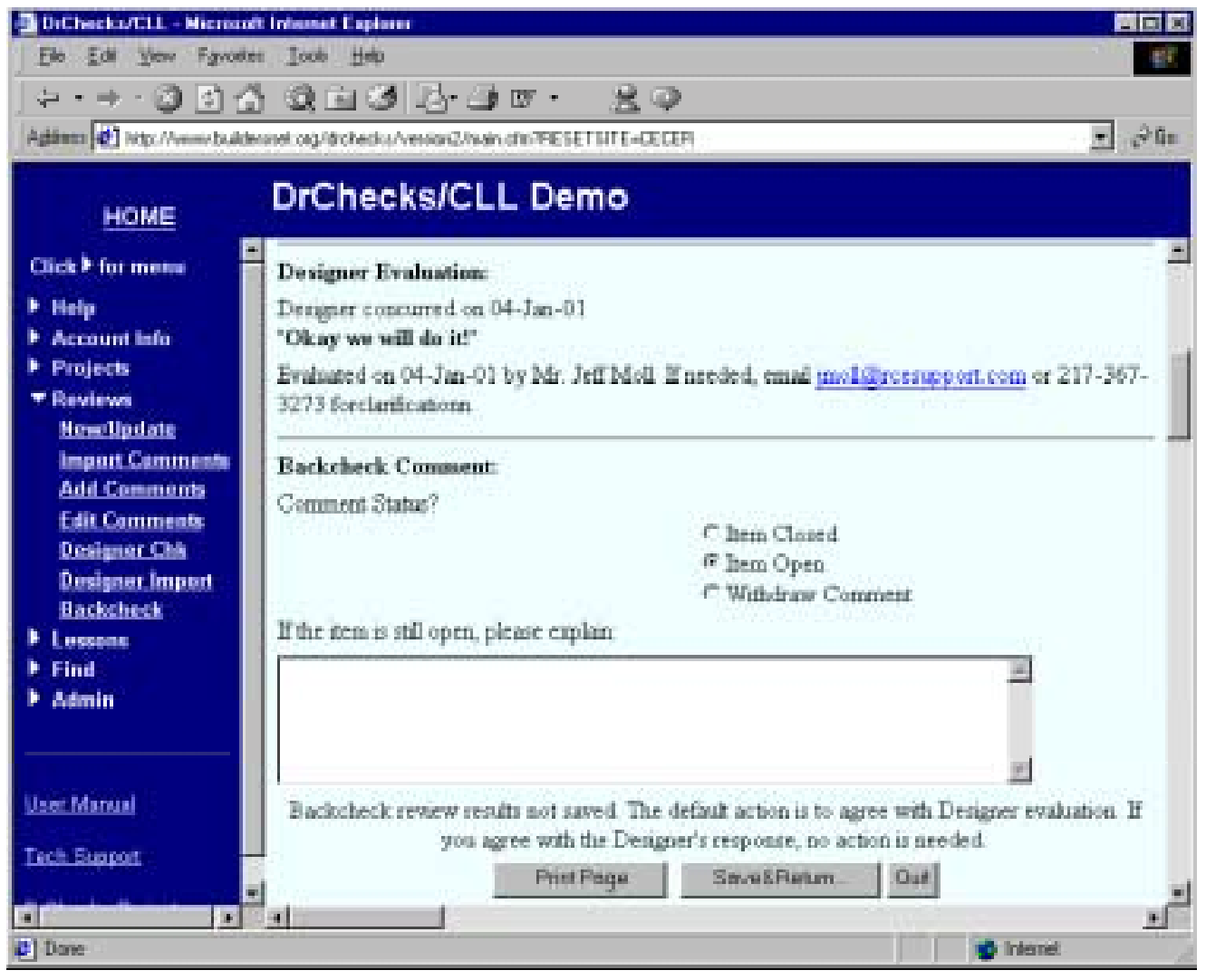

Figure 40. Backcheck Comments Part 4 (continued). 


\section{New Lesson}

Lessons learned are problems found or new information that could be shared with other users. Lessons are assigned to certain people for their approval or disapproval. Figure 41 shows the process steps.

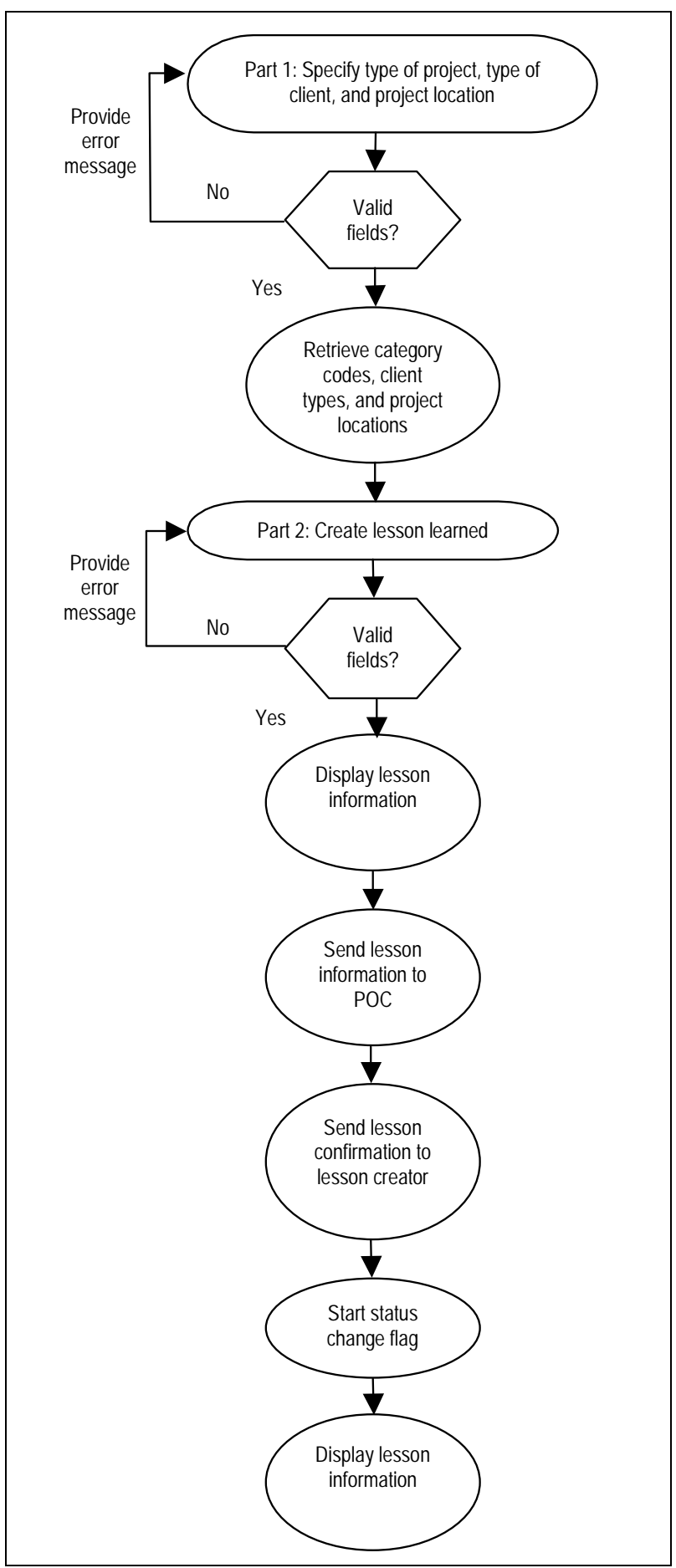

Figure 41. Process of adding a new lesson. 
To add a Lesson Learned, the user specifies the type of project, type of customer, and where the project is located. These specifics are selected on Part 1 of the "New/ Update" screen (Figure 42).

In Part 2 (Figure 43), the category code, customer, location, discipline, spec section, reason, topic, effects, lesson title, problem, solution, and file attachments should also be specified. Clicking on the [Submit] button takes the user to Part 3.

Part 3 is where the user receives confirmation that the lesson has been sent and notification that the POC will send the user an email regarding the lesson. To print a hardcopy of this page, right-click the mouse button and select "Print" from the popup menu. The [Close Page] button at the bottom completes the submission.

Project Category: When creating a lesson, the user needs to choose a project category that shows what lesson activities are involved. MILCON codes will show tasks needed for a specific facility. The Civil Works category code will show activities not broken down into specific facilities or tasks. The HTRW category code will show task-specific activities that may include handling dangerous materials. Other codes will show activities for local facilities. This field is required.

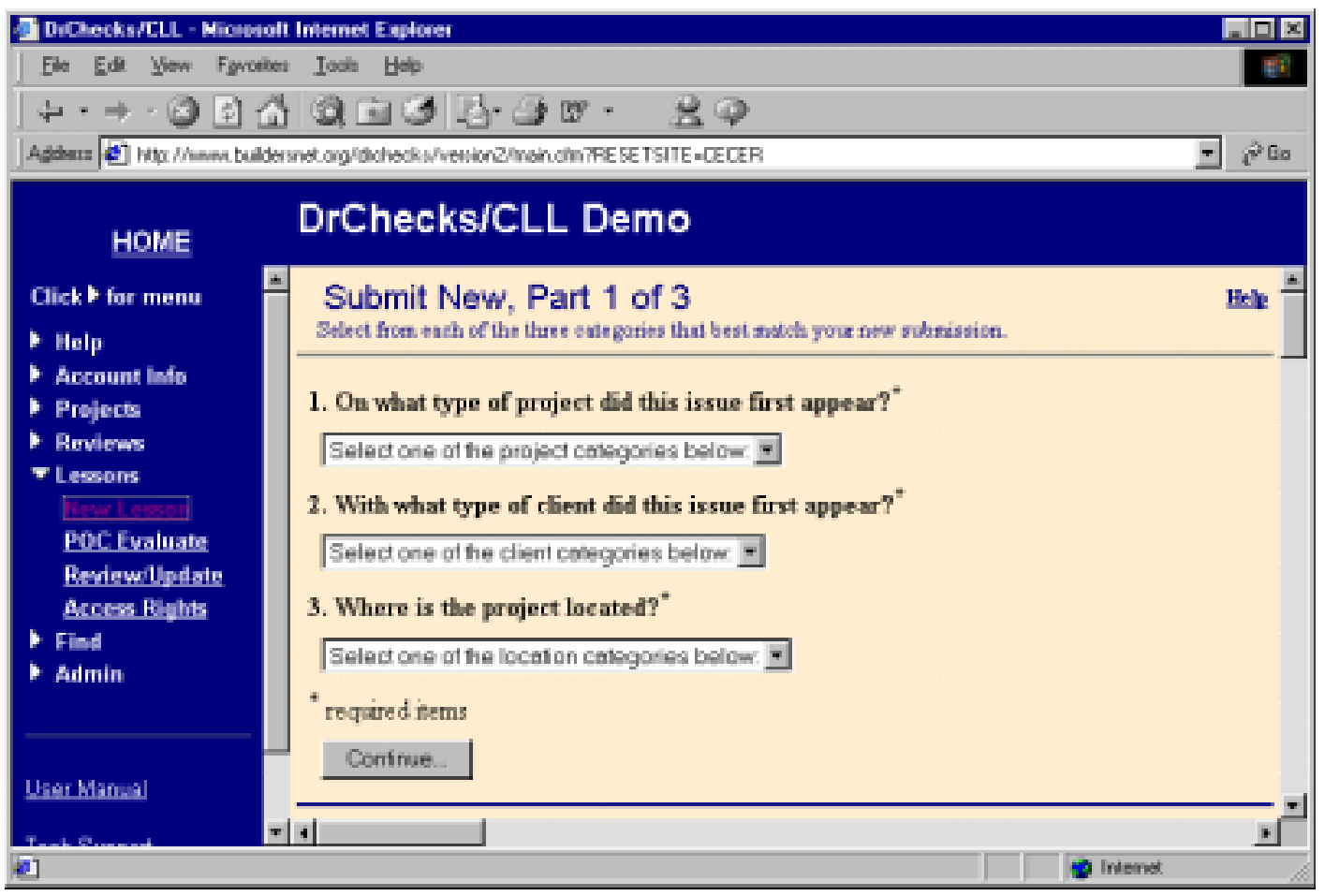

Figure 42. New Lesson Part 1. 


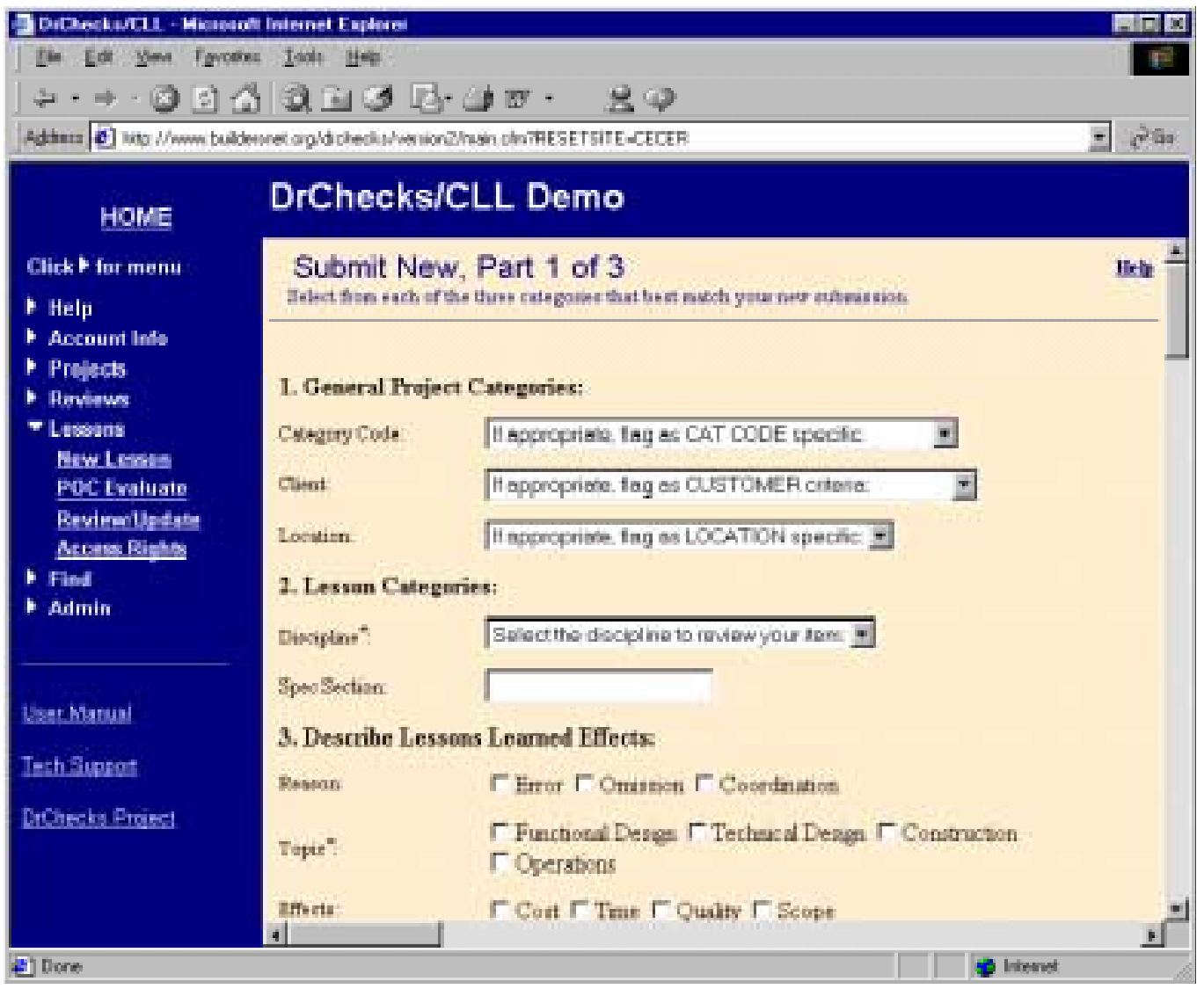

Figure 43. New Lesson Part 1 (continued).

Customer Categories: While creating a lesson, the user will need to choose the customer category that shows the project customer. Army customers are branches of the U.S. Army. Non-Army Military Customers are the branches of the military not included under Army Customers. Other Government Agencies are customers that work for the U.S. Government and are not included in the military. Foreign Governments are non-U.S. governments doing business with the DrChecks agency. Other customers are not U.S. Government or military specific. This field is required.

Location Categories: While creating a lesson, the user chooses the location category to show where the project is. Outside categories will show the names of various foreign countries. District Specific Sites will show nearby locations. The "Within U.S." category will list names of all U.S. states. This field is required.

Cat Code: The Cat Code is a more specific Civil Works HTRW, or Military category depending on what Project Category Code was chosen. If the category was Civil Works, the user can choose an activity not meant for specific facilities or tasks. If the category was HTRW, the user can choose a task-specific activity that may include handling dangerous materials. If the category was Military, the user can choose a task needed for a specific facility. 
Customer: The customer is a more specific customer category code. The customer refers to the group or organization requesting the project. Army customers are the branches of the U.S. Army. Federal Government Agencies are customers that work for the U.S. Government and are not included in the military. Foreign Governments are non-U.S. governments doing business with the DrChecks agency. Local Customers are not U.S. Government or military specific. Other Military Customers are the branches of the military that cannot be included under Army Customers.

Location: The location targets the specific area where the project is taking place. After a customer has chosen a larger area such as a foreign site, a local site, or a U.S. state, a site within that larger area needs to be chosen.

Discipline: The comment discipline defines the area of the task. For example, if the user's comment was that more outlets are needed, the comment discipline would be "Electrical." If a certain discipline cannot be found in the list, the user will need to choose "Other." This field is required.

Spec Section: When a user needs to refer to the project, he/she can enter a specification reference. The specification reference helps the reviewer identify the individual project specification of the comment.

Lesson Learned Effects: When creating a new lesson, the user needs to specify the effects on the lesson. Three ways to specify are by determining the reason, topic, and effects. The reason can be described as the cause of the error or effect. The topic is a required field that specifies in what stage of the design or operation the lesson occurred. The effect specifies what type of effect occurred. This field is required.

Lesson Learned Description: The Lesson Learned Description should include the title of the lesson, the problem, the suggestion of change, and the solution. The problem field should contain the complete description of the problem found. The suggestion of change allows a user to recommend a change to fix the problem. The change could be made in manuals, regulations, or specifications. The description of the solution should go in the solution field. This field is required.

File Attachments: When entering the problem and solution of the lesson, it may be necessary to include supplemental materials. The supplemental materials can be attached by using the "Problem Backup" and "Solution Backup" fields. Both fields need the file path specified. These fields are not required. 


\section{POC Evaluate Lessons}

After the lesson has been submitted, the POC needs to evaluate the lesson or reassign it to another POC. Figure 44 shows the process steps.

To view the details about a particular lesson, the ID number beside it needs to be chosen in Part 1.

All comments about the lesson are located in Part 2 of "POC Evaluate" (Figures 45 and 46). If he/she does not want to approve the lesson, it can be sent to another POC.

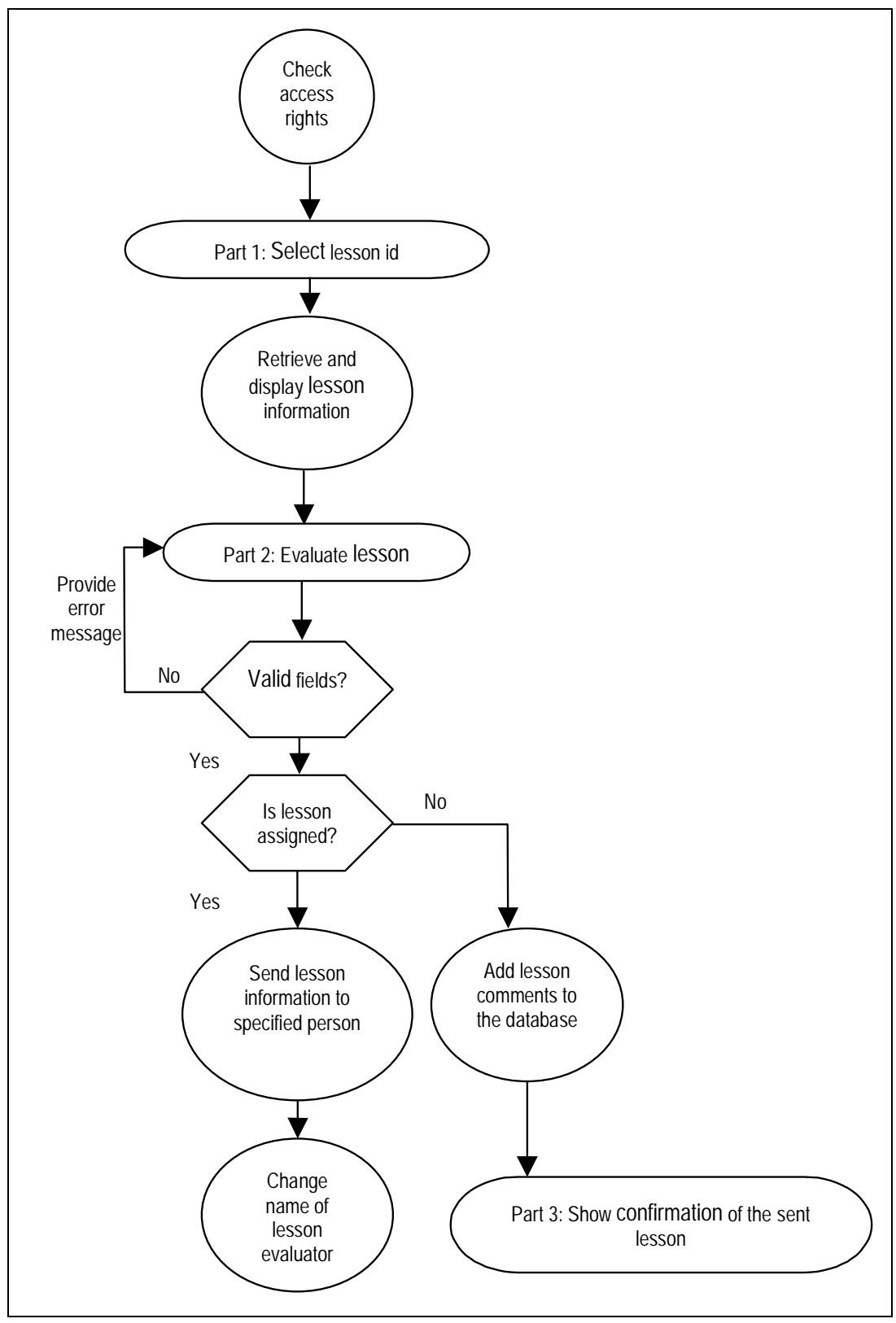

Figure 44. Process of POC Evaluate. 


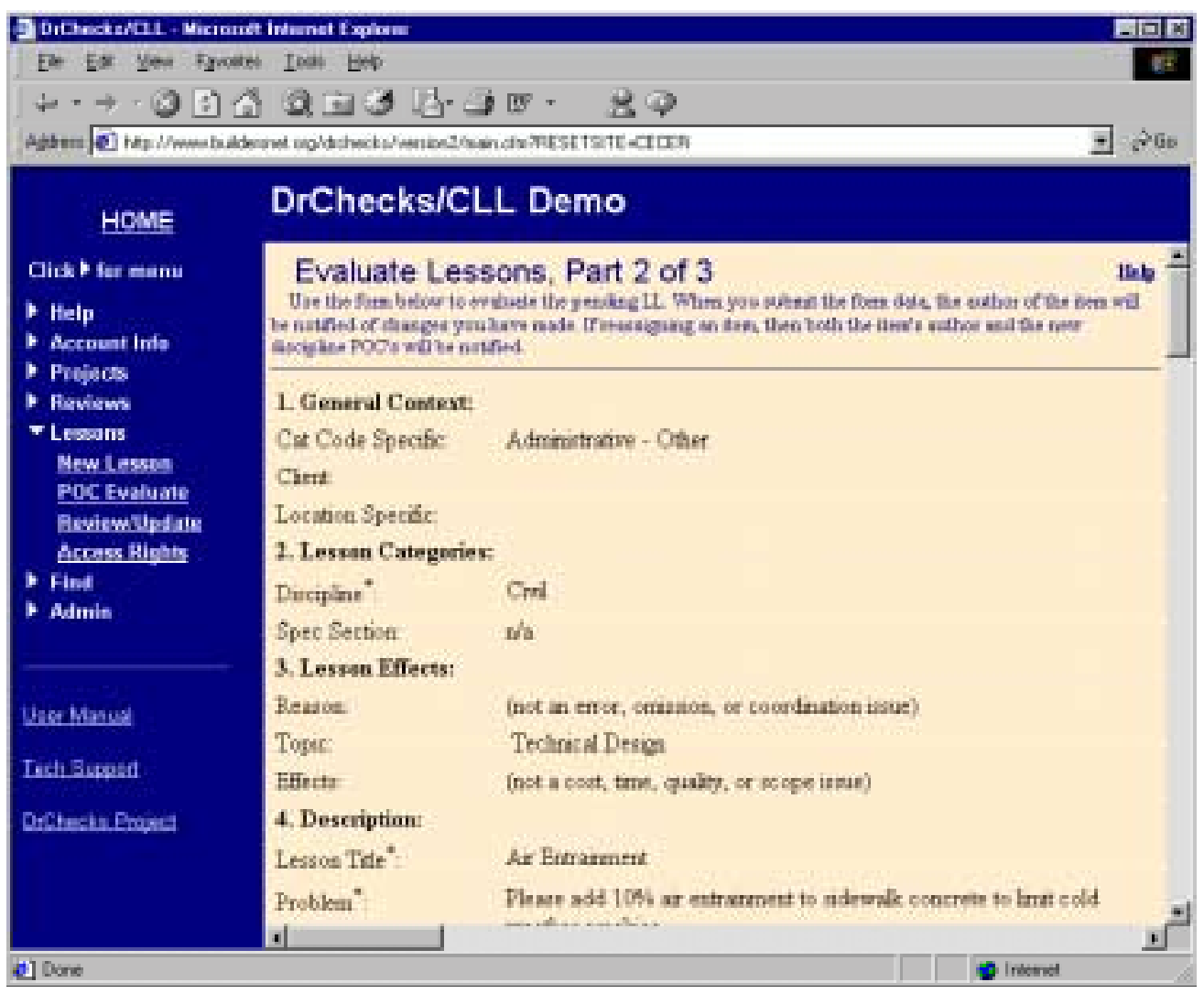

Figure 45. POC Evaluate Part 2.

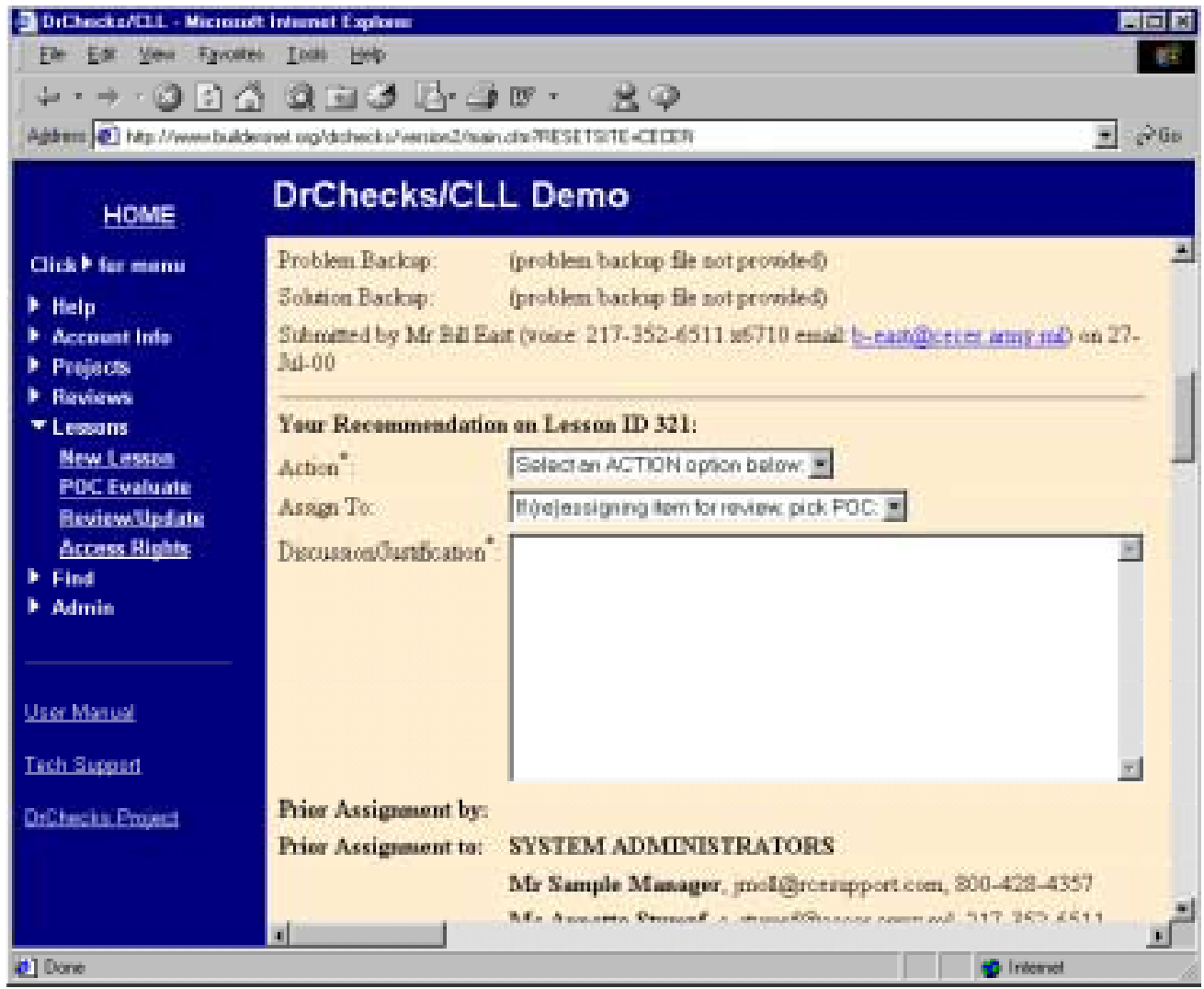

Figure 46. POC Evaluate Part 2 (continued). 
After the evaluation is complete, clicking the [Submit] button will take the user to Part 3, where he/she receives a confirmation message of the submittal.

Action: After a lesson has been chosen, the user will need to decide how he/she will handle the lesson. The user can choose to approve the lesson, deny the lesson, reassign it to a different $\mathrm{POC}$, or request backup from the author. This is a required field.

Assign To: If the user wants to reassign the lesson to another POC, he/she needs to select a name from the "Assign To" dropdown list. The names on the list are administrators for the site.

Discussion/Justification: If the POC wants to evaluate the lesson, he/she will need to specify an action and then discuss the reason for the action in the "Discussion/Justification" field. This field is required regardless if the lesson has been evaluated or reassigned. 


\section{Review/Update Lesson}

To change information about the lesson submitted or delete the lesson altogether, the user can do so by using the "Review/Update" screen. Figure 47 shows the process steps.

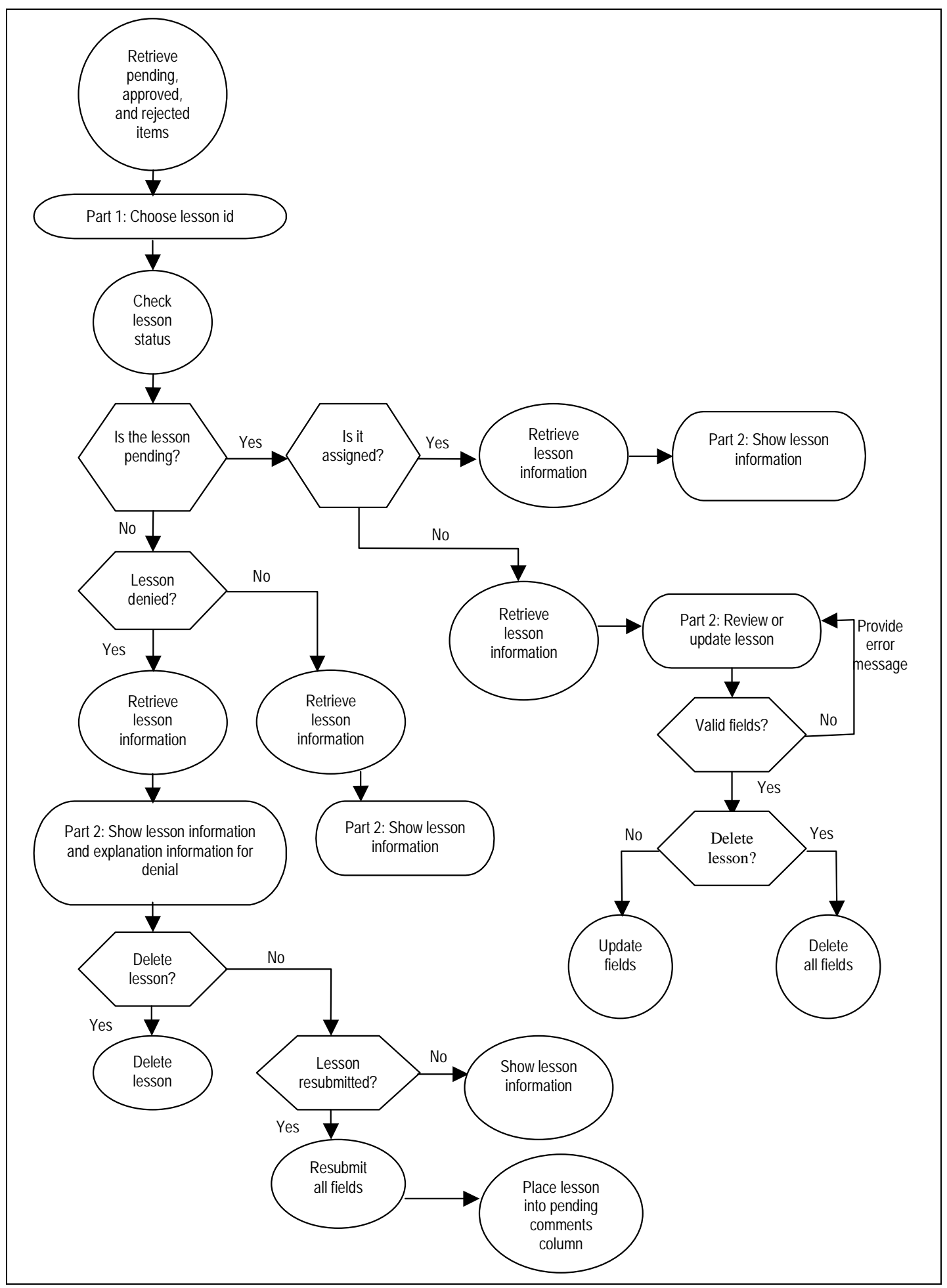

Figure 47. Process of review/updating a lesson. 
Part 1 will show a list of all of the pending, unapproved, and approved lessons. If the user clicks on an unapproved or approved lesson, a screen showing all details of the lesson will appear in Part 2 (Figure 48).

Cat Code: The Cat Code is a more specific Civil Works, HTRW, or Military category depending on what Project Category Code was chosen. If the category was Civil Works, a user can choose an activity not meant for specific facilities or tasks. If the category was HTRW, a user can choose a task-specific activity that may include handling dangerous materials. If the category was Military, a user can choose a task needed for a specific facility.

Customer: The customer is a more specific customer category code. It refers to the group or organization requesting the project. Army customers are the branches of the U.S. Army. Federal Government Agencies are customers that work for the U.S. Government and are not included in the military. Foreign Governments are non-U.S. governments doing business with the DrChecks agency. Local Customers are not U.S. Government or military specific. Other Military Customers are the branches of the military that cannot be included under Army Customers.

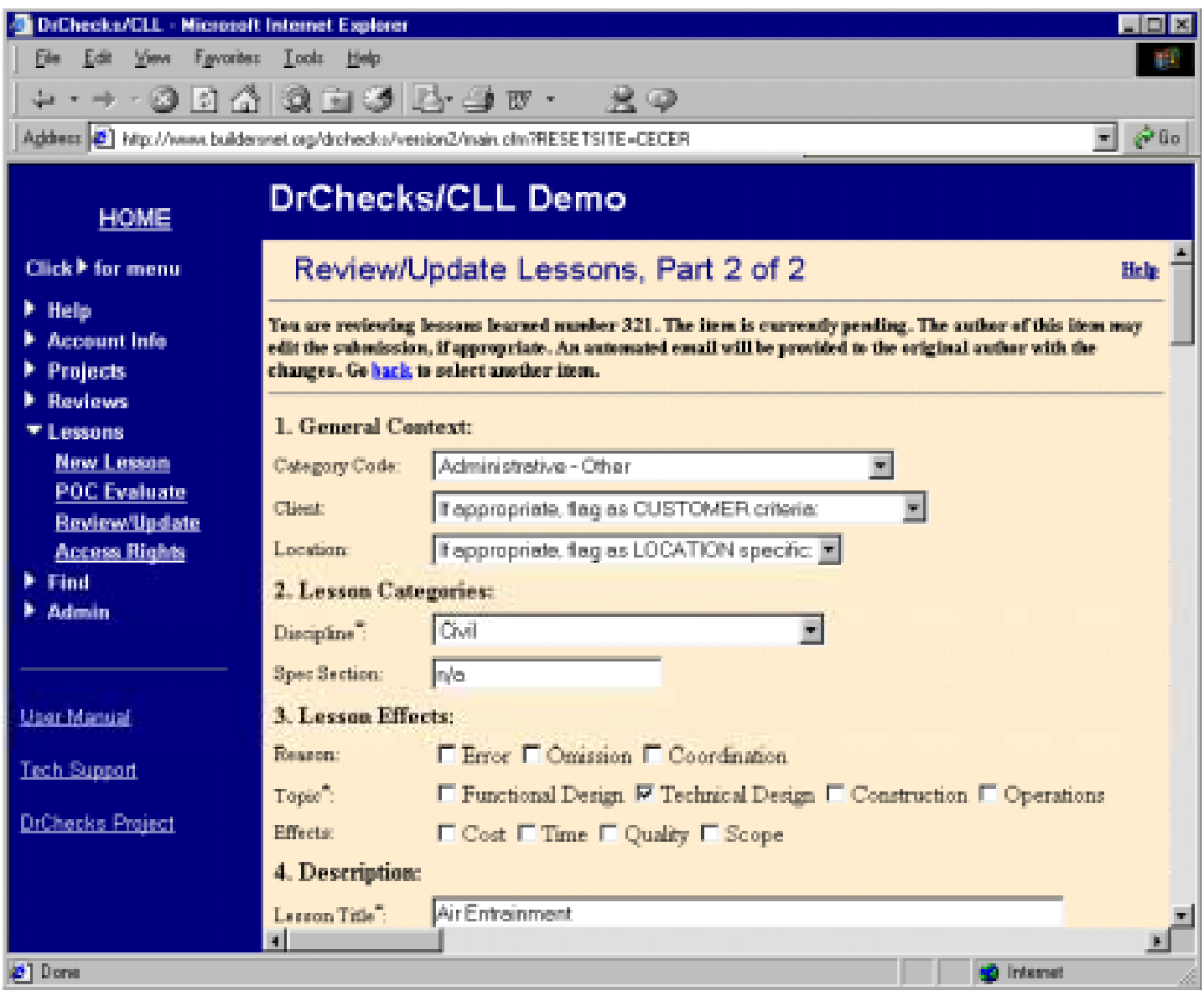

Figure 48. Review/Update Lessons Part 2. 
Location: The location targets the specific area where the project is taking place. After a customer has chosen a larger area such as a foreign site, a local site, or a U.S. state, a site within that larger area needs to be chosen.

Discipline: The comment discipline defines the area of the task. For example, if the user's comment was that more outlets are needed, the comment discipline would be "Electrical." If a certain discipline cannot be found on the list, the user will need to choose "Other." This field is required.

Spec Section: When a user needs to refer to the project, he/she can enter a specification reference. The specification reference helps the reviewer identify the individual project specification of the comment.

Lesson Learned Effects: The effects on the lesson can be specified by determining the reason, topic, and effects. The reason can be described as the cause of the effect or error. The topic is a required field that specifies in what stage of the design or operation the lesson occurred. The effect specifies what type of effect occurred. This field is required.

Lesson Learned Description: The Lesson Learned Description should include the title of the lesson, the problem, the suggestion of change, and the solution. The problem field should contain the complete description of the problem found. The suggestion of change allows a user to recommend a change in order to fix the problem. The change could be made in the manuals, regulations, or specifications. The description of the solution should go in the solution field. This field is required.

File Attachments: When entering the problem and solution of the lesson, it may be necessary to include supplemental materials. The supplemental materials can be attached by using the "Problem Backup" and "Solution Backup" fields. Both fields need the file path specified. These fields are not required. 


\section{Access Rights}

If only certain people are to review the lesson submitted, the access rights may be changed to accommodate new reviewers. Figure 49 shows the process steps.

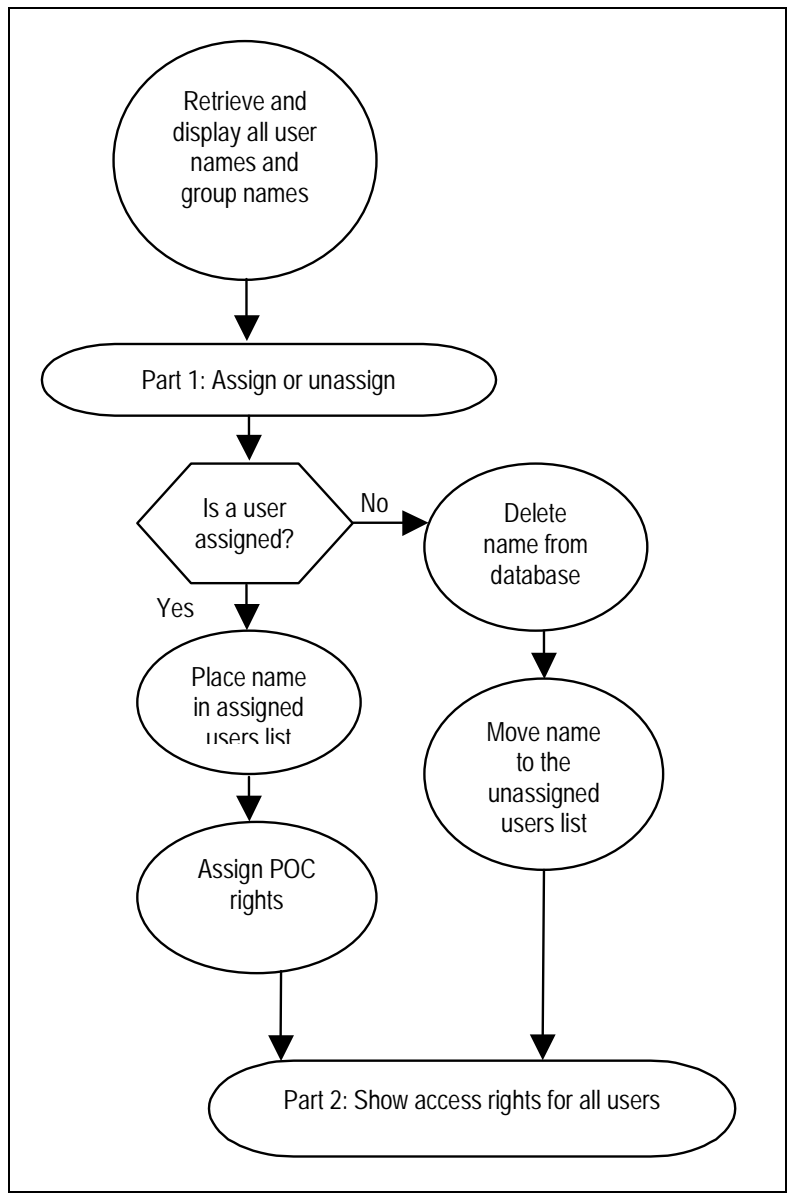

Figure 49. Process of assigning access rights to a lesson.

To assign access rights, the user should highlight his/her name in the box and click on the [Add] button in Part 1 (Figure 50). This will add the name to the reviewer list. In Part 2 the user confirms that the name has been added. Clicking on the [Return] button returns the user to Part 1 of "Access Rights." 


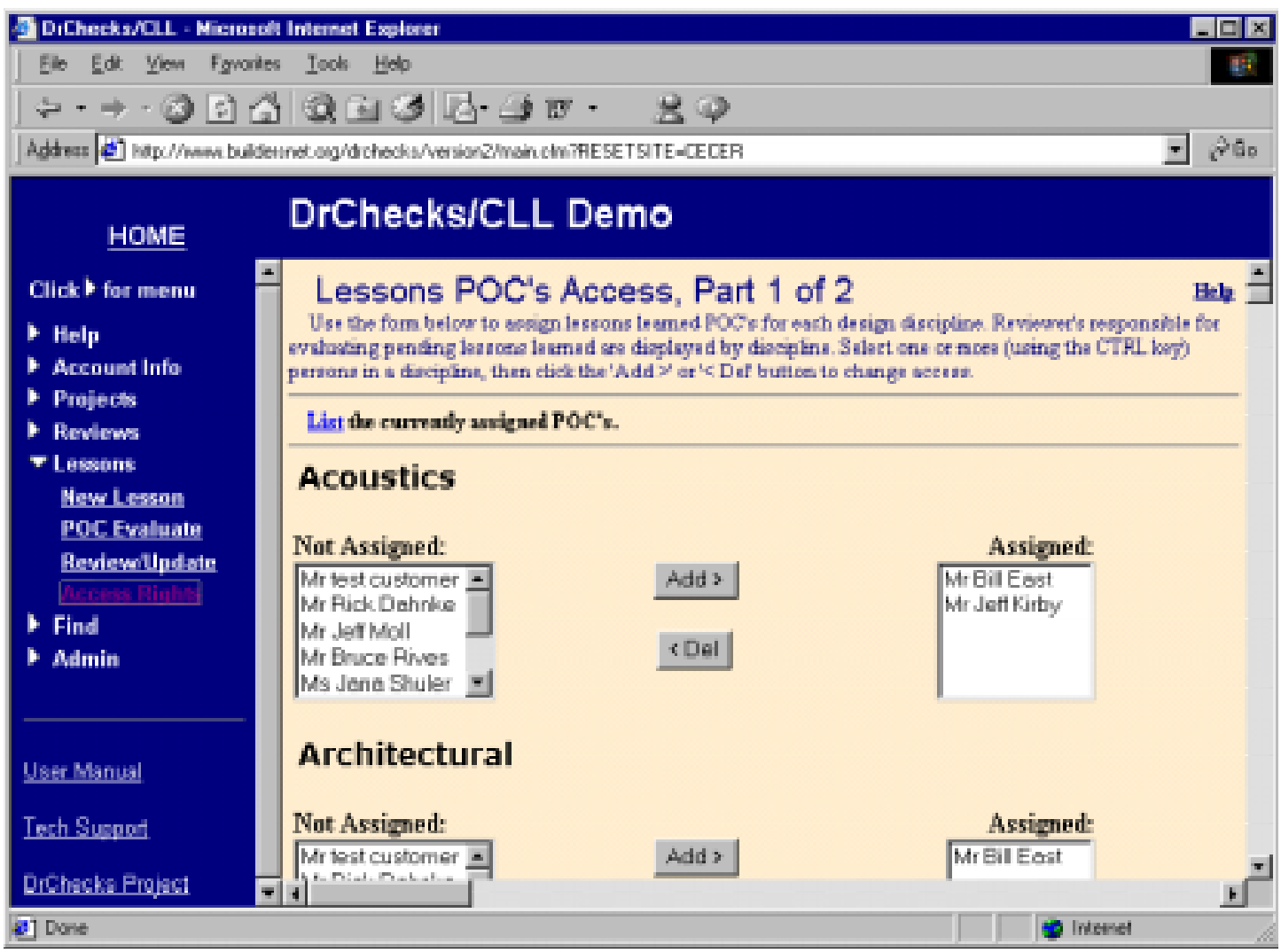

Figure 50. Lesson Access Rights Part 1.

Unassigned Users: A person's name is in the default unassigned box until he/she has been given certain access rights. Each box of unassigned users are teams or individuals that meet the criteria of the assignment type chosen. These individuals or groups are also divided into reviewers, designers, managers, and customers. This field is required.

Assigned Users: An assigned user has access rights to a certain project. Each time a user's name appears in the assigned box gives access rights in that division. For example, if a user is assigned as a reviewer and designer, the only access rights the user has are reviewer and designer rights. This field is required. 


\section{Quick Find Comments}

If a user wants to find a certain comment without having to search through the whole database, he/she can use the "Find Comments" process. Figure 51 shows the process steps.

Part 1 of the comment search (Figure 52) provides a quick method to access a specific comment or comments by key words. The search will be executed against either "your" comments or everyone's comments, depending upon the specifications. The search is not case sensitive.

Once the search is complete, a list of all comments found in the search will be presented in Part 2 (Figure 53). The top section of the page lists the criteria used during the search and the number of cases returned. If the correct comment was not found, the user may want to click on the link "Quick" to go back to Part 1.

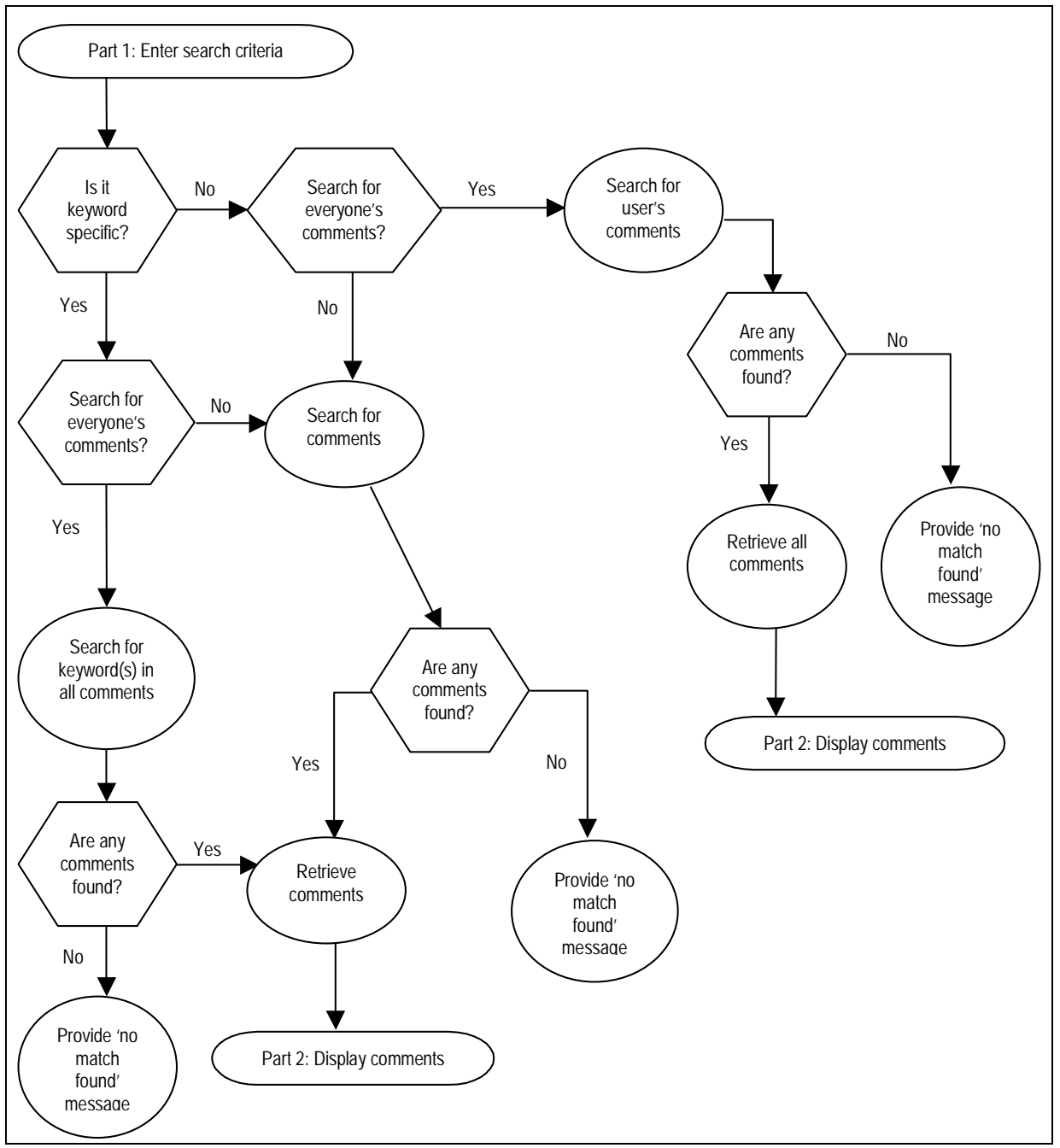

Figure 51. Process of quick find comments. 


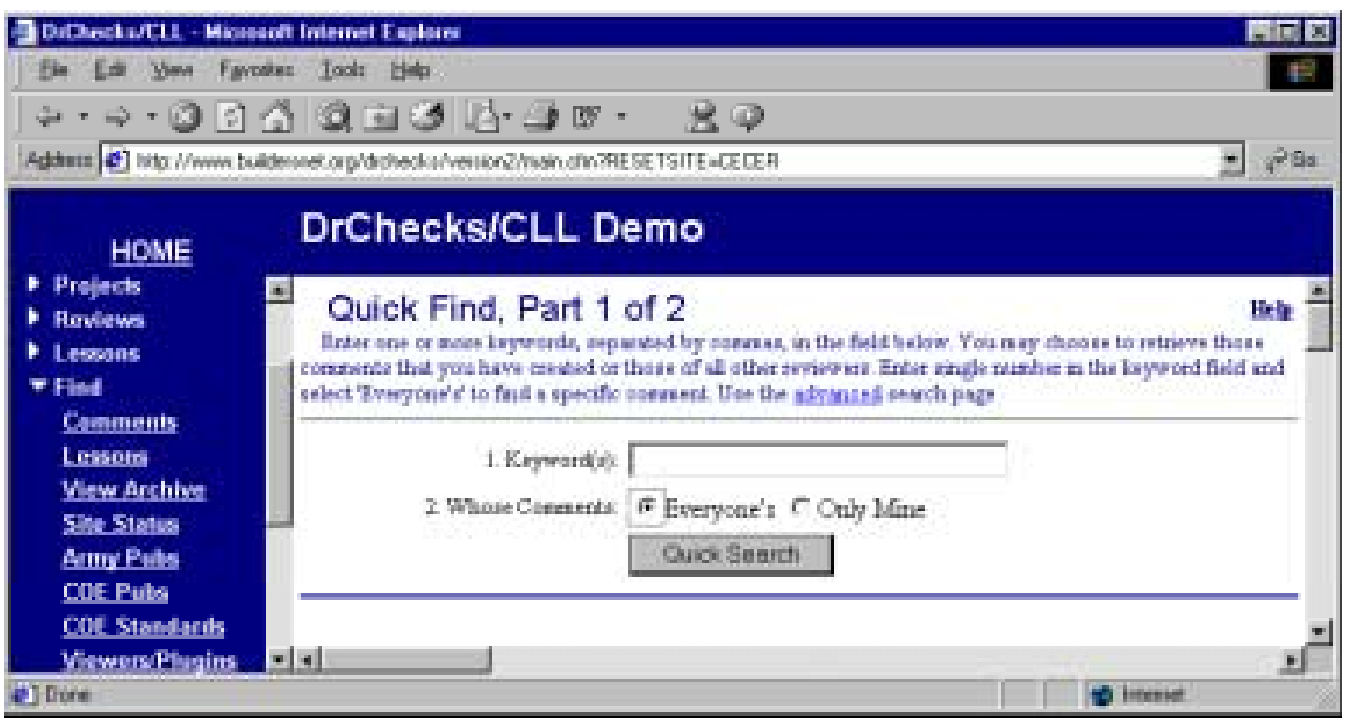

Figure 52. Quick Find Comments Part 1.

\begin{tabular}{|c|c|c|c|c|c|}
\hline \multicolumn{6}{|c|}{ 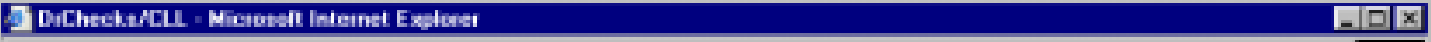 } \\
\hline \multicolumn{6}{|c|}{ 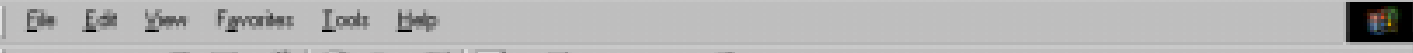 } \\
\hline \multicolumn{6}{|c|}{ 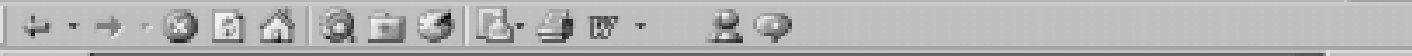 } \\
\hline \multicolumn{6}{|c|}{ 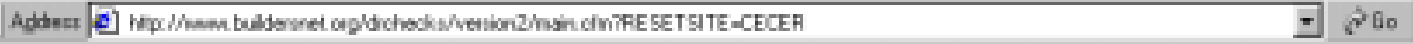 } \\
\hline \multicolumn{6}{|l|}{ HOME } \\
\hline Cilck $\mathbf{b}$ for menu & \multicolumn{4}{|c|}{ Quick Find, Part 2 of 2} & Hely \\
\hline Hels & \multicolumn{5}{|c|}{ 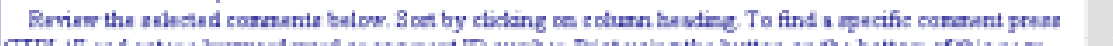 } \\
\hline - Acresunt Info & \multirow{2}{*}{\multicolumn{5}{|c|}{ 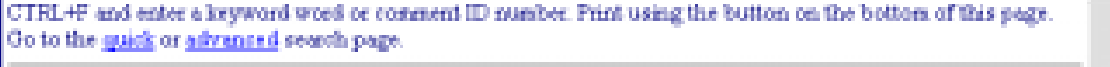 }} \\
\hline Prniarts & & & & & \\
\hline D Reulews & Yaur so & reh returned 350 Canuarats. & & & \\
\hline \multicolumn{6}{|l|}{ L Lessong } \\
\hline \multicolumn{6}{|l|}{$\boldsymbol{*}$ Find } \\
\hline \multicolumn{6}{|l|}{ Comments } \\
\hline \multicolumn{6}{|l|}{ Lessons } \\
\hline \multicolumn{6}{|l|}{ Yirnw Arethive } \\
\hline Site Status & 10 & $2 \cos$ & geas & Beter & Getion \\
\hline Armypuhs & & & & & \\
\hline COE Puhs & 140 & $\begin{array}{l}\text { Drom, Finfive and Shen } \\
\text { Metal }\end{array}$ & $\begin{array}{l}\text { (not } \\
\text { idietified) }\end{array}$ & (not identistd) & Asthalectural \\
\hline COE-Standards & \multirow{8}{*}{\multicolumn{5}{|c|}{ 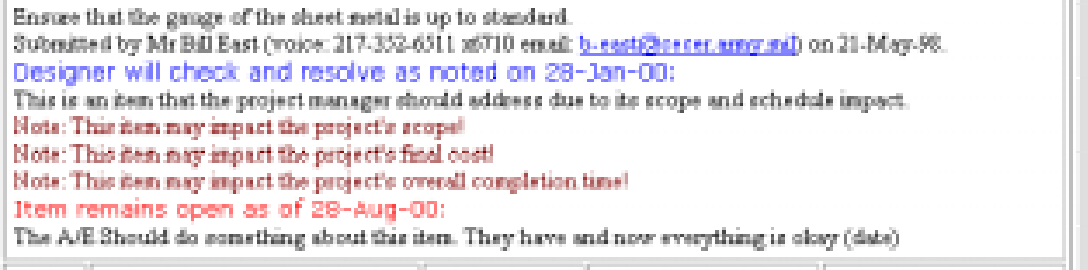 }} \\
\hline Vierwers Plagins & & & & & \\
\hline \multirow[t]{3}{*}{ Admin } & & & & & \\
\hline & & & & & \\
\hline & & & & & \\
\hline \multirow[t]{2}{*}{ Mear Mroupl } & & & & & \\
\hline & & & & & \\
\hline Iroh_suport & & & & & \\
\hline Dretarks Priest & 141 & Or600, Fuatizg wed Shert & (not & (net isent 6.5 ) & Aathitecturel \\
\hline & & & & & s) \\
\hline e] & & & & & 9 intsent \\
\hline
\end{tabular}

Figure 53. Quick Find Comments Part 2. 
Keyword(s): To do a quick search on comments, a user may want to specify a word that can be found in the desired comment. If two or more words can be specified, the search will look for those two words as a combination. These words can also be separated by a comma to search for either word.

Whose Comments: If a user wants to search on his/her own comments, he/she needs to specify the "Only Mine" option; otherwise, the "Everyone's" option should be selected. If selected, the search will be for all users. This field is required. 


\section{Advanced Find Comments}

To do a more advanced search, the user clicks on the "Advanced" link to go to a screen where he/she can specify the project, customer, or location. Figure 54 shows the process steps.

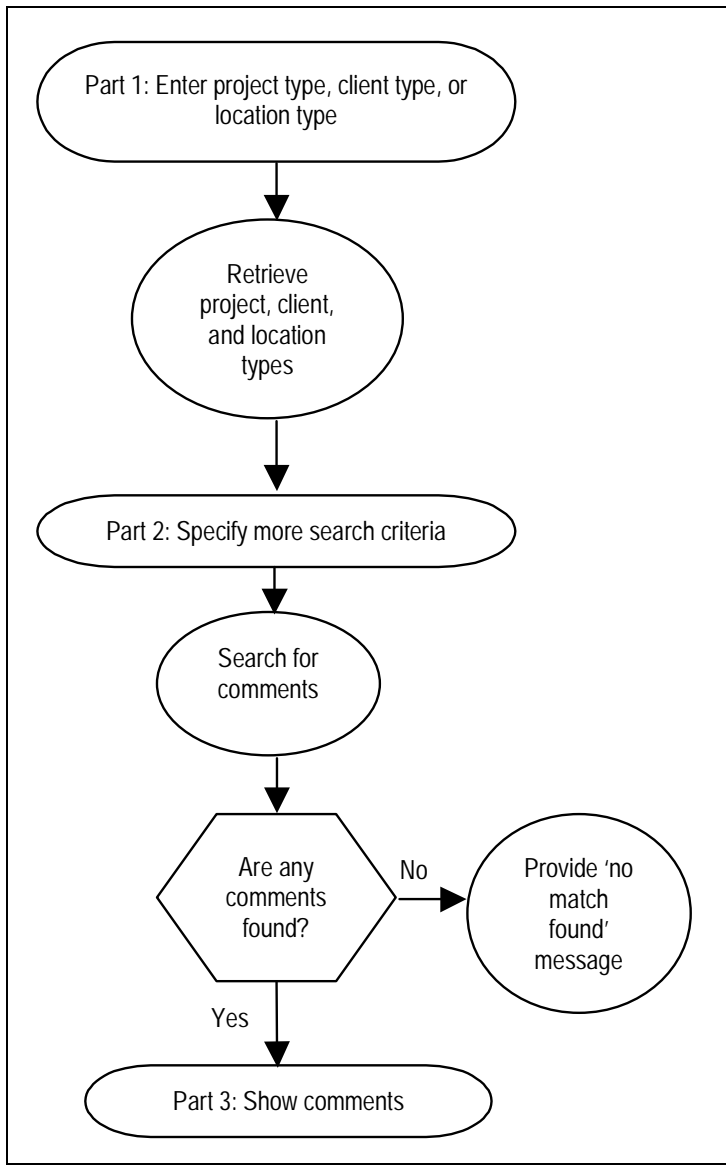

Figure 54. Process of advanced find comments.

When the search criteria are filled in, clicking on the [Continue] button in Part 1 (Figure 55) will start the search. Based on the criteria specified in Part 1 of the advanced search, the user will be able to narrow down the search criteria in Part 2 (Figure 56).

Once all desired fields have been filled in, clicking on [Continue] in Part 2 finishes the search. Part 3 of the ad- vanced search shows the search results based on the search criteria specified in Part 2.

Project Category Code: The project category code will show what the project activities involve. The project category code can be one of three types. The Civil Works category code shows activities not broken down into specific facilities or tasks. The HTRW category code shows task-specific activities that may include handling dangerous materials. Military codes show tasks needed for a specific facility.

Customer Categories: The customer category shows the project customer. Army customers are branches of the U.S. Army. NonArmy Military Customers are the branches of the military not included under Army Customers. Other Government Agencies are those customers who work for the U.S. Government and are not included in the military. Foreign Governments are non-U.S. governments doing business with the DrChecks agency. Other customers are not U.S. Government or military specific. 


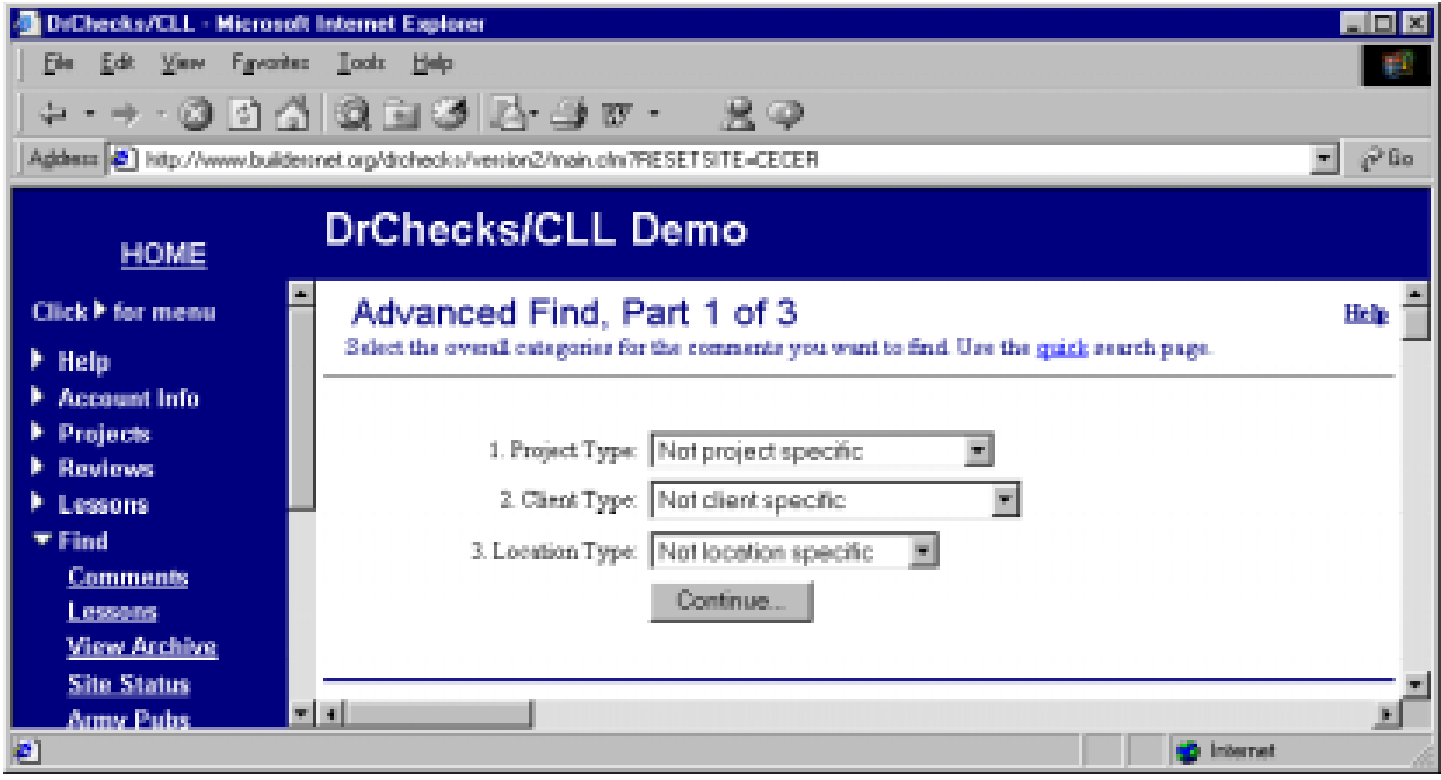

Figure 55. Advanced Find Comments Part 1.

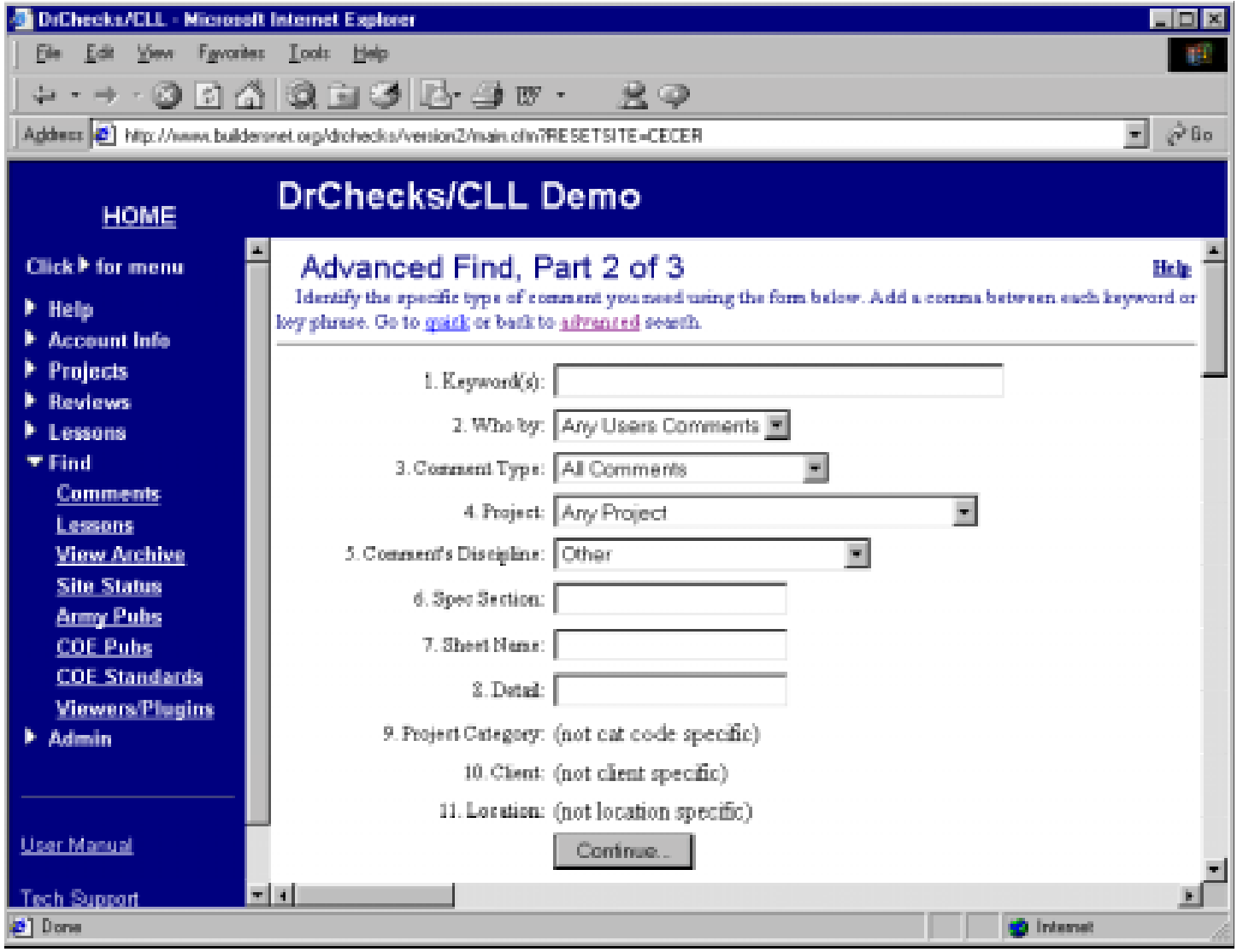

Figure 56. Advanced Find Comments Part 2. 
Location Categories: The location category shows where the project is. Outside categories show the names of various foreign countries. District Specific Sites show nearby locations. The "Within U.S." category lists names of all U.S. states.

Keyword(s): To do a quick search on comments, the user may want to specify a word that can be found in the desired comment. If two or more words can be specified, the search will look for those two words as a combination. These words can also be separated by a comma to search for either word.

Who By: The "Who By" field allows a user to specify whose comments to view. The names included in the drop down list are users in the site. Only one name can be chosen but, if a name is not found, the default "Any User Lessons" can be used.

Comment Type: The comment type describes the stage of the comment. For example, a new comment is considered "pending," but another reviewer might want to see pending comments. Instead of the new reviewer viewing all comments, he/she can choose to view all pending comments in the comment type list box.

Project: The project name is the standard project reference name. In "Advanced Find" the project name is the project where the comment search is to be performed.

Comment Discipline: The comment discipline defines the area of the task. If this is specified, the search will find all matches for that discipline. A search can also be done across all disciplines.

Spec Section: When a user needs to refer to the project, he/she can enter in a specification reference. The specification reference helps the reviewer identify the individual project specification of the comment.

Specific Sheet: The "Specific Sheet" field is a reference to an architectural drawing. This field is not a required, but it is the equivalent of the "Drawing Sheet" in "Add Comment."

Specific Detail: The "Drawing Sheet" field is a reference to a collection of architectural drawings. For example, if a user wanted to show all outlets in a building, the drawing sheet could reference the specific drawing that shows the outlets. 


\section{Find Lessons}

If a user is in a hurry to find a certain lesson, it is easy to type in specific criteria instead of searching the database manually. With the "Find Lesson" process, this search can be done easily. Figure 57 shows the process steps.

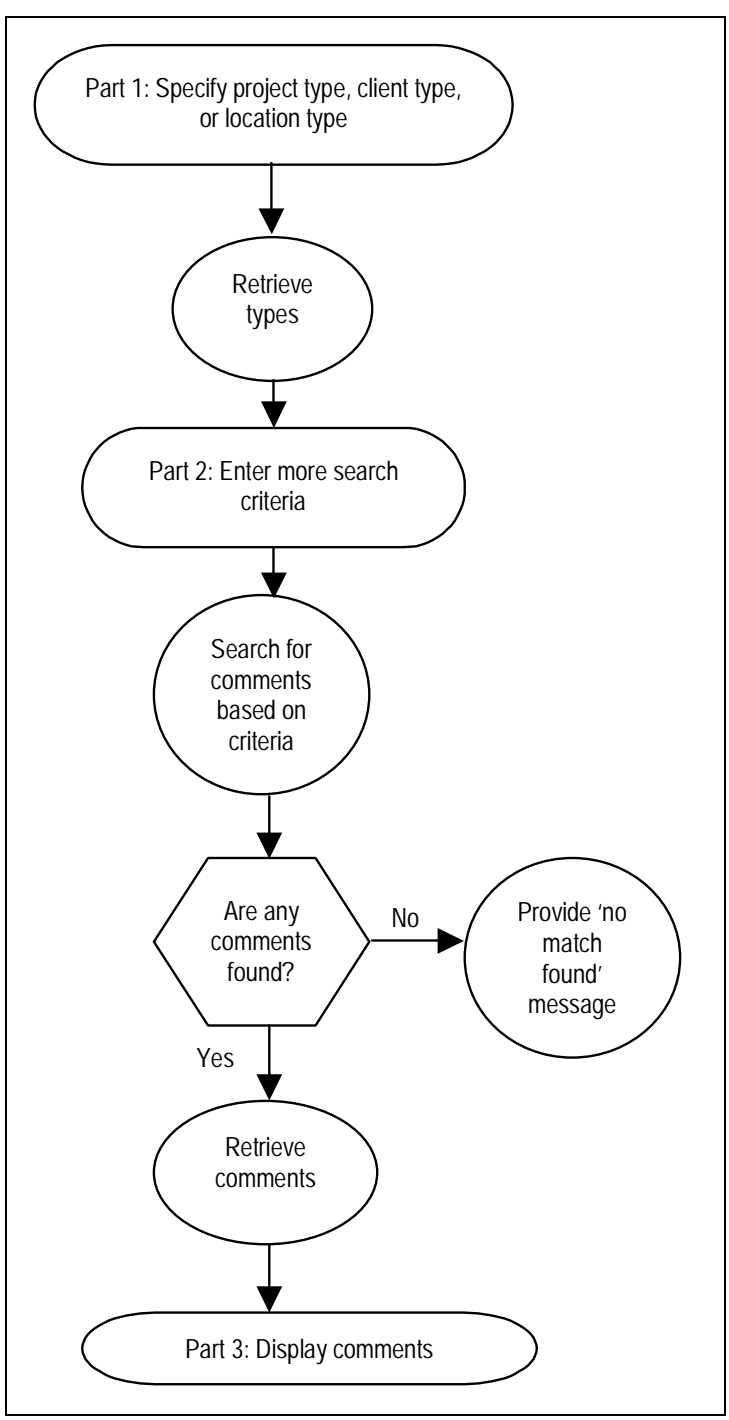

Figure 57. Process of finding lessons.

The first part of finding lessons is to specify some search criteria. A user can choose to specify project type, customer type, and location type in Part 1 (Figure $58)$.

In Part 2 (Figure 59), the user can narrow a search further. Depending on what was chosen in Part 1, the category types are narrowed down. Also, the user can add additional search criteria such as who the lesson was created by, comment discipline, and lesson learned effects. These are not required, however. 


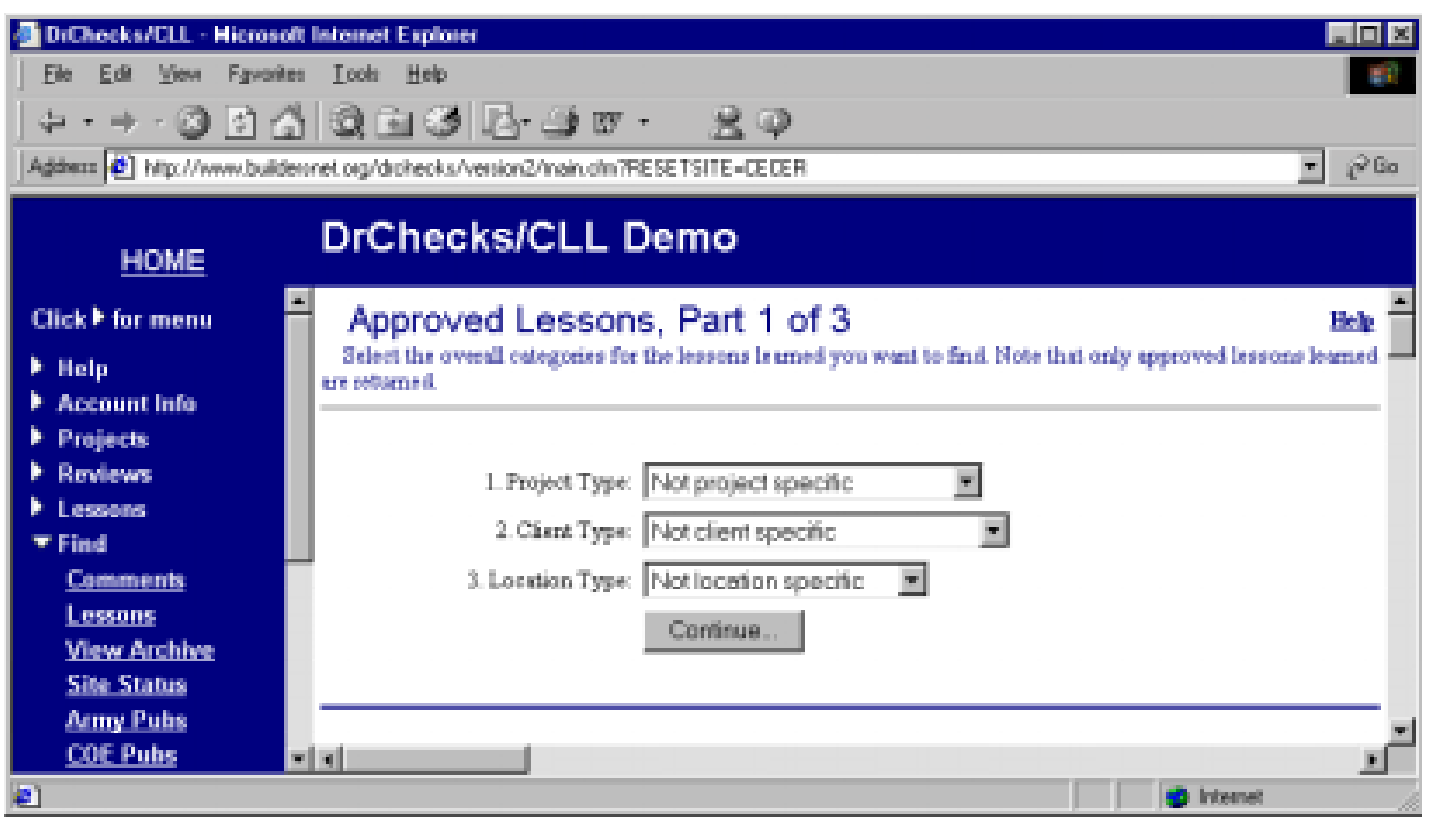

Figure 58. Find Lessons Part 1.

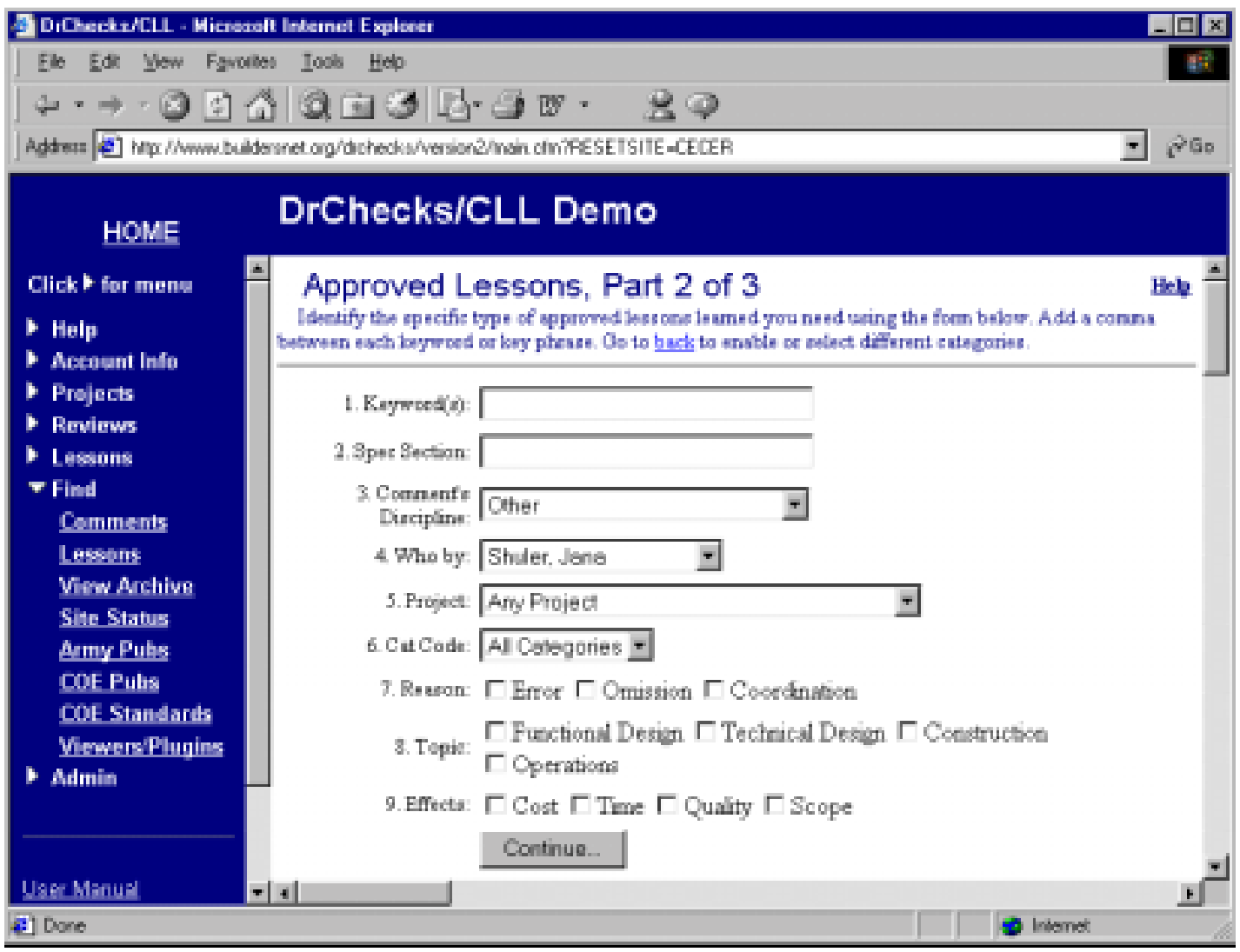

Figure 59. Find Lessons Part 2.

The search results based on the specified criteria are shown in Part 3. To conduct another search, the user clicks on the "Back" link to return to Part 1. 
Project Type: A Project Type shows what the lesson involves. MILCON codes show tasks needed for a specific facility. The Civil Works category code shows activities not broken down into specific facilities or tasks. The HTRW category code shows task-specific activities that may include handling dangerous materials. Other codes show activities for local facilities.

Customer Type: The customer category shows the project customer. Army customers are the branches of the U.S. Army. Non-Army Military Customers are the branches of the military not included under Army Customers. Other Government Agencies are customers that work for the U.S. Government and are not included in the military. Foreign Governments are non-U.S. governments doing business with the DrChecks agency. Other customers are not U.S. Government or military specific.

Location Type: The location type shows where the project is. Outside categories show the names of various foreign countries. District Specific Sites show nearby locations. The "Within U.S." category lists names of all U.S. states.

Keyword(s): To do a quick search on comments, a user may want to specify a word that can be found in the desired comment. If two or more words can be specified, the search looks for those two words as a combination. These words can also be separated by a comma to search for either word.

Spec Section: When a user needs to refer to the project, he/she can enter in a specification reference. The specification reference helps the reviewer identify the individual project specification of the comment.

Comment Discipline: The comment discipline defines the area of the task. If this is specified, the search will find all matches for that discipline. A search can also be done across all disciplines.

Who By: The "Who By" field allows a user to specify whose comments to view. The names included in the drop down list are users in the site. Only one name can be chosen but, if a name is not found, the default "Any User Lessons" can be used.

Project: The project name is the standard project reference name. In "Advanced Find" the project name is the project where the comment search is to be performed.

Cat Code: The Cat Code is a more specific Civil Works, HTRW, or Military category depending on what Project Category Code was chosen. If the category 
was Civil Works, a user can choose an activity not meant for specific facilities or tasks. If the category was HTRW, a user can choose a task-specific activity that may include handling dangerous materials. If the category was Military, a user can choose a task needed for a specific facility.

Lesson Learned Effects: The effects on the lesson can be specified in three ways by determining the reason, topic, and effects. The reason can be described as the cause of the effect or error. The topic is a required field that specifies in what stage of the design or operation the lesson occurred. The effect specifies what type of effect occurred.

\section{List Archive}

After a user has archived a project, it is possible to refer back to it later by using "View Archive." To archive, the user clicks on the project ID located to the left of the project name. Once the ID is clicked, the user will be presented with all archived reviews for the project and locations of the archive. To view an archive, the address needs to be clicked to automatically return to the archive. Figure 60 shows the process steps, and Figures 61 and 62 show the associated program menus.

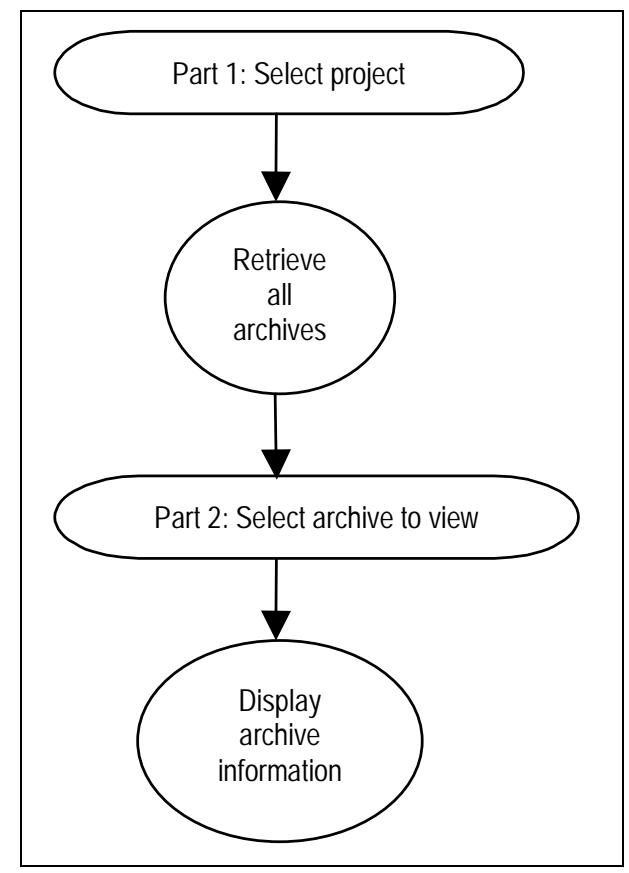

Figure 60. Process of listing an archive. 


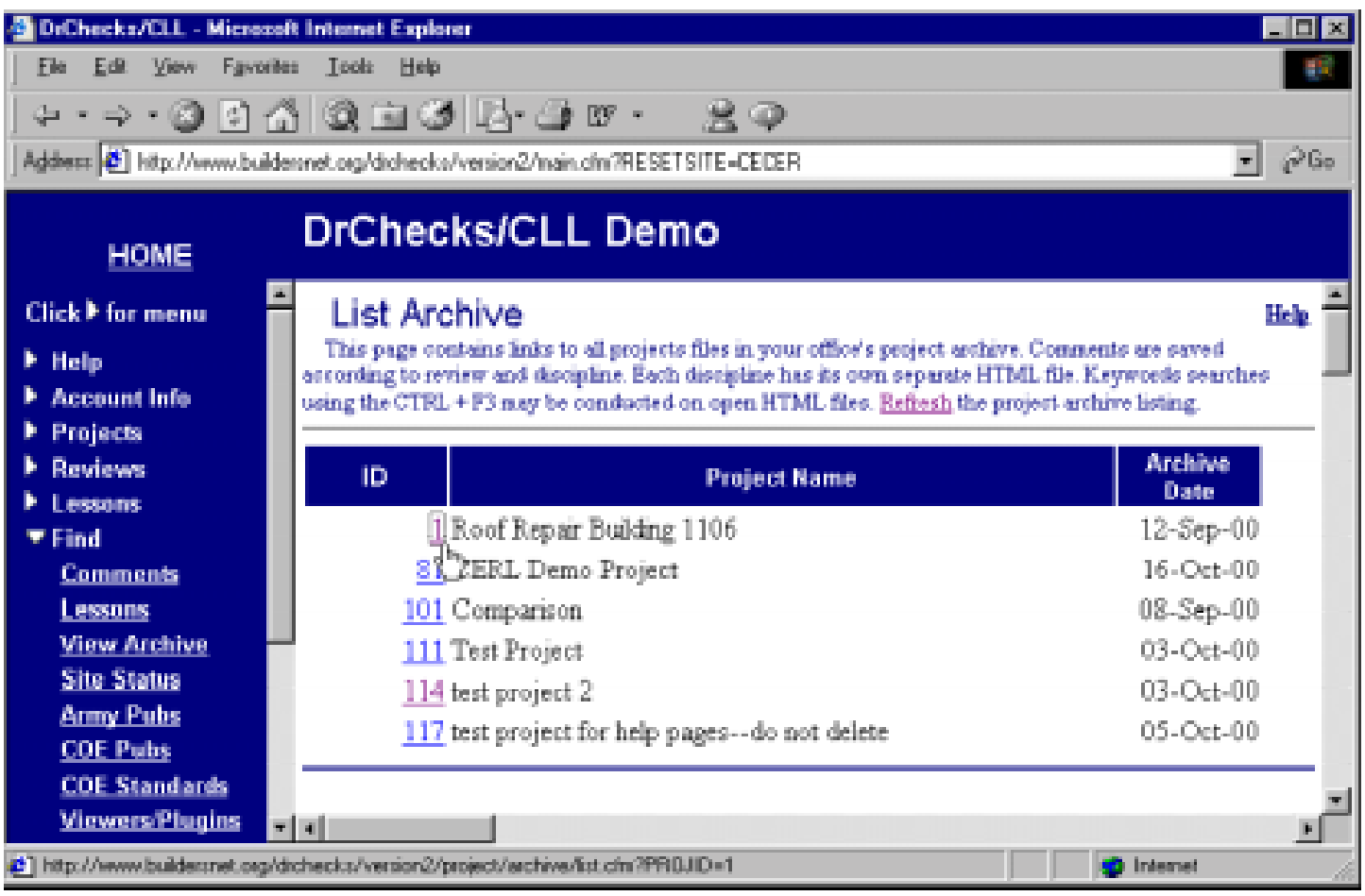

\section{Figure 61. View Archive Part 1.}

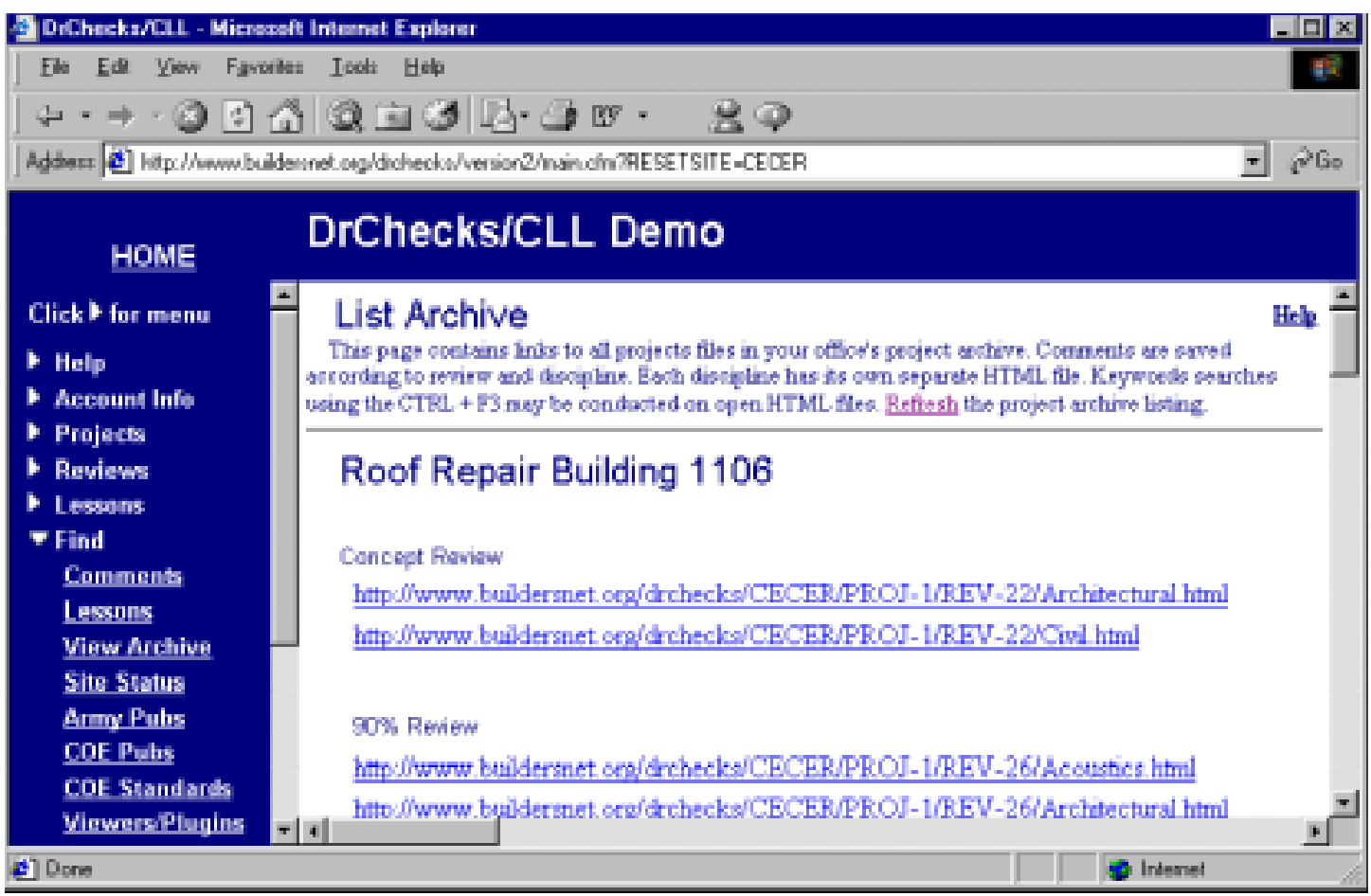

Figure 62. View Archive Part 2. 


\section{Site Status}

The "Site Status" screen allows a user to view various summaries about projects and comments. The discipline, category, location, and customer reports can also be viewed. If reviewing a summary, the user will be presented with a graph that shows the summary statistics. If viewing a report, the user will need to specify the criteria of the report. Figure 63 shows the process steps, and Figure 64 shows the associated program menu.

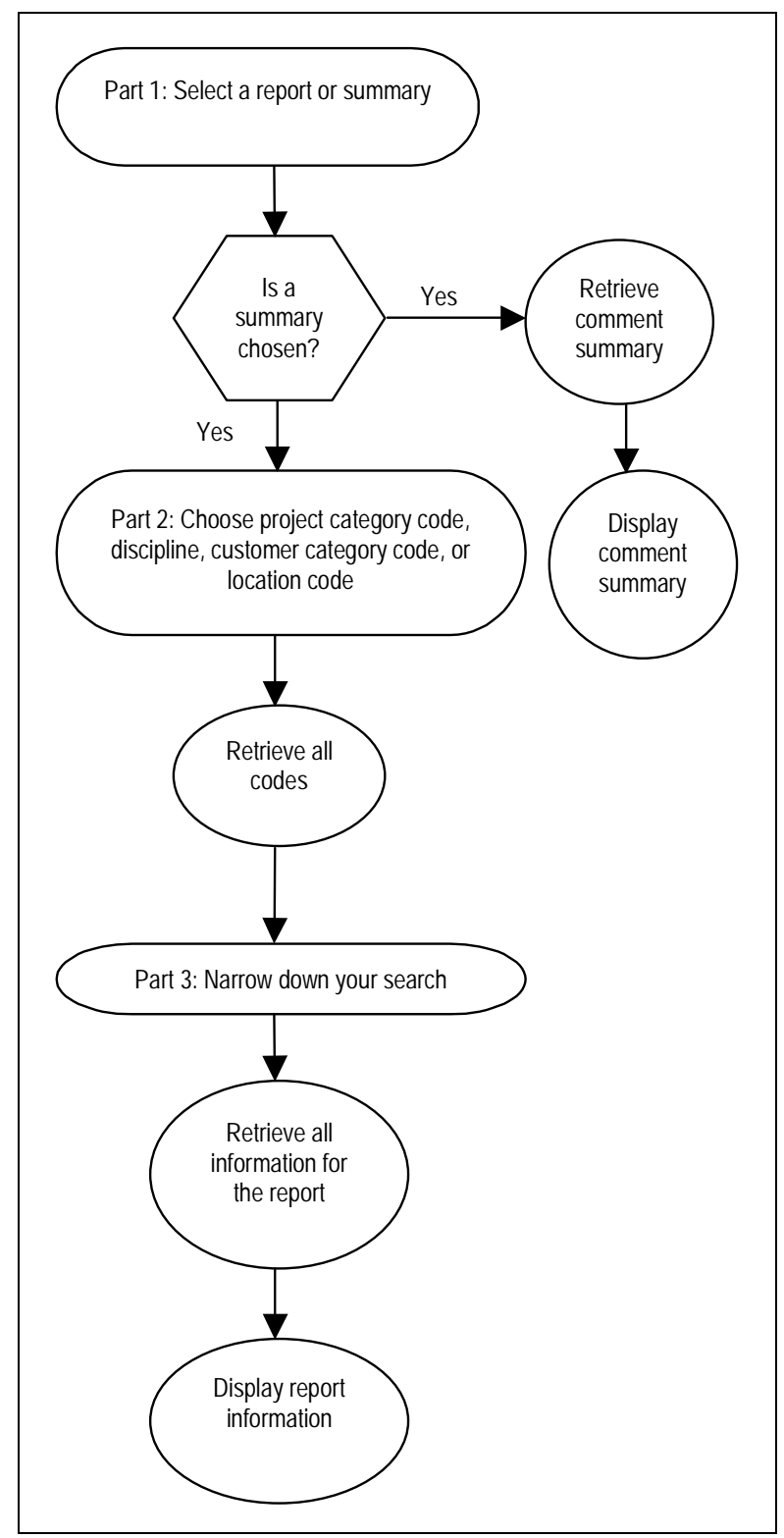

Figure 63. Process of showing site status. 


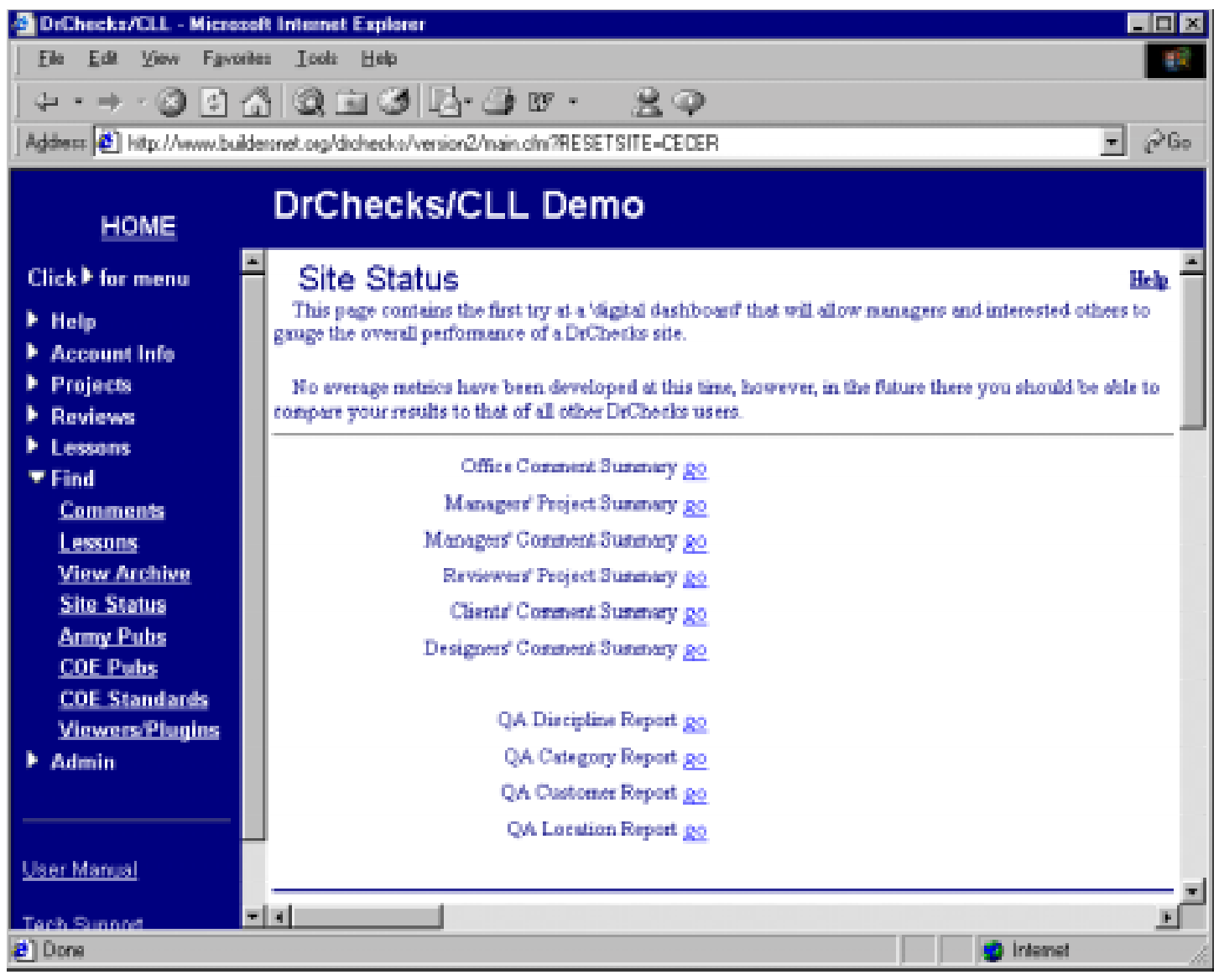

Figure 64. Site Status Part 1. 


\section{Update Category Codes}

Category codes define the type of funding a project will be under or what type of activity the project is. The four category codes are Military, Civil Works, HTRW, and local category codes. Figure 65 shows the process steps.

To update or add a new category code, a user should specify the code by clicking on a type in the pick box and clicking on the [Continue] button in Part 1.

A grid of the current category codes will be presented in Part 2 (Figure 66). To add a category code, the user fills in information about the new category and clicks on the [Add] button. This places the new code into the grid with the others. To delete a category code, the user clicks on the [Del] button. Deleting a category code will cause all links to it to be removed.

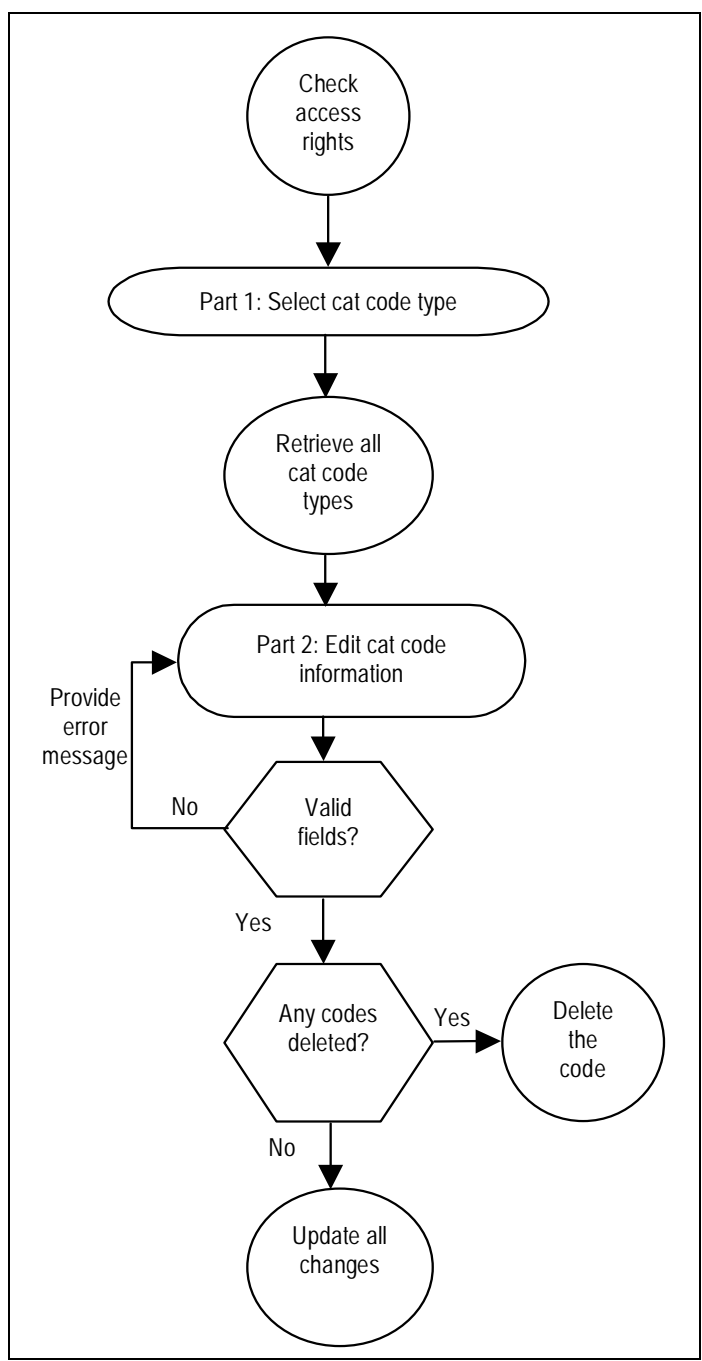

Figure 65. Process of updating cat codes.
Cat Code: The Cat Code is a more specific Civil Works, HTRW, or Military category, depending on what Project Category Code was chosen. If the category was Civil Works, a user can choose an activity not meant for specific facilities or tasks. If the category was HTRW, a user can choose a task-specific activity that may include handling dangerous materials. If the category was Military, a user can choose a task needed for a specific facility. This field is required.

Parent: To show one row is under, subordinate to, or part of another row, the user should enter the toplevel ID number in the "Parent" data field of the child row. This field is required. 


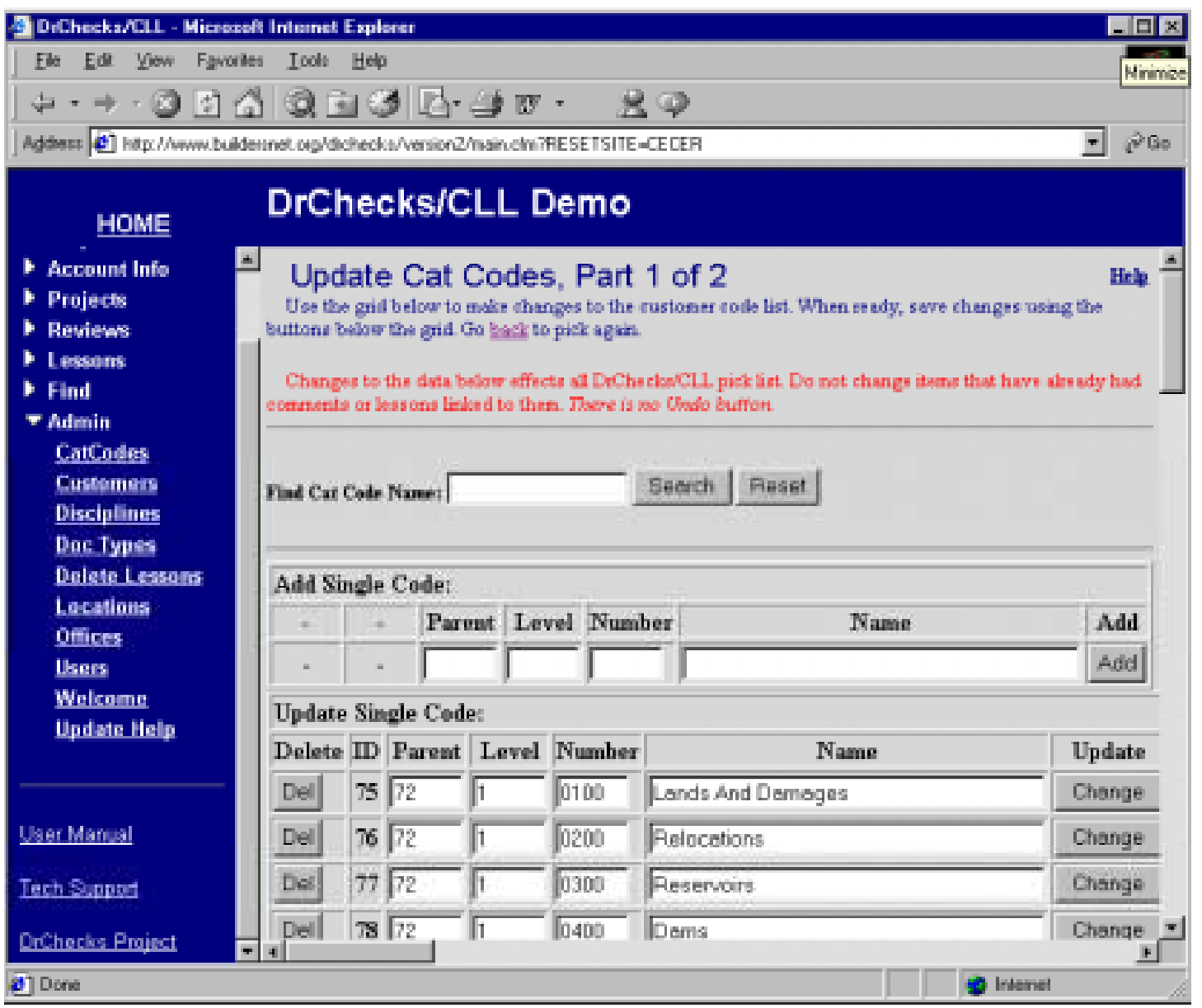

Figure 66. Update Cat Codes Part 1.

Level: The level number shows in what row the category code can be found. If the level is higher than 1 , the code is subordinate code from an upper layer. The top level is 1 . This field is required.

Number: A category code can be referenced by a unique number or character. This required field could be alphanumeric (a combination of letters and numbers).

Name: For all names, this field provides the description of the Cat Code that is associated with the number. If the description is changed for a number, it will be reflected in all comments or lessons where it is referenced. This field is required. 


\section{Update Customers}

Customers in DrChecks are considered to be for whom the individual works. To add a customer or update the customer specifics, a user needs to go to "Customers." Figure 67 shows the process steps.

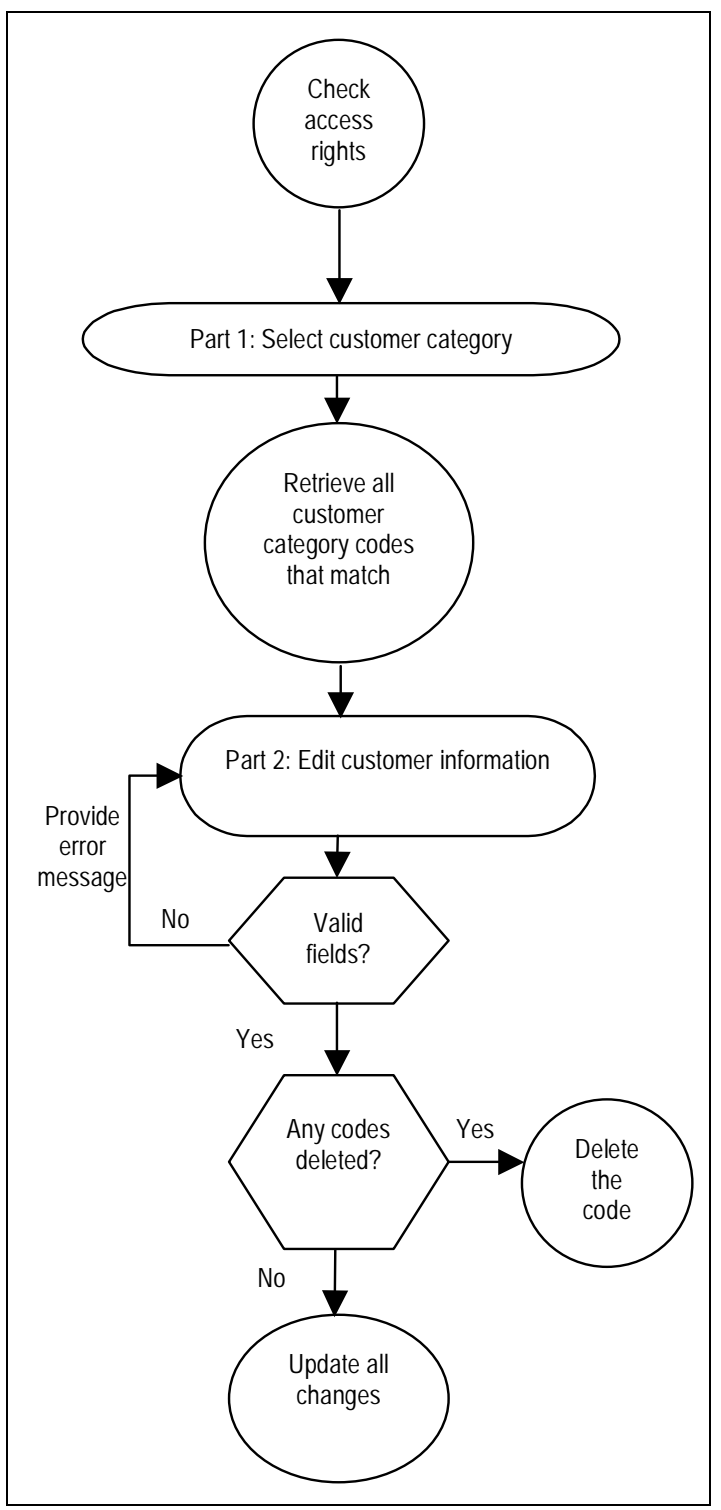

Figure 67. Process of updating customer codes.
The type of customer should be chosen in Part 1. The customer types available are: Army Customers, Federal Government Agencies, Foreign Governments, Local Customers, and Other Military Customers.

Once the customer type is chosen, the user clicks on [Continue] to be presented with the current customer codes. To add a customer code in Part 2 (Figure 68), fill in the information about the new customer and click on the [Add] button. The new code will be placed into the grid with the other codes. A customer code in this screen can be deleted by clicking on the [Del] button. This will cause all customer links to it to be removed.

Customer Category Code: The customer category code will show to whom the project pertains. Army customers are the branches of the U.S. Army. Federal Government Agencies are customers that work for the U.S. Government and are not included in the military. Foreign Governments are non-U.S. governments doing business with the DrChecks agency. Local customers are not U.S. Government or military specific. Other Military Customers are the branches of the military not included under Army Customers. This field is required. 


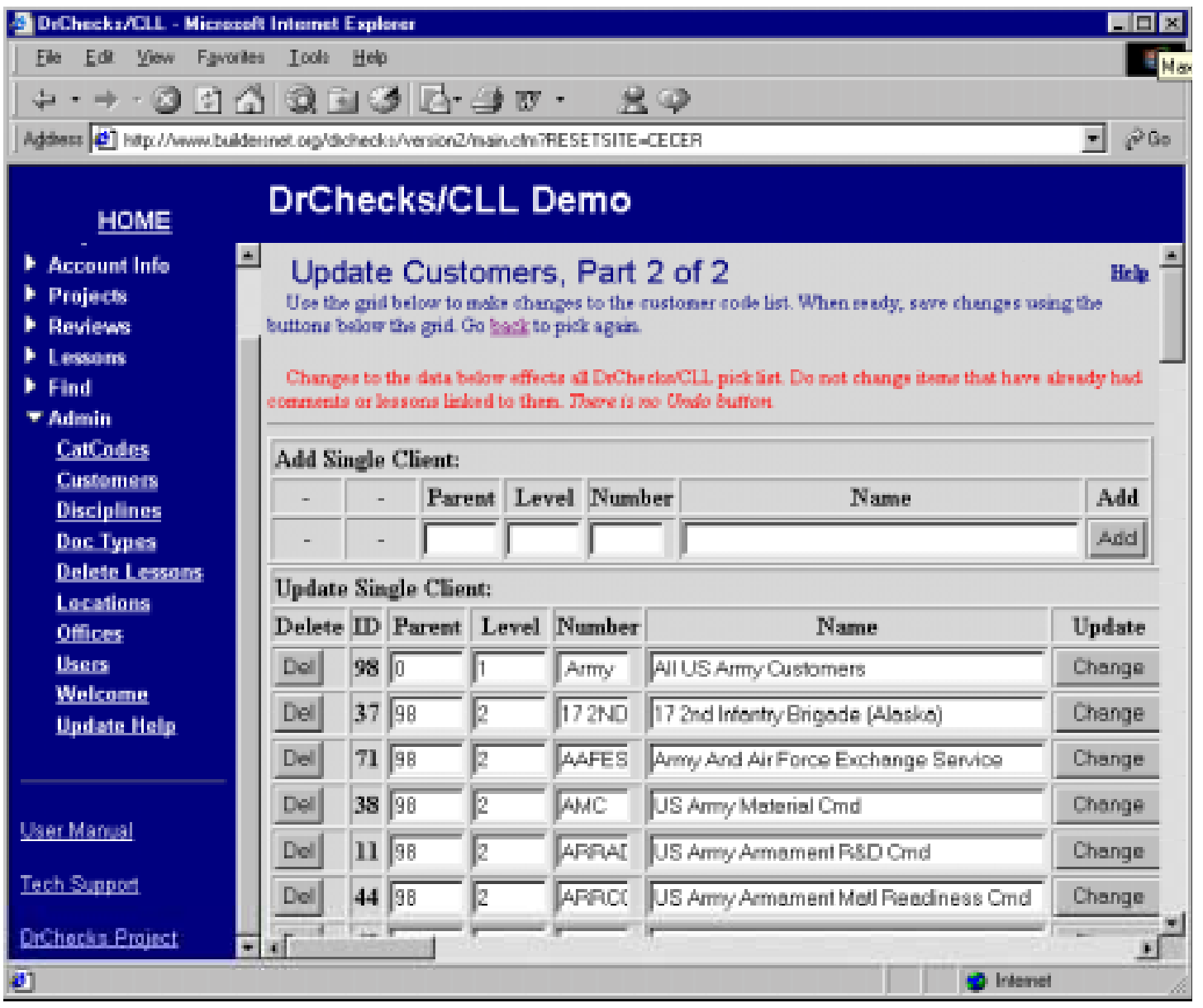

Figure 68. Update Customers Part 2.

Parent: To show one row is under, subordinate to, or part of another row, the user should enter the top-level ID number in the "Parent" data field of the child row. This field is required.

Level: The level number shows in what row a customer category can be found. If the level is higher than 1 , the code is subordinate code from an upper layer. The top level is 0 . This field is required.

Number: A customer category can be referenced by a unique number or character. This field is required.

Name: For all names, this field provides the description of the Customer Category that is associated with the number. If the description is changed for a number, it will be reflected in all comments or lessons where it is referenced. This field is required. 


\section{Update Disciplines}

Disciplines describe the type of job required. The types of jobs can be mechanical, architectural, etc. If a discipline is not shown or information about a discipline needs to be changed, this can be done in the "Disciplines" screen that shows all current disciplines and the corresponding information. Figure 69 shows the process steps.

If a user desires to add a discipline, he/she needs to enter the information in the boxes at the top in Part 1 (Figure 70). The user clicks on the [Add] button to save these changes. Once it is added, it shows in the "Discipline" grid. To change information about the disciplines, the user makes the necessary changes and then clicks on the [Change] button. A discipline can also be deleted by clicking the [Del] button on the left of the grid. Deleting a discipline will cause all links to the discipline to be removed.

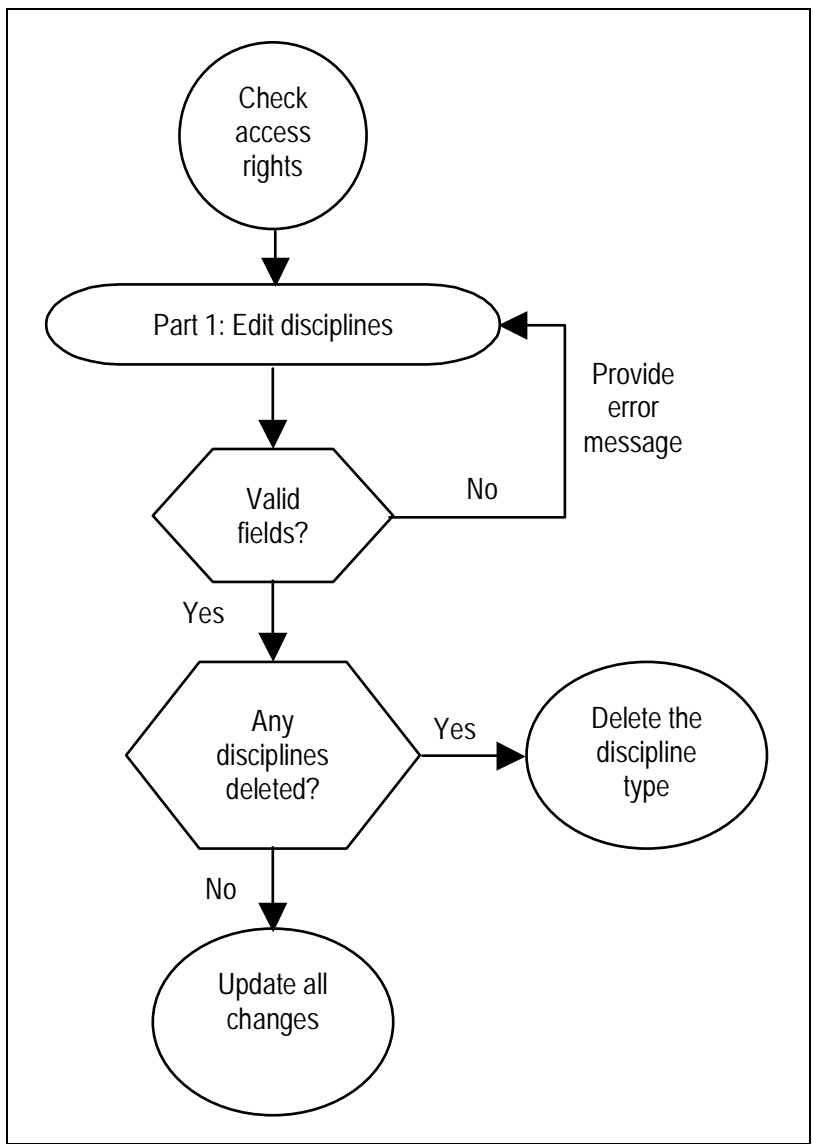

Figure 69. Process of updating disciplines. 


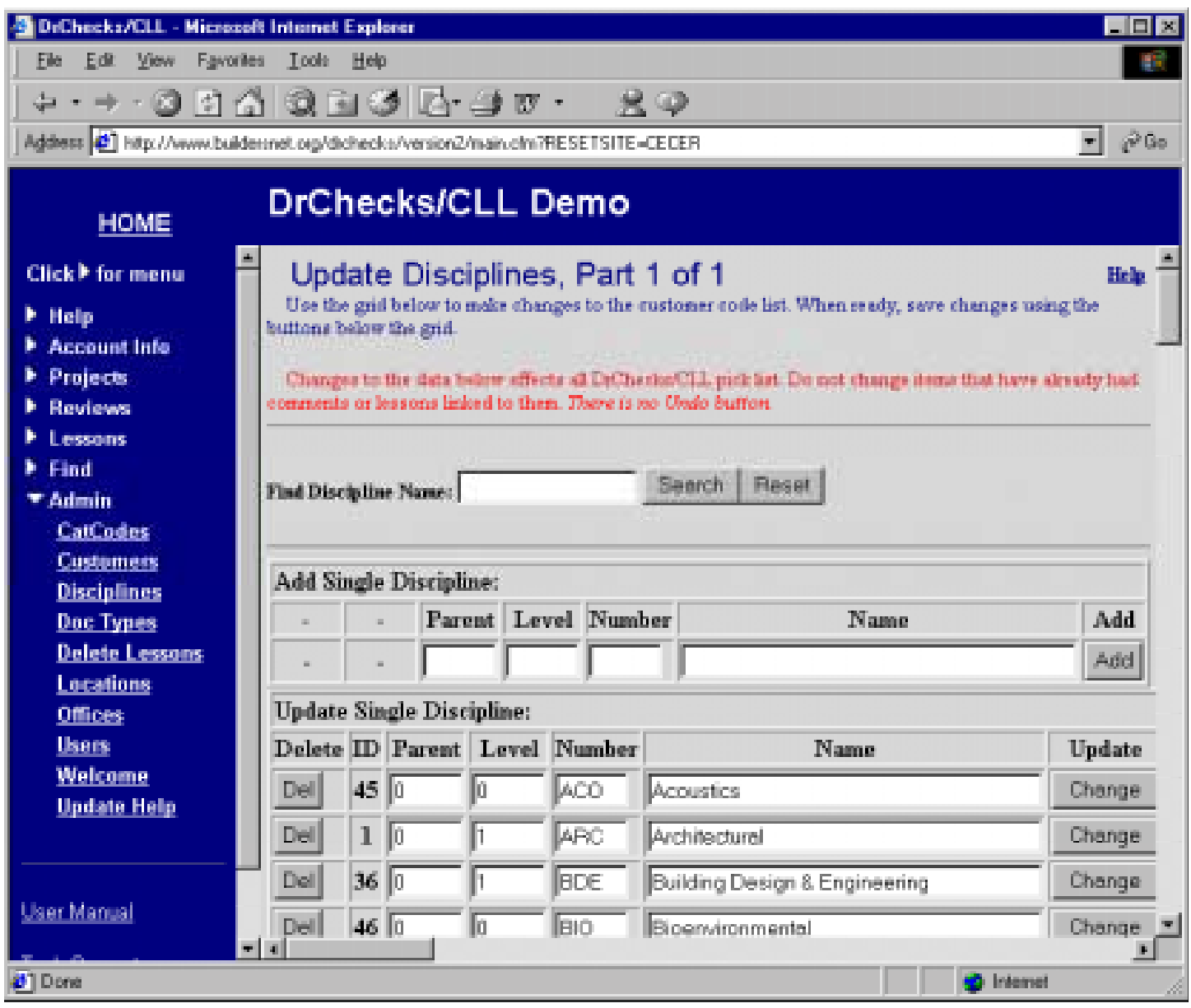

Figure 70. Update Disciplines Part 1.

Parent: To show one row is under, subordinate to, or part of another row, the user should enter the top-level ID number in the "Parent" data field of the child row. This field is required.

Level: The level number shows in what row a discipline category can be found. If the level is higher than 1 , the code is subordinate code from an upper layer. The top level is 0 . This field is required.

Number: A discipline can be referenced by a unique number or character. This field is required.

Name: For all names, this field describes the discipline that is associated with the number. If the description is changed for a number, it will be reflected in all comments or lessons where it is referenced. This field is required. 


\section{Update Document Types}

To add, delete, or make changes to doc types, a user will need to go to the "Update Doc Types" screen. The document type is the part of the project comments effect. Figure 71 shows the process steps.

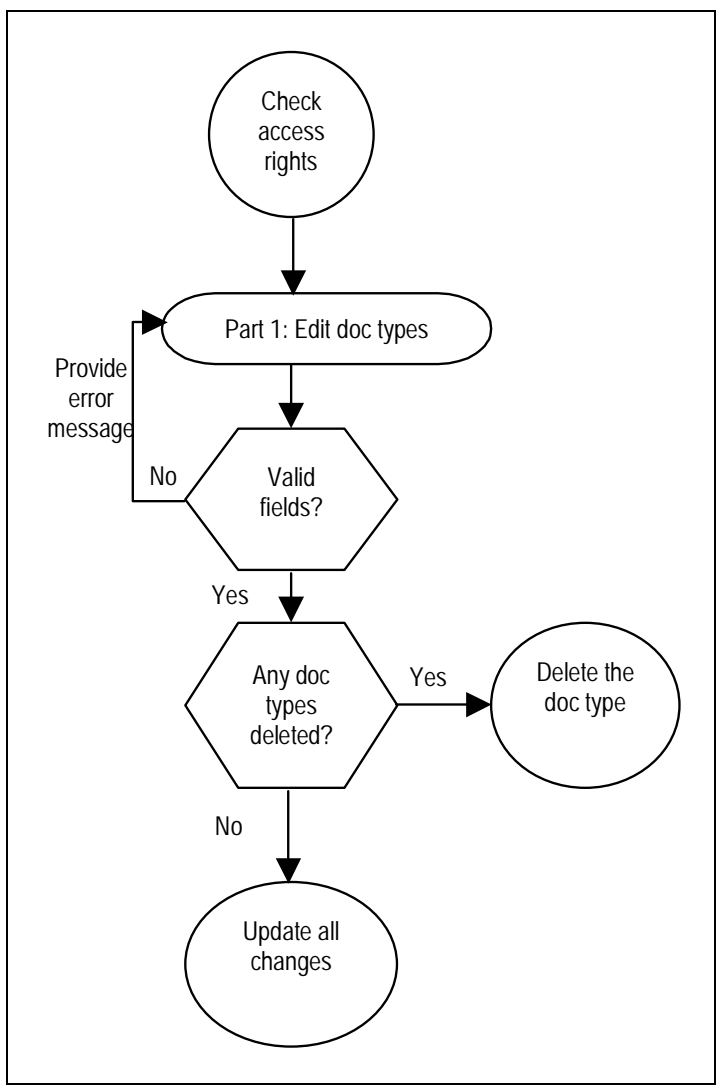

Figure 71. Process of deleting a doc type.

To add a "doc type" in Part 1, the name of the new "doc type" should be entered into the first box shown under "Add Single Discipline" and the [Add] button clicked (Figure 72). The new doc type is placed at the bottom of the list. To change a doc type, the user needs to locate the correct type, make the necessary changes, and click on the [Change] button to update. Deleting a doc type can also be done by locating the desired type in the list and clicking on the [Del] button located to the left of the type ID number. The user will not be warned that deleting a type deletes associated links.

Name: For all names, this field describes the Doc Type associated with the number. If the description is changed for a number, it will be reflected in all comments or lessons where it is referenced. This field is required. 


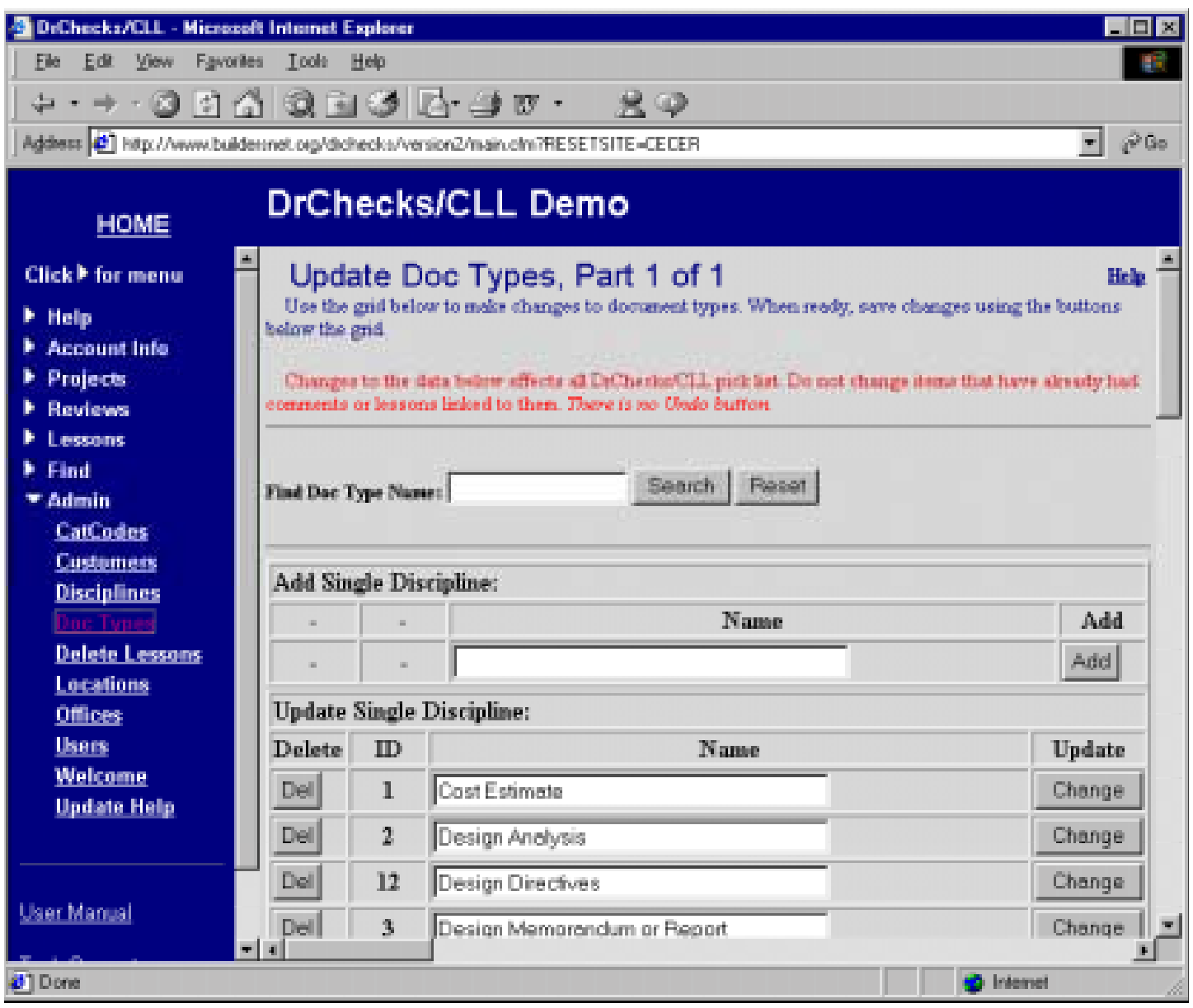

Figure 72. Update Doc Types Part 1. 


\section{Delete Lessons}

To delete an approved lesson, a user goes to the "Delete Lessons" screen. Keep in mind that the deletion cannot be undone. Figure 73 shows the process steps.

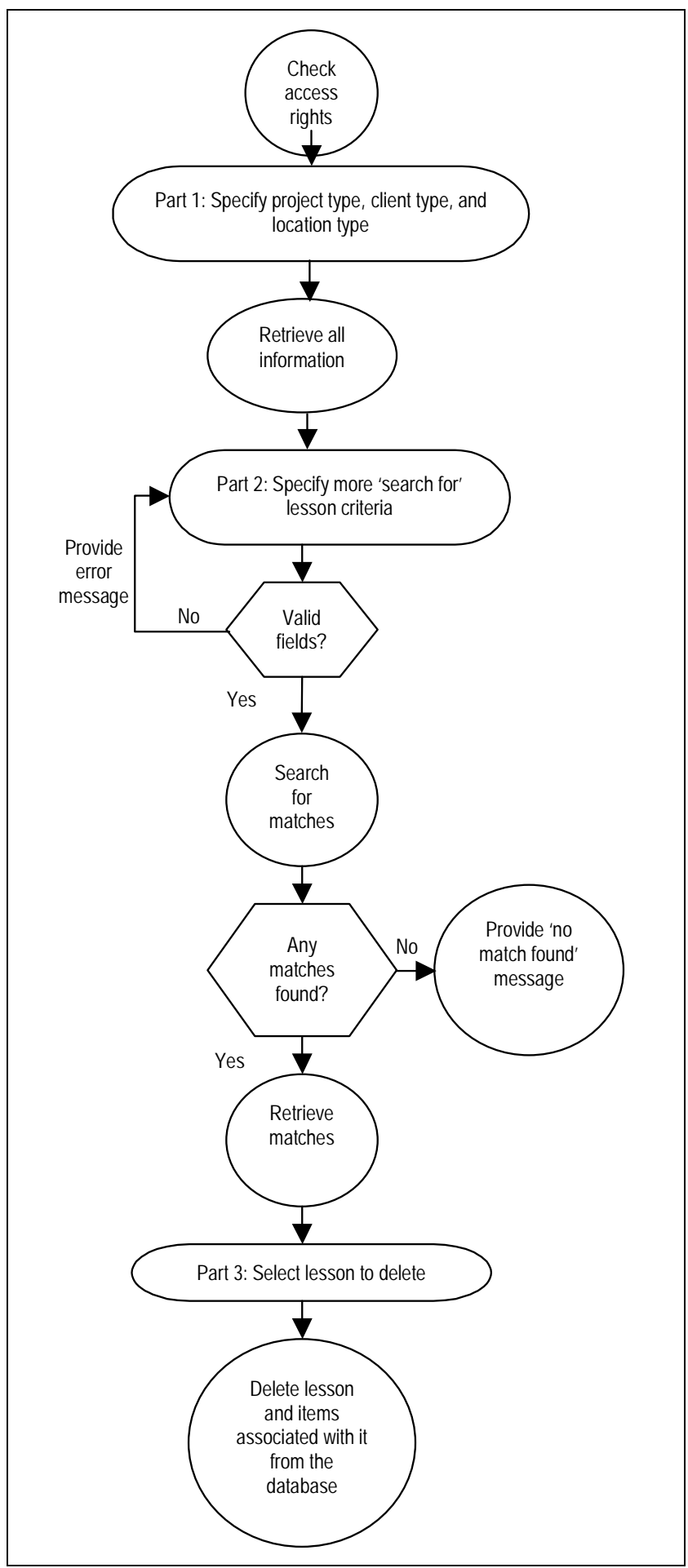

Figure 73. Process of deleting a lesson. 
In Part 1 (Figure 74), the lesson can be chosen in two ways. Search for a lesson by typing in the lesson ID number and clicking on [Find], or specify the project type, customer type, or location type and click on the [Continue] button. These fields are not required, however.

In Part 2 (Figure 75), the user will be allowed to narrow the search by entering more criteria. Criteria can be project, location, and customer types. These are not required, however.

Part 3 shows all lessons that meet the criteria specified in Parts 1 and 2. The user finds the lesson to delete and clicks on [Delete] located to the right of each lesson. The closest match will be found. Deleting a lesson causes all links to the lesson to be removed.

Project Category: A project category shows what the lesson will involve. MILCON codes will show tasks needed for a specific facility. The Civil Works category code will show activities not broken down into specific facilities or tasks. The HTRW category code will show task-specific activities that may include handling dangerous materials. Other codes will show activities for local facilities.

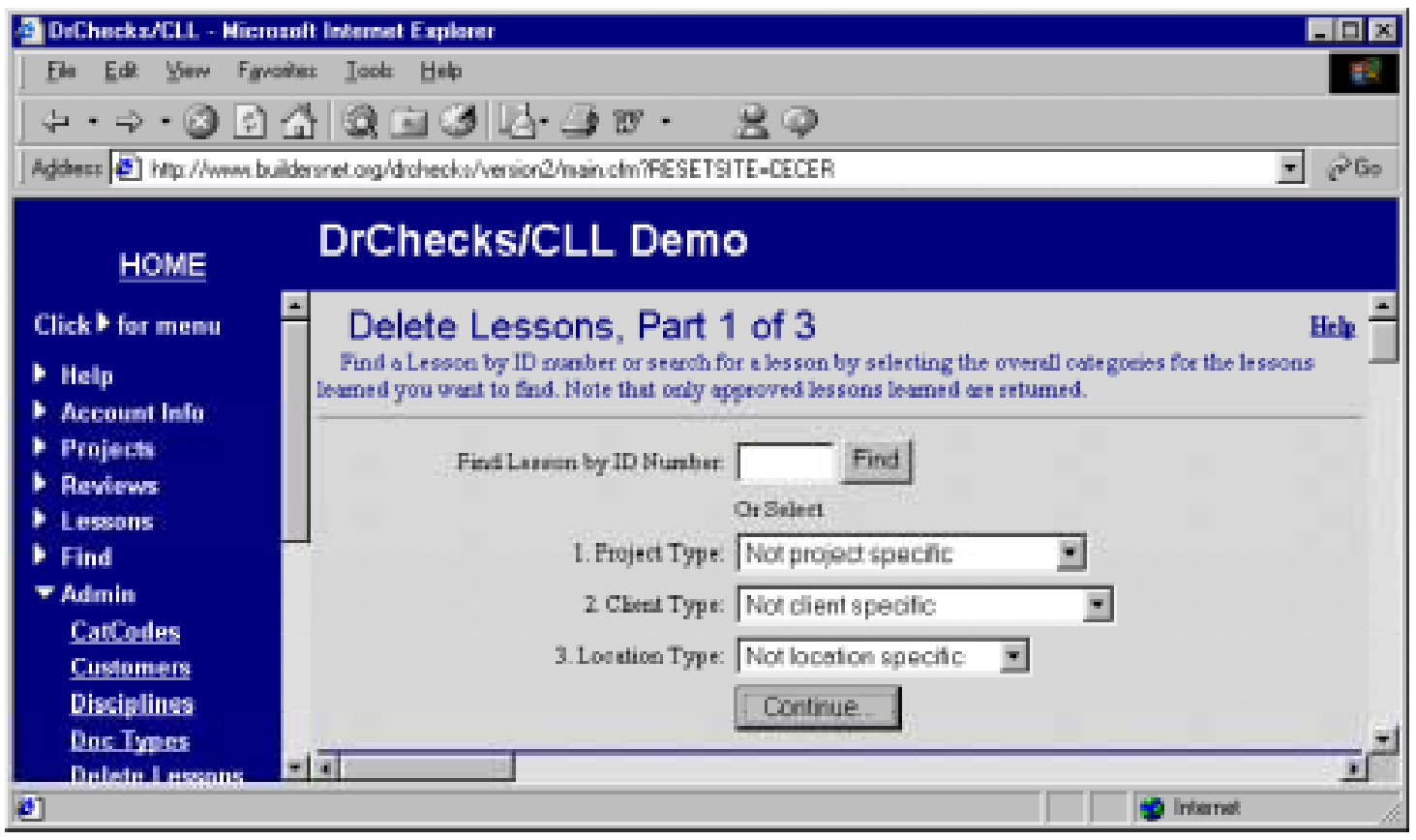

Figure 74. Delete Lessons Part 1. 


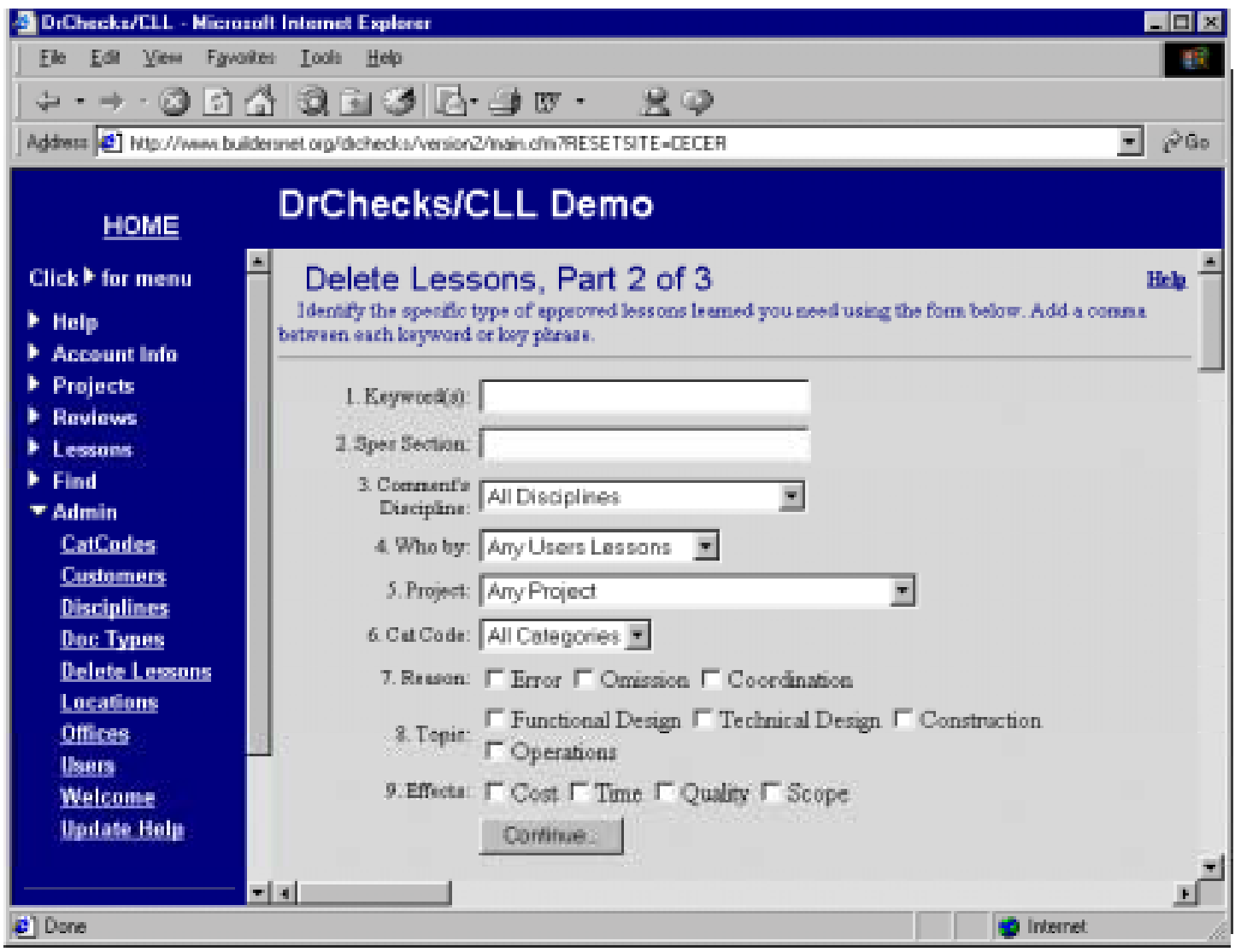

Figure 75. Delete Lessons Part 2.

Customer Type: The customer category shows the project customer. Army customers are the branches of the U.S. Army. Non-Army Military Customers are the branches of the military not included under Army Customers. Other Government Agencies are customers that work for the U.S. Government and are not included in the military. Foreign Governments are non-U.S. governments doing business with the DrChecks agency. Other customers are not U.S. Government or military specific.

Location Type: The location type shows where the project is. Outside categories show the names of various foreign countries. District Specific Sites shows nearby locations. The "Within U.S." category lists all names of U.S. states.

Keyword(s): To do a quick search on comments, a user may want to specify a word that can be found in the desired comment. If two or more words can be specified, the search will look for those two words as a combination. These words can also be separated by a comma to search for either word.

Spec Section: When a user needs to refer to the project, he/she can enter a specification reference. The specification reference helps the reviewer identify the individual project specification of the comment. 
Comment Discipline: The comment discipline defines the area of the task. If this is specified, the search will find all matches for that discipline. A search can also be done across all disciplines.

Who By: The "Who By" field allows a user to specify whose comments to view. The names in the dropdown list are users in the site. Only one name can be chosen but, if a name is not found, the default "Any User Lessons" can be used.

Project: The project name is the standard project reference name. In "Delete Project" the project contains reviews where comments can be found.

Cat Code: The Cat Code is a more specific Civil Works, HTRW, or Military category depending on what Project Category Code was chosen. If the category was Civil Works, a user can choose an activity not meant for specific facilities or tasks. If the category was HTRW, a user can choose a task-specific activity that may include handling dangerous materials. If the category was Military, a user can choose a task needed for a specific facility.

Lesson Learned Effects: The effects on the lesson can be specified in three ways by determining the reason, topic, and effects. The reason can be described as the cause of the effect or error. The topic is a required field that specifies in what stage of the design or operation the lesson occurred. The effect specifies what type of effect occurred. 


\section{Update Locations}

Location codes define the project location. The three location codes are Foreign Country Codes, Local Sites, and U.S. State Names. Updating a location code is used to enter new locations or edit existing location codes. Figure 76 shows the process steps.

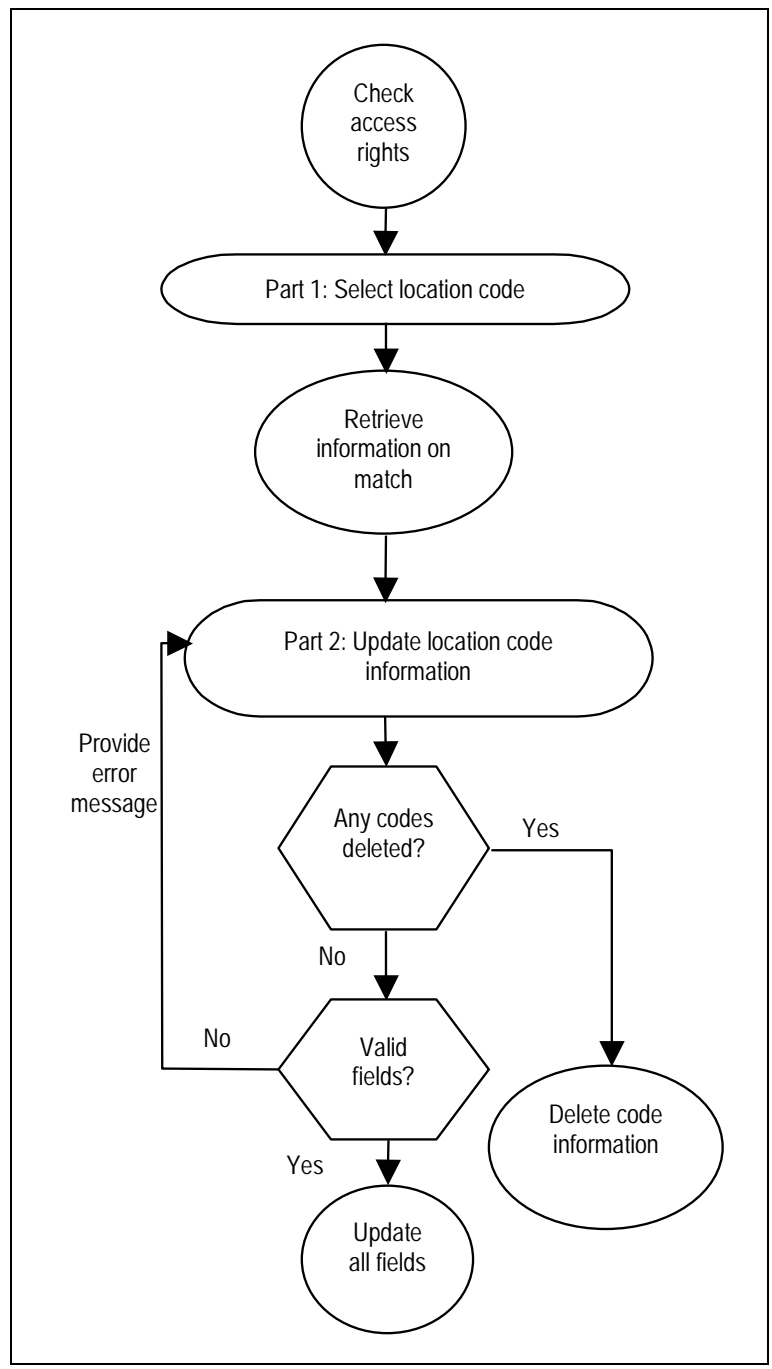

Figure 76. Process of updating locations.

To update or add a new location code in Part 1, a user specifies the type by clicking on the type in the pick box and clicking on the [Continue] button.

A grid of the current location codes will be presented in Part 2 (Figure 77). To add a code, a user fills in information about the new location and clicks on [Add]. This places the new code into the grid with the other location codes. A location code can be deleted by clicking on the [Del] button. The Foreign Country Codes and the U.S. State names are standard sets and typically do not require changes 
by the administrator. The Local Sites section is designated as the area for company-specific locations. Additions to locations typically should be limited to the Local Sites. Names can be edited with no impact on link information.

Location Category Code: The location category code shows where the project is. Foreign Country Codes show the names of various foreign countries. Local Sites shows nearby locations. U.S. State Names lists all names of U.S. states. This field is required.

Parent: To show one row is under, subordinate to, or part of another row, the user should enter the top-level ID number in the "Parent" data field of the child row. This is a required field.

Level: The level number shows in what row the location category can be found. If the level is higher than 1 , the code is subordinate code from an upper layer. The top level is 0 . This field is required.

Number: A location can be referenced by a unique number or character. This field is required.

Name: To reference a code on many different screens, it is easier to remember a name rather than a number or combination of characters. Such a name can be entered in the "Name" field. This is a required field.

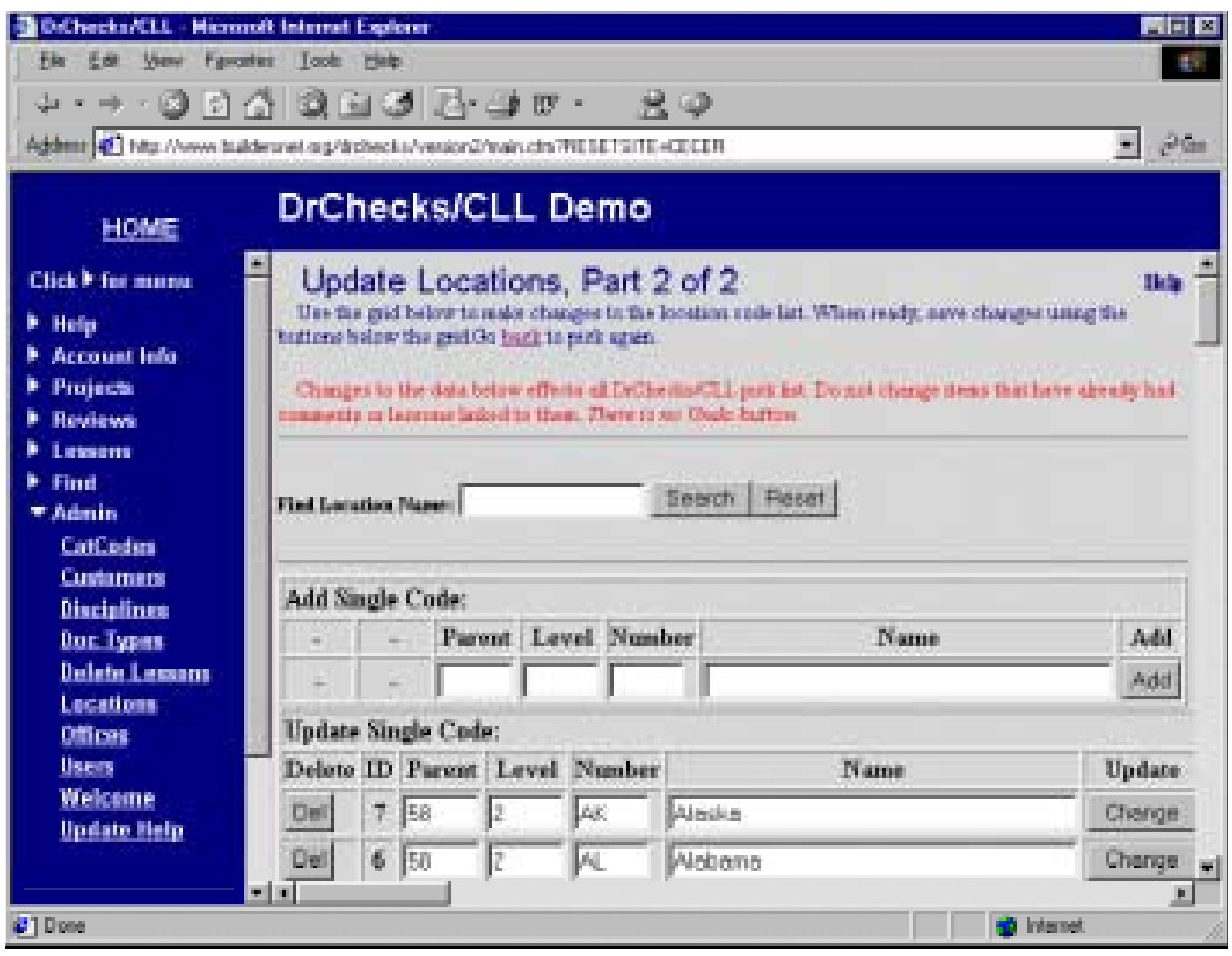

Figure 77. Update Locations Part 2. 


\section{Update Offices}

The "Offices" screen shows information about the office and allows a user to add or make changes accordingly. If a user wants to view a list of office passwords, he/she clicks on the "List" link. Figure 78 shows the process steps. To add an office in Part 1, the name of the office should be entered, the access rights should be assigned, and the parent ID needs to be specified (Figure 79). To change the access rights of the office, the user clicks on the "yes" or "no" located under each column.

To see more information about the office, the user needs to click on the ID located in Part 2 on the left side of the grid. Additional changes can be made here. Clicking on the [Update] button updates the changes. The [Update and Clone] button uses the office as a template to build sub-offices. Clicking on the [Delete] button deletes an office completely.

Parent Office ID: To show one row is under, subordinate to, or part of another row, the user should enter the top-level ID number in the Parent data field of the child row. This field is required.

Office Name: In the "Office Name" field, the user enters the office name as it would appear in reports. This field is required.

Default User Permissions: The "Default User Permissions" are those access rights a user automatically has when he/she registers under an office name. An office can have more than one assigned permission. This field is required.

Fkey Parent: This field is also known as the "Parent Office ID" that shows one row is under, subordinate to, or part of another row. The user should enter the top level ID number in "Parent Office ID" field of the child row. This field is required.

Office Address: The "Office Address" is a combination of items. These items are "OfcStreet," "OfcBox," "OfcStop," "OfcCity," "OfcState," and "OfcZip." These fields are not required. 


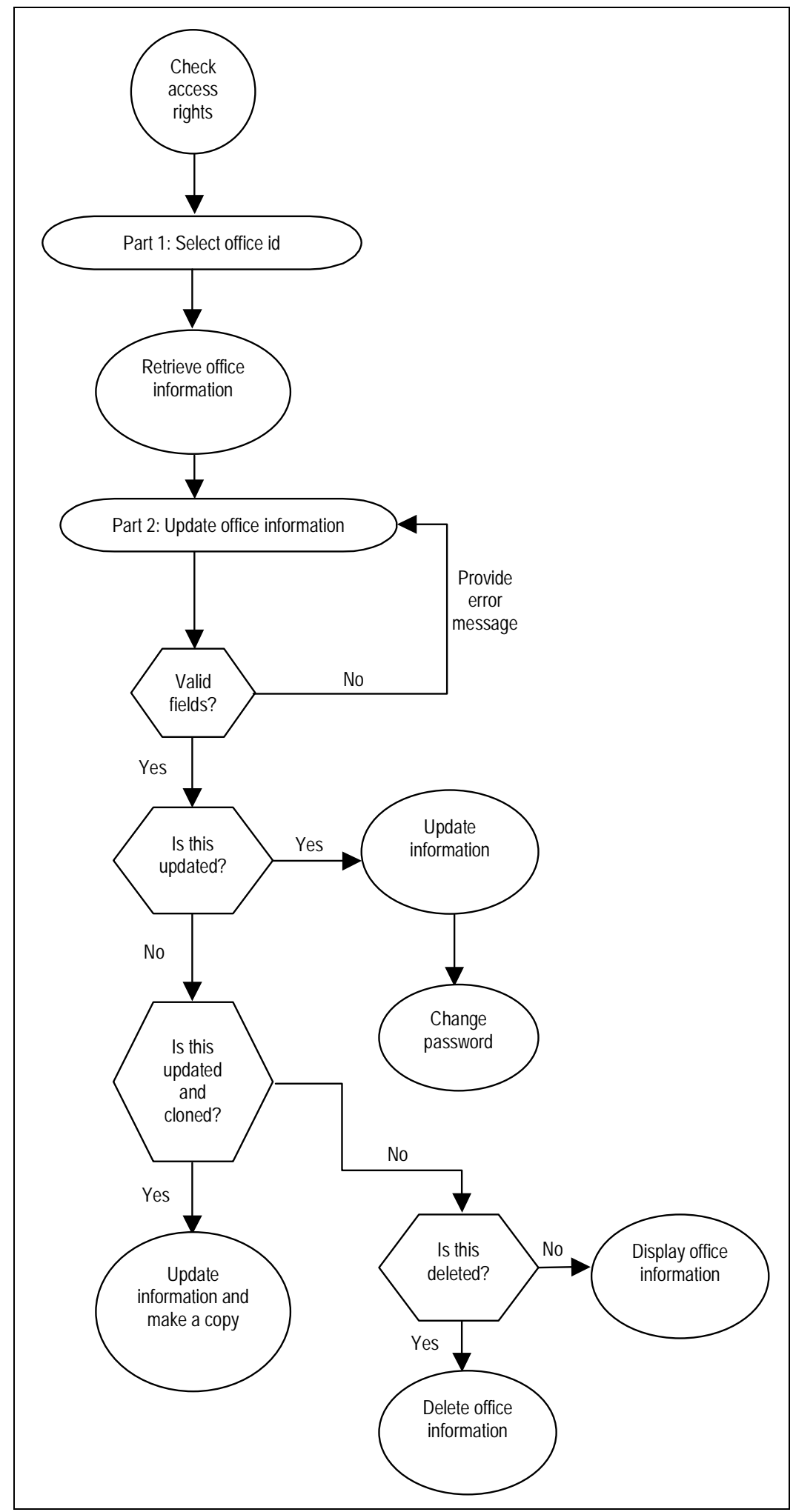

Figure 78. Process of updating offices. 


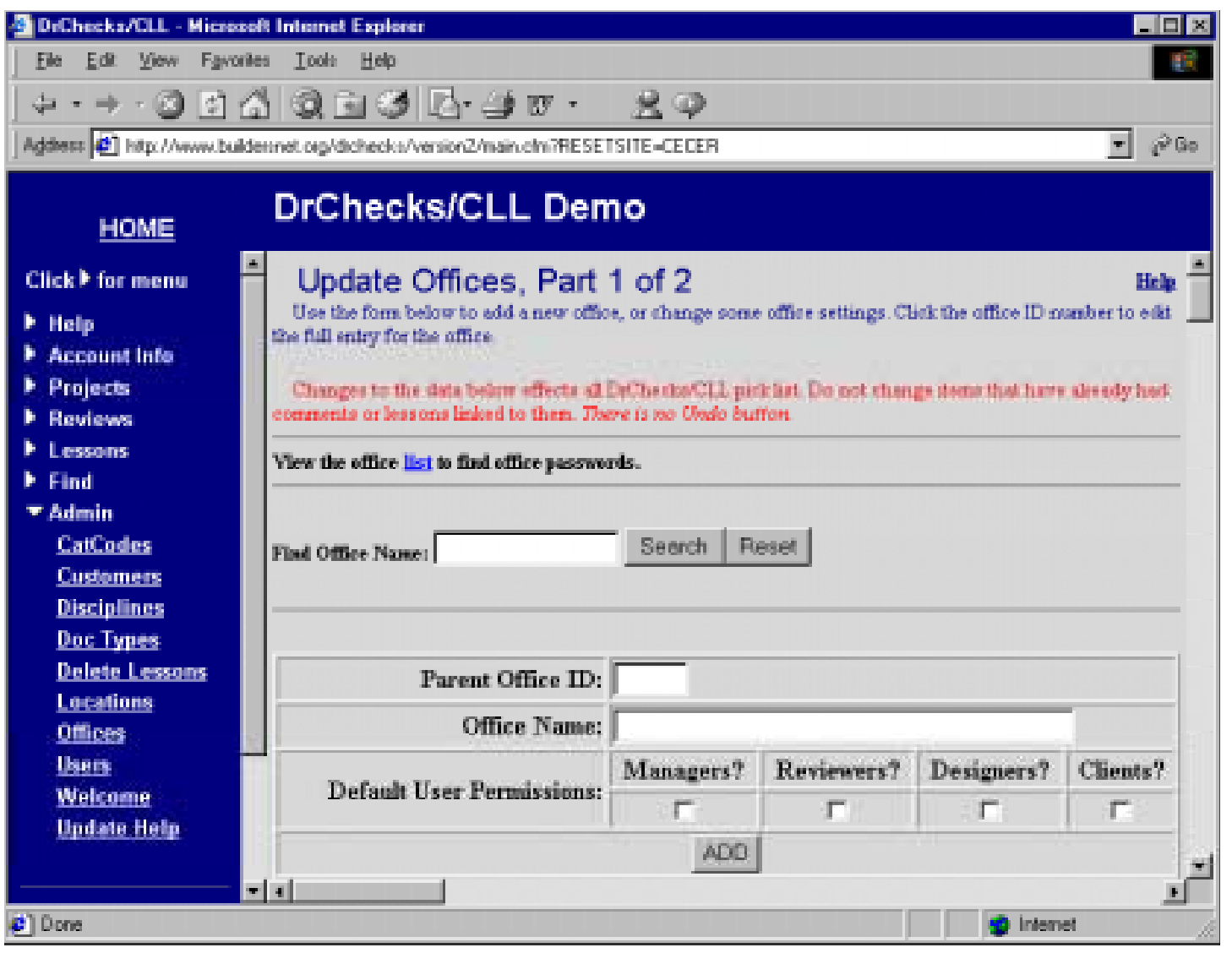

Figure 79. Update Offices Part 1.

OfcPhone: The telephone number is where a user can be contacted regarding DrChecks questions or concerns. The default telephone number is that of the user's office. A user can keep this number or change it to a telephone number that can also be reached for DrChecks questions or concerns.

OfcFAX: The fax number is the number where a copy of a document can be sent electronically without using a computer.

OfcEmail: If an office has a single address that receives email, this field is where a user can enter the email address. This field is not required, however. 


\section{Update Users}

The "Update User" page provides administrators the option to add, edit, or delete user records. It is restricted to key information necessary to hold a place for the user until they register and fill in their own critical data. The user table is presented in a grid used throughout DrChecks data entry and management. Clicking on the "Report" link at the top of the page is a way to view user information. Figure 80 shows the process steps.

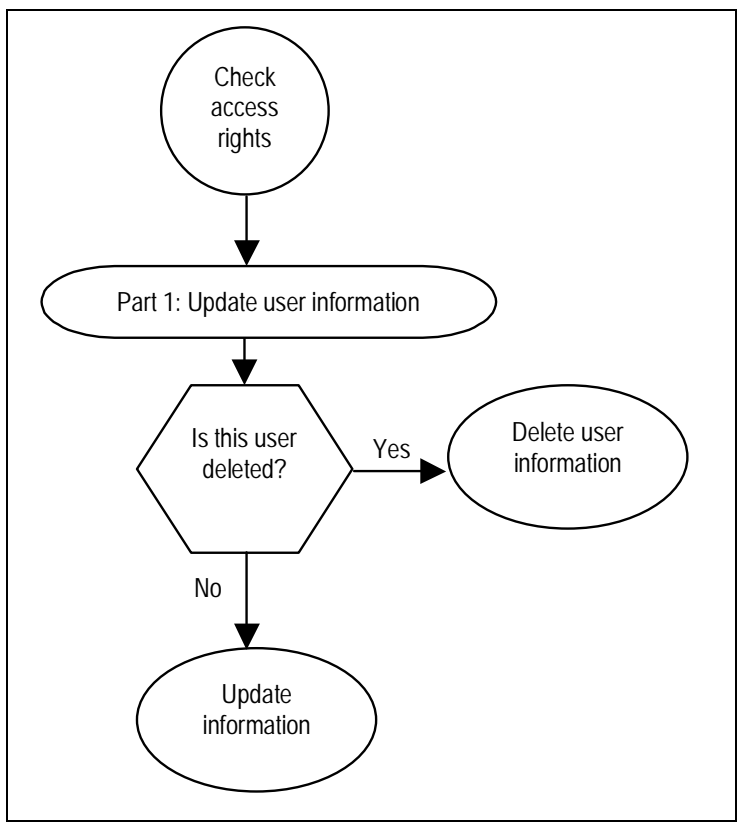

Figure 80. Process of updating users. 


\section{Update Welcome}

The "Welcome" page is used to modify the appearance of the initial DrChecks page. It includes the program title, company information, and the general message presented on arrival (including the message presented to new users). In several parts of this page, it is possible to use HTML code to provide more interesting displays to the users; however, it is best to keep the display as clean and simple as possible to support easier reading. Figure 81 shows the process steps.

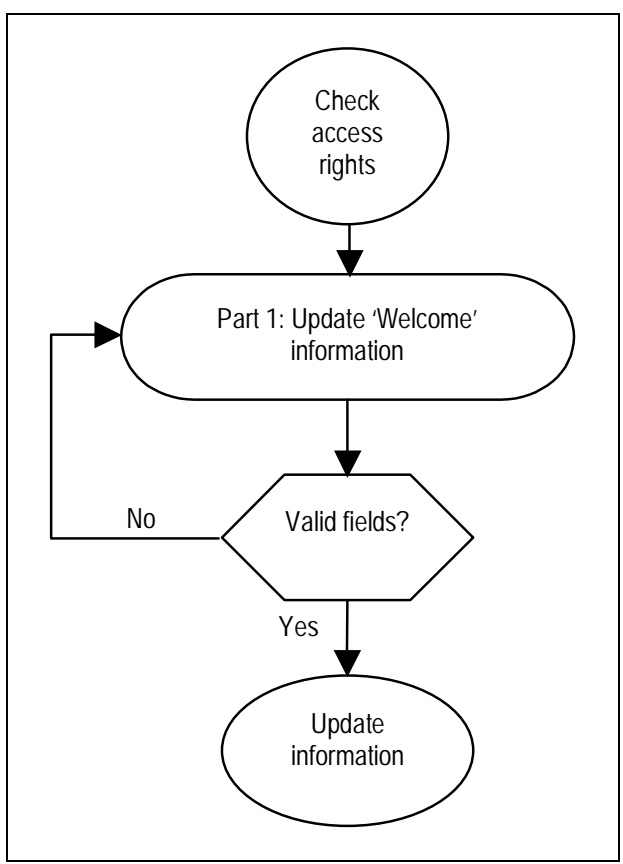

Figure 81. Process of updating welcome.

In Part 1 of the "Update Welcome" process (Figure 82), a user may change the system name, the top and bottom messages, and the footer. This is done with HTML code. 


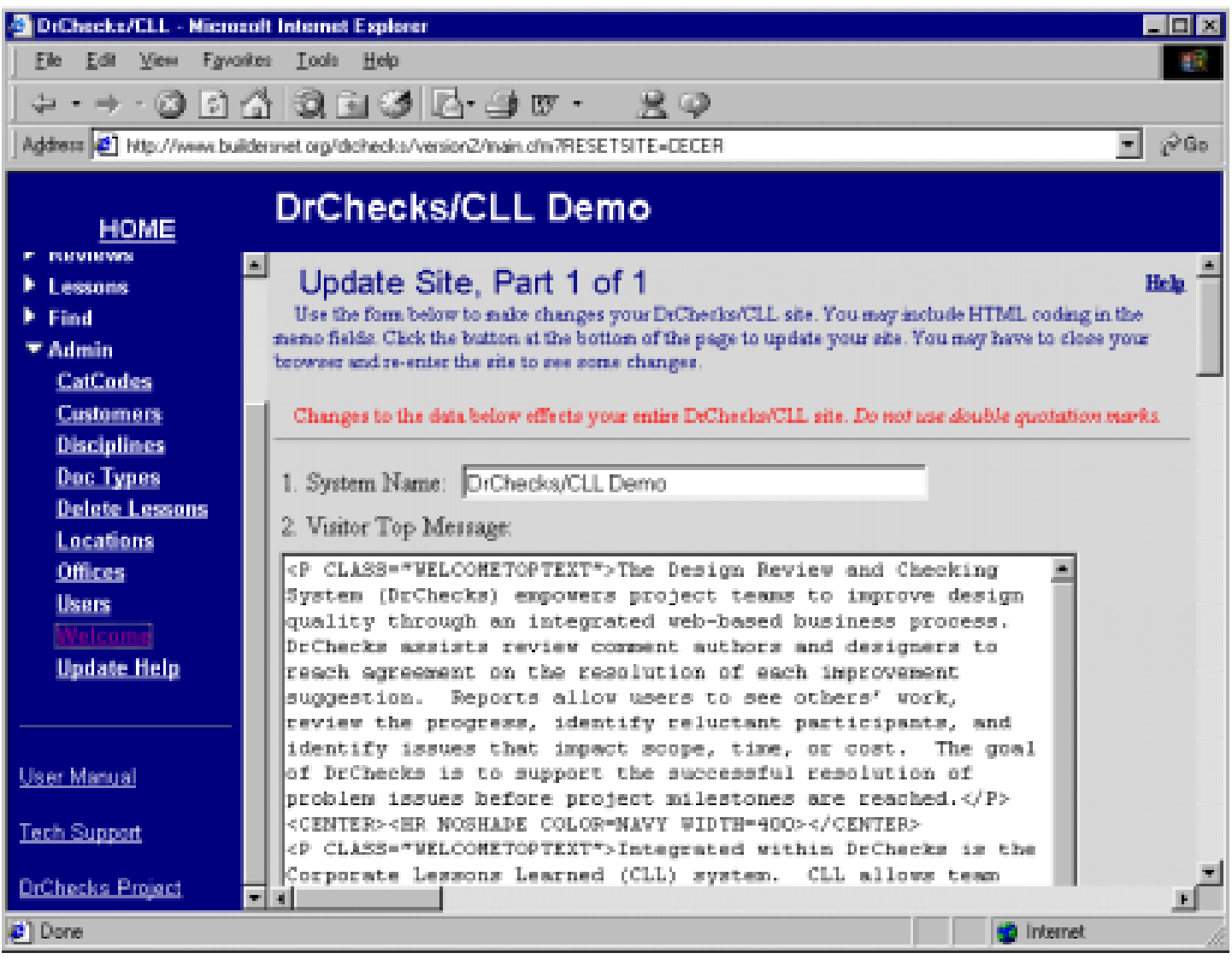

Figure 82. Update Welcome Part 1.

System Name: Provide the company name and contact information in this area. The company name is plotted above the general content frame for DrChecks. Use the browser refresh button to see changes in the company name after changes have been made.

Top and Bottom Messages: Both of the message boxes enable the user to edit the content of displayed messages. Since each message is an HTML message box, the browser will format the text to fit the page. If lists or bullets, text size or color changes, centering, or other formatting commands are desired, they must be inserted with HTML coding. This field is required.

Footer: The information contained on the bottom of the page is the contact information for the site. The items included should be the office name, office URL (website), POC name, POC email address, and POC telephone number. This field is required. 


\section{DrChecks Current Usage Statistics}

\section{DrChecks User Locations}

Comments serve as the primary measure of the active use of the DrChecks web site by the subscriber organizations. During calendar years 1999 and 2000, the number of subscriber organizations increased from 2 to 16. Subscribers exist on four different servers. Korea has a DrChecks server with very limited use of the program to date. Honolulu District has a server on which approximately 1,600 comments are stored. The Department of State maintains their own server and has over 17,000 comments stored online. The remaining 13 subscribers are on a single server where more than 36,000 comments are stored online.

\section{Measuring Usage}

This section presents several graphs of program use. The measure used is the number of comments per month, which is only a rough measure of the actual program usage. Statistics of web use are available but have been excluded from this publication. It is difficult to determine if web accesses are useful or productive. Therefore, even though impressive "hit" counts are available, the number of comments actually registered against a review provides a better indicator of use of the program to do actual work. Unfortunately, this measure fails to address advantages such as a review of online data through searches. These uses contribute to the hit count and are likely of significant advantage to the reviewers and designers involved in a project, but are not as easily measured.

Figure 83 displays comments per month summed across all program users. The graph indicates that use in 1999 was limited. During the first 9 months, only two districts were actively recording comments in the system. During the last 3 months of 1999, the Department of State entered the group and used the system heavily. In December 1999, the comment count per month across users exceeded 1,000 for the first time. Except for a drop below 1,000 in January 2000, the comment rate has not again dropped below 1,000 per month. For all of year 2000 , the count averaged 4,202 comments submitted per month. 


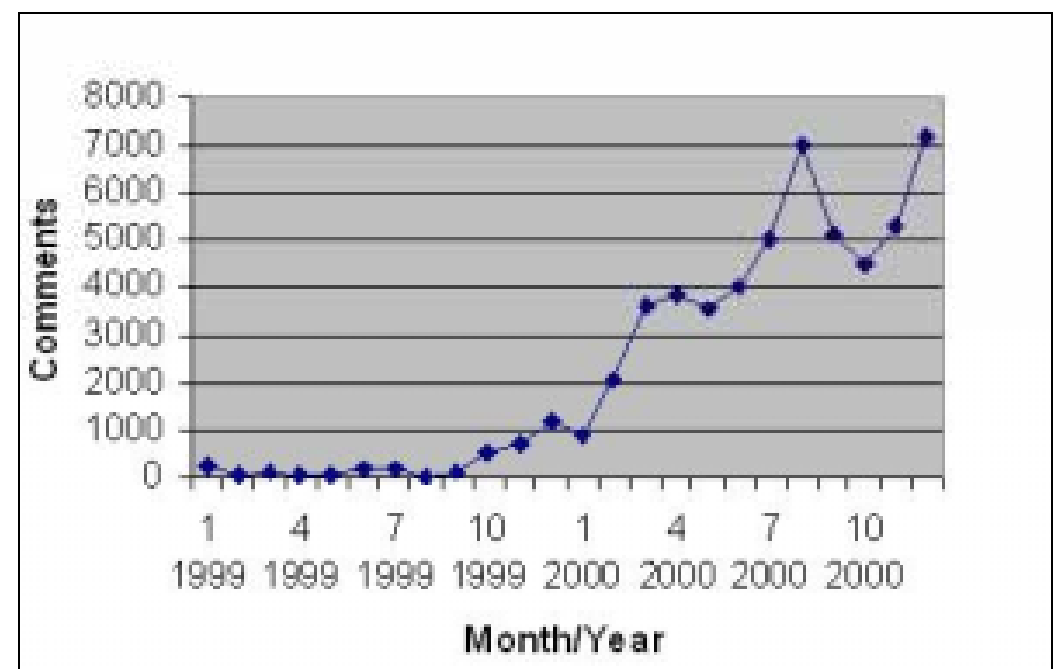

Figure 83. Total comments for 1999 and 2000 arranged by months.

Comments summed across subscribers show a notable saddle in the plot in August, September, and October. This reduction is expected due to the nature of project funding. When the end of the Federal fiscal year approaches, there is typically a flurry of activity as funds are committed. After the start of the new fiscal year, new funds become available and the comment frequency climbs back up.

\section{Examining Use Patterns for High-Use Subscribers}

It is useful to review use patterns in the charts (Figures 84 to 87) that display comments per month for the four largest users of the DrChecks program. The graphs demonstrate the consistent activity drop between fiscal years as just mentioned. Additional features are worth noting.

The graph for CELRH - Huntsville District (Figure 84) indicates that activity is markedly periodic. Based on review of the projects in that District, it appears that the distribution of comments relates to the nature of the projects they are involved in reviewing. More of their projects are larger, Civil Works projects that go through distinct cycles and impact the workload of the organization in bursts. Comment totals by month in the graph demonstrate the effect.

Graphs for CENPS - Seattle District and for CENAB - Baltimore District (Figures 85 and 86) demonstrate a smoother activity level from month to month. The majority of the projects at both sites are military and include more small projects than at a District involved with Civil Works projects. Again, both organizations demonstrate the fiscal year effect discussed initially. 


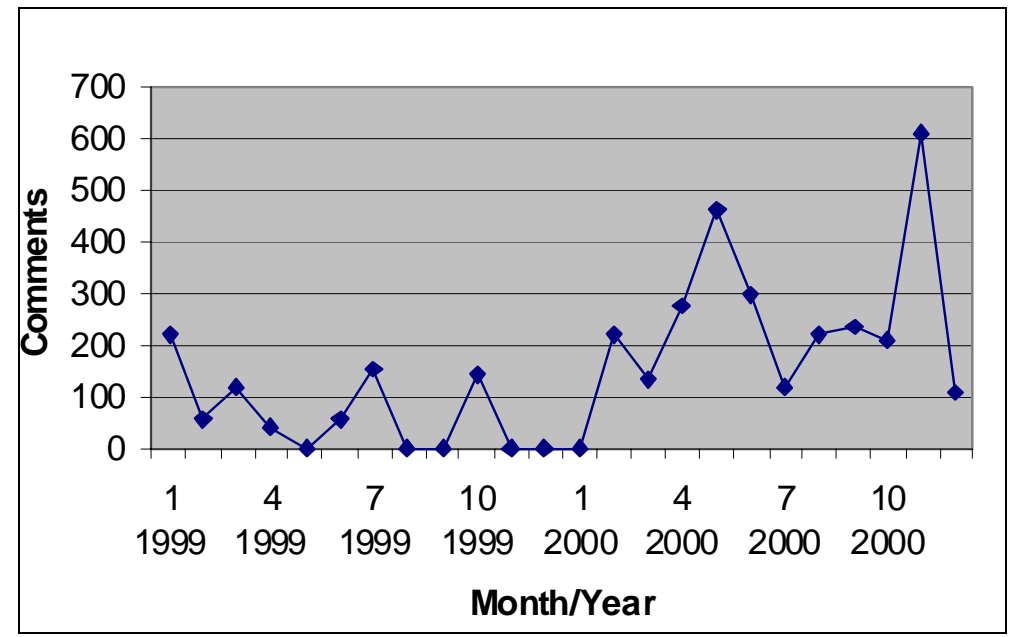

Figure 84. CELRH District total comments for 1999 and 2000.

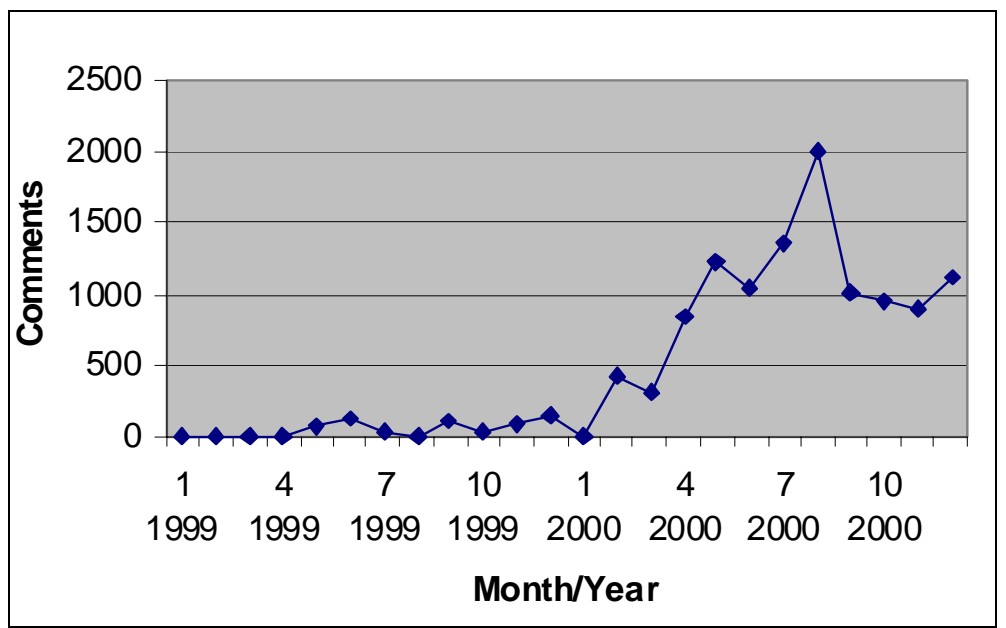

Figure 85. CENPS District total comments for 1999 and 2000.

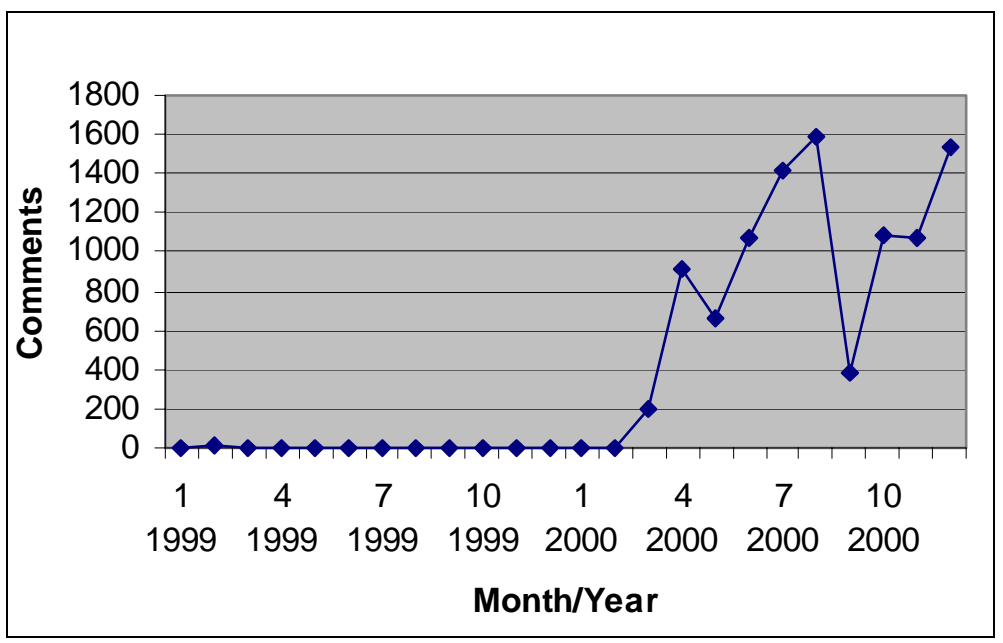

Figure 86. CENAB District total comments for 1999 and 2000. 
Finally, Figure 87 shows the activity for Department of State users. Again, the effect at the fiscal year boundary is demonstrated. Otherwise, their use pattern was generally a steady increase. The significant activity drop in the fifth and sixth months of year 2000 were a result of failure of the server used by the Department of State at that time, making it unavailable for recording comments for approximately 2 months. After this server was repaired, use continued to increase. Server failure had a profound effect on the activity's ability to accomplish work and reemphasized the need for a good plan for information management by DrChecks users.

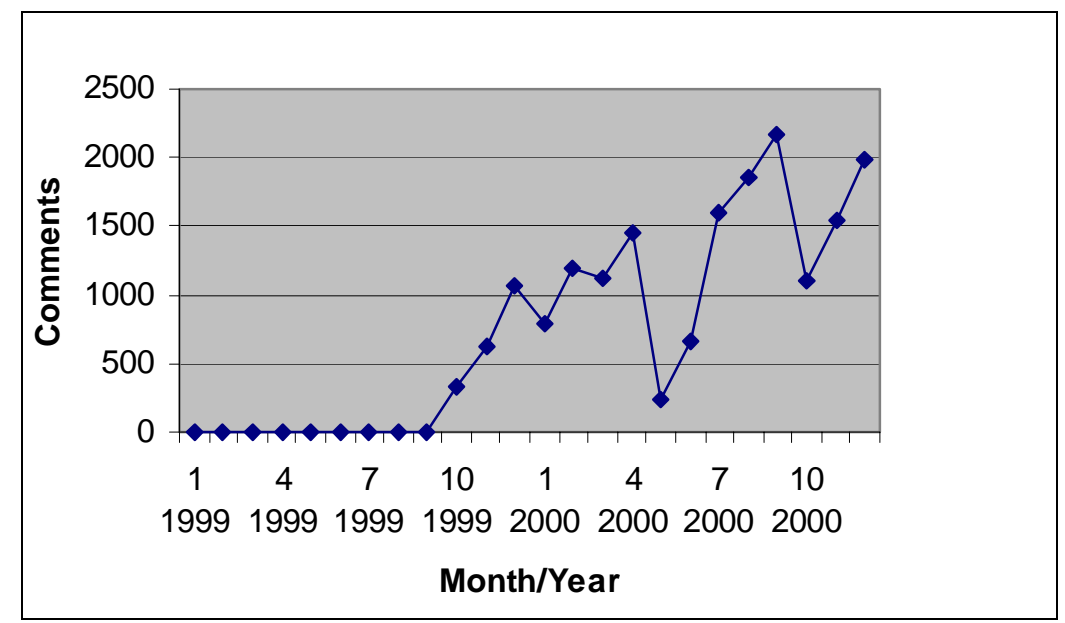

Figure 87. Department of State total comments for 1999 and 2000. 


\section{Conclusion and Future Work}

\section{Conclusion}

It is difficult to say more than that DrChecks program use has steadily increased since the program was made available for general use. Additional subscribers will be added during the current fiscal year, and it is expected that both existing and new users will add significant data to the current database. Further, as Districts adopt DrChecks as their only review tool and include all projects, a number of additional measures should be of great value. In particular, the data will be evaluated to determine average length of reviews, length of comments, comment resolution time, and additional parameters.

\section{Future Work}

Development of DrChecks Version 3 is nearing completion. A significant change in user interface will be fielded along with additional features comprised by the Design Quality Suite of tools. Incorporated with Version 3 will be the Request for Information (RFI) Module. RFI will support the management and resolution of bidder inquiries during the construction bidding process. In addition, the Criteria Management System (CMS 2) will be included to automatically review any DrChecks potential lessons learned for criteria impact. Copies of potential lessons will be routed to a local POC for review. If it is determined that the potential lesson learned does have a criteria impact, the POC will identify the appropriate criteria for automatic emails to notify (1) the national criteria manager that a request for review has been forwarded and (2) the original submitter that his/her suggestion has been forwarded for review and action. 


\section{CERL Distribution}

Chief of Engineers

ATTN: CEHEC-IM-LH (2)

ATTN: CECW-ET (2)

Engineer Research and Development Center (Libraries)

ATTN: ERDC, Vicksburg, MS

ATTN: Cold Regions Research, Hanover, NH

ATTN: Topographic Engineering Center, Alexandria, VA

Defense Tech Info Center 22304

ATTN: DTIC-O

8

$5 / 01$ 


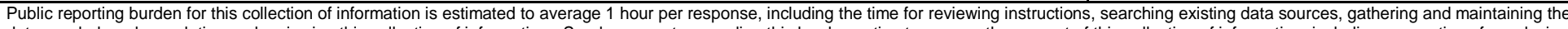

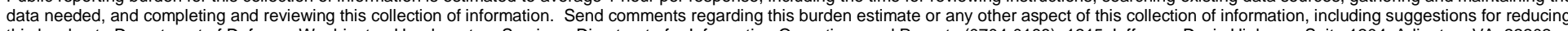

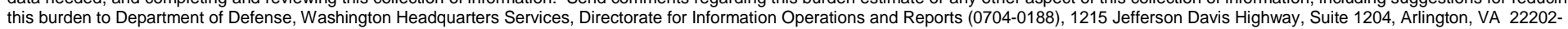

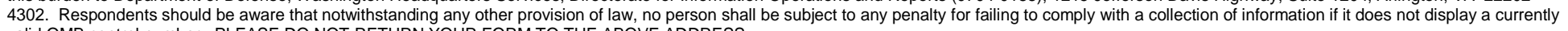
valid OMB control number. PLEASE DO NOT RETURN YOUR FORM TO THE ABOVE ADDRESS.
1. REPORT DATE (DD-MM-YYYY)
2. REPORT TYPE
3. DATES COVERED (From - To)

09-2001

Final

4. TITLE AND SUBTITLE

Design Review and Checking System (DrChecks)

5a. CONTRACT NUMBER

5b. GRANT NUMBER

5c. PROGRAM ELEMENT NUMBER

6. $\operatorname{AUTHOR}(\mathrm{S})$

E. William East, Jeffrey G. Kirby, and Jana Kelly

5d. PROJECT NUMBER

MIPR

5e. TASK NUMBER

5f. WORK UNIT NUMBER

WX3JR902219476

7. PERFORMING ORGANIZATION NAME(S) AND ADDRESS(ES)

U.S. Army Engineer Research and Development Center (ERDC)

8. PERFORMING ORGANIZATION REPORT

Construction Engineering Research Laboratory (CERL)

NUMBER

P.O. Box 9005

Champaign, IL 61826-9005

ERDC/CERL SR-01-20

\section{SPONSORING / MONITORING AGENCY NAME(S) AND ADDRESS(ES)}

Headquarters, U.S. Army Corps of Engineers (HQUSACE)

441 G Street, NW.

Washington, DC 20314-1000

10. SPONSOR/MONITOR'S ACRONYM(S)

CECW-ET

11. SPONSOR/MONITOR'S REPORT NUMBER(S)

\section{DISTRIBUTION / AVAILABILITY STATEMENT}

Approved for public release; distribution is unlimited.

\section{SUPPLEMENTARY NOTES}

Copies are available from the National Technical Information Service, 5285 Port Royal Road, Springfield, VA 22161.

\section{ABSTRACT}

Design Review and Checking System (DrChecks), developed by the Engineer Research and Development Center's Construction Engineering Research Laboratory (CERL), is Government-Off-the-Shelf software that supports the capture and use of organizational experience in the context of the design review process. DrChecks and its companion, Corporate Lessons Learned (CLL), are being used to turn personal experience, lessons learned, success stories, and good work practices identified by experienced staff members into corporate knowledge that can be shared throughout the organization.

\section{SUBJECT TERMS}

Design Review and Checking System (DrChecks)

Corporate Lessons Learned (CLL)

16. SECURITY CLASSIFICATION OF:

a. REPORT

Unclassified

b. ABSTRACT

Unclassified

c. THIS PAGE

Unclassified project management

design quality
OF ABSTRACT

SAR corporate knowledge

knowledge management

\begin{tabular}{l|l} 
& \\
\hline
\end{tabular}

18. NUMBER 19 19. NAME OF

OF PAGES

114

\section{E. William East}

19b. TELEPHONE NUMBER (include area code)

(217) $373-6710$ 